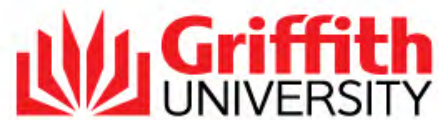

Griffith Business School

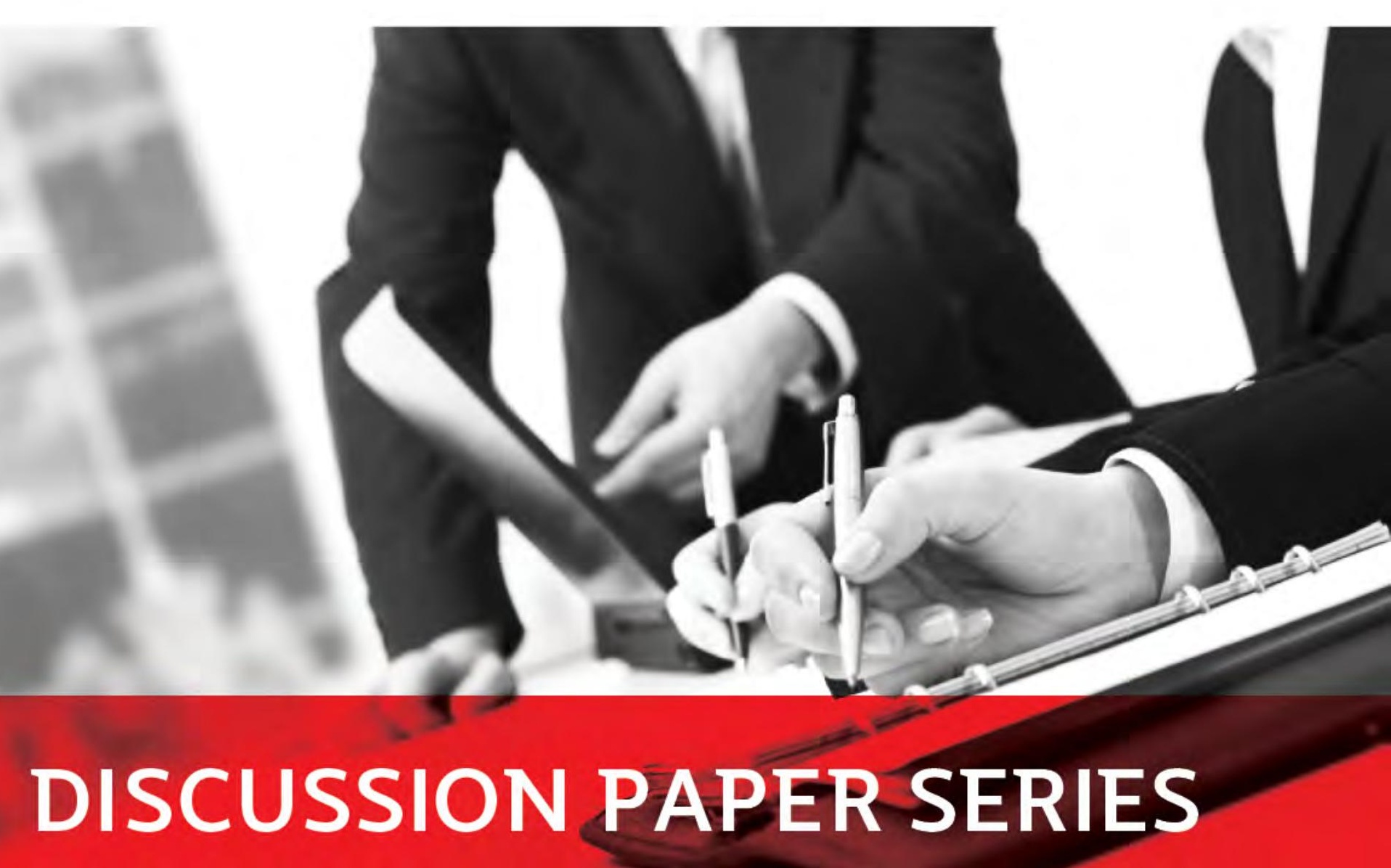

Economics and business statistics

\section{PIIGS in the Euro area. An empirical DSGE model.}

Alice Albonico, Alessia Paccagnini and Patrizio Tirelli

No. $2017-10$ 


\title{
PIIGS in the Euro Area. An Empirical DSGE Model.*
}

\author{
Alice Albonico \\ University of Milan Bicocca \\ Alessia Paccagnini \\ University College Dublin and University of Milan Bicocca \\ Patrizio Tirelli \\ University of Milan Bicocca
}

February 8, 2017

\begin{abstract}
We build up and estimate a two-region DSGE model of the Euro area, investigating the interactions between the peripheral countries (PIIGS) and the rest of EMU. Our main focus is on the 2008-2009 financial crisis and on the subsequent 2010-sovereign bond crisis. One striking result is that the two crises are characterized by demand shocks in the core Euro area countries, whereas region-specific permanent technology shocks explain most of output growth slowdown in the PIIGS countries. Our results suggest that the capital flows reversals caused important supply-side effects in the Eurozone periphery.
\end{abstract}

Keywords: PIIGS, Euro crisis, two-country DSGE, Bayesian estimation

JEL codes: C11, C13, C32, E21, E32, E37

*The paper is part of the RastaNews project funded by the European Community's $7^{\text {th }}$ Framework Programme (FP7). EC project 320278-RASTANEWS. We wish to thank, without implicating Giovanni Di Bartolomeo, Federico Signoretti, participants at the 2016 ICMAIF conference in Rethymno, Nora Traum and participants at the 2016 IAAE annual conference in Milan. 


\section{Introduction}

Following the 2008-2009 financial crisis, the sovereign bond crisis severely hit the "peripheral" members of the Euro area countries (Portugal, Ireland, Italy, Greece and Spain, PIIGS henceforth). The most striking feature of the crisis was the apparent disintegration of EMU financial markets (Christiansen, 2014; Sensoy et al., 2015) and the large interest rate spreads in the PIIGS countries, that were also characterized by a sudden contraction in growth and by dramatic increases in unemployment rates in these countries. All this raised concerns of a possible breakup of the Euro area.

The sovereign bond crisis was triggered by disclosure of hitherto hidden public deficits in Greece and by fears of contagion, but it has also been described as a sudden stop in financial flows that caused, among other things, a collapse in the risk-sharing mechanism between PIIGS and the rest of the Eurozone (Kalemli-Ozcan et al., 2014). As pointed out by De Grauwe and Ji (2013), this might have been caused by self-fulfilling expectation of EMU breakup. A complementary view emphasizes the role of underlying balance of payments problems (Giavazzi and Spaventa (2011); Lane, 2012). As a matter of fact, in peripheral countries the early EMU years had been characterized by large capital inflows, decline in domestic real interest rate, real exchange rate appreciation. This could be seen as part of the catching up process triggered by monetary integration (Blanchard and Giavazzi, 2002), but after 2010, in the context of globally deteriorated business cycle conditions, the accumulated real exchange rate appreciations signaled fragility and impossibility to recover the pre-2007 growth rates (Lane, 2012).

The crisis triggered a controversy about which policies should be implemented to restore growth. European institutions and policymakers in the core EMU countries called for a combination of fiscal retrenchment (austerity) and efficiency-enhancing reforms in the PIIGS region. Critics argued that reforms may have contractionary short-run effects, especially if the nominal interest rate is constrained at the zero lower bound, and that austerity would dampen an already depressed domestic demand in the periphery (See Eggertsson et al. 2014, and references cited therein).

We build up and estimate a medium-scale two-region Euro area model, i.e. PIIGS countries and the rest of Euro area countries (CORE countries). This allows us both to estimate the structural interdependence between the regions, and to identify the shocks that caused PIIGS contractions in economic activity during the 2008-2009 and post-2010 crises. One may expect this model to answer questions which are crucial to understand the nature of the crisis and to identify policies that promote regional convergence. Did the disruption of EMU financial markets actually contribute to the slowdown in PIIGS economic activity? Was the crisis driven by demand shocks that brought down consumption and investments in the peripheral region, or was it determined by an underlying deterioration in productivity growth? Finally, which role was played by fiscal policies before and during the crisis? To this end we consider a number of region-specific supply and demand shocks. Supply shocks include standard temporary technology shocks and shocks to the productivity growth trend, entailing permanent variations in relative productivity levels between the PIIGS and the CORE countries. Non-policy demand shocks include shocks to the households subjective discount factor, "risk premium" shocks driving a wedge between the return on capital accruing to the households and the price of capital services paid by firms, and a standard investment-specific shock. In addition to that, we account for alternative characterizations of the possibly (dis)integrated EMU financial market, incorporating shocks that impair risk-sharing between households of the two regions. Our model does not explicitly model financial frictions, but the richness of the shocks structure should allow to capture the transmission channels of the two financial crises. 
According to our estimates, temporary disruptions to the risk-sharing mechanism that operates through the EMU financial market have potentially large contractionary effects in the periphery, entailing a persistent fall in investment, output and inflation. However, our variance and historical decompositions of output growth suggest that this shock had minimal effects. In addition, on the grounds of the obtained marginal data densities, the model specification accounting for permanent productivity shocks is strongly preferred to the alternative specifications, including the one based on financial market shocks.

The historical decomposition of growth suggests that the output response to the 2008-2009 financial crisis, quantitatively similar in the two regions, was in fact caused by different types of shocks. In the core region demand shocks were more important than in the PIIGS, where the main determinants were permanent and temporary technology shocks. The post-2010 period, when the PIIGS experienced slower recovery and then deeper recession, is mainly explained by adverse permanent technology shocks in the periphery and by demand shocks in the CORE region. Following Khan and Thomas (2013) and Gopinath et al. (2015), we discuss the possible connection between the capital flows reversals that hit the PIIGS countries and the estimated adverse productivity shocks.

Public consumption shocks played a negligible role throughout the EMU years, implying that the post-2008 deterioration in fiscal indicators such as the public-consumption-to-GDP ratio was driven by non-policy shocks. A crucial difference exists between the two regions. In the CORE countries the deterioration of fiscal indicators was mainly caused by temporary shocks, whereas in the PIIGS region permanent shocks were a key driver, so that one cannot expect their reversal when the economy recovers.

Our contribution is complementary to Kollmann et al. (2016) who investigate the post-crisis adjustment in the US and in the Eurozone in a medium scale DSGE model, finding that adverse shocks to productivity growth were relatively more important in the Eurozone. Recent attempts to model CORE-Periphery interactions in the Eurozone have begun to incorporate the role of deleveraging effects (Kushinov et al., 2016). However, their modelling approach neglects the potential connection between financial shocks and supply side effects which, according to our result, seem to have played an important role in determining the dismal performance of PIIGS countries. This apparent shortcoming is common to a rapidly expanding empirical DSGE literature incorporating non-trivial financial frictions which have no effect on productivity growth. Gerali et al. (2010) find that financial shocks contributed to explain the output fall during the 2007 financial crisis, but in their model a bank capital loss cannot replicate the amplitude of the 2007-2008 downturn. Brzoza-Brzezina and Kolasa (2013) find that modelling financial frictions is essential for replicating fluctuations in financial variables, but this is not sufficient to improve over the statistical fit of the workhorse New Keynesian model, such as Smets and Wouters (2007). An identical conclusion is reached in Suh and Walker (2016) and Lindé, Smets and Wouters (2016).

The paper is organized as follows. Section 2 describes the model, section 3 introduces the estimation strategy and section 4 presents the results. Section 5 concludes.

\section{The monetary union $\operatorname{model}^{1}$}

We assume there are two regions in the European monetary union, respectively corresponding to PIIGS countries ( $\operatorname{size} s$ ) and to the rest of the Euro area, or core region ( size $1-s$ ). Each region produces both non-tradable and tradable differentiated goods. Tradable good produced in

\footnotetext{
${ }^{1}$ The Appendix contains more details about the equations and the specifications of the model.
} 
the PIIGS and core regions are respectively indexed by $H$ and $F$. As in Rabanal (2009), there is no price discrimination across regions, i.e. the law of one price holds. In what follows our focus is on the PIIGS region, as the core region is characterized symmetrically. When needed, variables and parameters referring to the core region are marked by an asterisk.

In each country there is a continuum of households indexed by $i$. A share $1-\theta$ of households (Ricardian households, $i=o$ ) can access financial markets, trade government bonds, accumulate physical capital and rent capital services to firms. The remaining $\theta$ households (Non-Ricardian or LAMP households, $i=r t$ ) do not have access to financial markets and consume all their disposable labor income.

Each household supplies a continuum of size $s$ of differentiated labor inputs that firms demand

$$
h_{t}^{i}=\left\{\left(\frac{1}{s}\right)^{\frac{\lambda_{t}^{w}}{1+\lambda_{t}^{w}}} \int_{0}^{s}\left[h_{t}^{i}(j)\right]^{\frac{1}{1+\lambda_{t}^{w}}} d j\right\}^{1+\lambda_{t}^{w}}
$$

Demand for labor type $j$ is

$$
h_{t}^{j}=\left(\frac{W_{t}^{j}}{W_{t}}\right)^{-\frac{1+\lambda_{t}^{w}}{\lambda_{t}^{w}}} h_{t}^{d}
$$

where $W_{t}^{j}$ is type $j$ nominal wage and $W_{t}=\left[\frac{1}{s} \int_{0}^{s}\left(W_{t}^{j}\right)^{\frac{1}{\lambda_{t}^{w}}} d j\right]^{\lambda_{t}^{w}}$ is the aggregate nominal wage index.

\subsection{Preferences}

Households preferences are characterized by non separability between consumption and labor effort (Smets and Wouters, 2005, 2007):

$$
U_{t}^{i}\left(c_{t}^{i}, h_{t}^{i}\right)=\frac{1}{1-\sigma}\left(\frac{c_{t}^{i}}{c_{t-1}^{\zeta}}\right)^{1-\sigma} \exp \left(\frac{\sigma-1}{1+\phi_{l}}\left(h_{t}^{i}\right)^{1+\phi_{l}}\right)
$$

where $c_{t}^{i}=\frac{C_{t}^{i}}{z_{t}}$ and $c_{t}=\frac{C_{t}}{z_{t}}$ are individual and total real consumption levels normalized by a labour-augmenting non-stationary technology shifter $z_{t}$. The presence of $z_{t}$ in 3 guarantees that the model has a balanced growth path when productivity is non stationary.

Parameter $0<\zeta<1$ measures the degree of external habit in consumption. As in Albonico et al. $(2014,2016)$, our specification is based on habits in ratios. ${ }^{2}$

\subsection{Production}

In each region, perfectly competitive firms produce the consumption good $C_{t}$ and a final investment good, $Q_{t}^{I}$, using tradable $\left(C_{t}^{T}, Q_{t}^{I, T}\right)$ and nontradable $\left(C_{t}^{N}, Q_{t}^{I, N}\right)$ intermediate goods. Tradables incorporate domestic $\left(C_{t}^{H}, Q_{t}^{I, H}\right)$ and imported $\left(C_{t}^{F}, Q_{t}^{I, F}\right)$ tradable intermediate goods as inputs. Thee goods are produced by monopolistically competitive firms. Brands of tradable goods are

\footnotetext{
${ }^{2}$ The habits-in-ratio specification limits the possibility that a non-negligible share of non-Ricardian households causes indeterminacy. In empirical DSGE model the existence of a relatively large indeterminacy region may bias posterior estimates. See Albonico et al. (2014 and 2015), for an extended dicussion.
} 
indexed by $h \in[0, s]$ in the domestic region and by $f \in[s, 1]$ in the foreign region. Indexes $n \in[0, s]$ and $n^{*} \in[s, 1]$ identify the corresponding notation for nontradable goods .

$$
\begin{aligned}
& C_{t}^{H}=\left[\left(\frac{1}{s}\right)^{\frac{\lambda_{t}^{p, H}}{1+\lambda_{t}^{p, H}}} \int_{0}^{s} C_{t}^{H}(h)^{\frac{1}{1+\lambda_{t}^{p, H}}} d h\right]^{1+\lambda_{t}^{p, H}} \\
& C_{t}^{F}=\left[\left(\frac{1}{1-s}\right)^{\frac{\lambda_{t}^{p, F}}{1+\lambda_{t}^{p, F}}} \int_{s}^{1} C_{t}^{F}(f)^{\frac{1}{1+\lambda_{t}^{p, F}}} d f\right]^{1+\lambda_{t}^{p, F}} \\
& Q_{t}^{I, H}=\left[\left(\frac{1}{s}\right)^{\frac{\lambda_{t}^{p, H}}{1+\lambda_{t}^{p, H}}} \int_{0}^{s} Q_{t}^{I, H}(h)^{\frac{1}{1+\lambda_{t}^{p, H}}} d h\right]^{1+\lambda_{t}^{p, H}} \\
& Q_{t}^{I, F}=\left[\left(\frac{1}{1-s}\right)^{\frac{\lambda_{t}^{p, F}}{1+\lambda_{t}^{p, F}}} \int_{s}^{1} Q_{t}^{I, F}(f)^{\frac{1}{1+\lambda_{t}^{p, F}}} d f\right]^{1+\lambda_{t}^{p, F}} \\
& C_{t}^{N}=\left[\left(\frac{1}{s}\right)^{\frac{\lambda_{t}^{p, N}}{1+\lambda_{t}^{p, N}}} \int_{0}^{s} C_{t}^{N}(n)^{\frac{1}{1+\lambda_{t}^{p, N}}} d n\right]^{1+\lambda_{t}^{p, N}} \\
& Q_{t}^{I, N}=\left[\left(\frac{1}{s}\right)^{\frac{\lambda_{t}^{p, N}}{1+\lambda_{t}^{p, N}}} \int_{0}^{s} Q_{t}^{I, N}(n)^{\frac{1}{1+\lambda_{t}^{p, N}}} d n\right]^{1+\lambda_{t}^{p, N}}
\end{aligned}
$$

The composite price indexes are defined as:

$$
\begin{aligned}
& P_{t}^{N}=\left[\frac{1}{s} \int_{0}^{s} P_{t}^{N}(n)^{\frac{1}{\lambda_{t}^{p, N}}} d n\right]^{\lambda_{t}^{p, N}} \\
& P_{t}^{H}=\left[\frac{1}{s} \int_{0}^{s} P_{t}^{H}(h)^{\frac{1}{\lambda_{t}^{p, H}}} d h\right]^{\lambda_{t}^{p, H}} \\
& P_{t}^{F}=\left[\frac{1}{1-s} \int_{s}^{1} P_{t}^{F}(f)^{\frac{1}{\lambda_{t}^{p, F}}} d f\right]^{\lambda_{t}^{p, F}}
\end{aligned}
$$

where $\lambda_{t}^{p, H}, \lambda_{t}^{p, F}, \lambda_{t}^{p, N}$ denote time-varying net price markups.

The consumption index $C_{t}$ is defined as a CES aggregate of tradable $C_{t}^{T}$ and nontradable goods $C_{t}^{N}$ :

$$
C_{t}=\left[\gamma_{c}^{\frac{1}{e}}\left(C_{t}^{T}\right)^{\frac{e-1}{e}}+\left(1-\gamma_{c}\right)^{\frac{1}{e}}\left(C_{t}^{N}\right)^{\frac{e-1}{e}}\right]^{\frac{e}{e-1}}
$$

where $\gamma_{c}$ represents the share of tradable goods in the consumption basket at home, $e>1$ is the elasticity of substitution between tradable and nontradable goods, and $C_{t}^{T}$ is defined as

$$
C_{t}^{T}=\left[\varpi^{\frac{1}{v}}\left(C_{t}^{H}\right)^{\frac{v-1}{v}}+(1-\varpi)^{\frac{1}{v}}\left(C_{t}^{F}\right)^{\frac{v-1}{v}}\right]^{\frac{v}{v-1}} ; v>1
$$


The home country consumer price indexes $P_{C, t}$ and $P_{t}^{T}$ are:

$$
\begin{aligned}
P_{C, t} & =\left[\gamma_{c}\left(P_{t}^{T}\right)^{1-e}+\left(1-\gamma_{c}\right)\left(P_{t}^{N}\right)^{1-e}\right]^{\frac{1}{1-e}} \\
P_{t}^{T} & =\left[\varpi\left(P_{t}^{H}\right)^{1-v}+(1-\varpi)\left(P_{t}^{F}\right)^{1-v}\right]^{\frac{1}{1-v}}
\end{aligned}
$$

CES aggregators also define final investment goods and the price index of tradables: ${ }^{3}$

$$
\begin{aligned}
Q_{t}^{I} & =\left[\gamma_{i}^{\frac{1}{e}}\left(Q_{t}^{I, T}\right)^{\frac{e-1}{e}}+\left(1-\gamma_{i}\right)^{\frac{1}{e}}\left(Q_{t}^{I, N}\right)^{\frac{e-1}{e}}\right]^{\frac{e}{e-1}} \\
Q_{t}^{I, T} & =\left[\varpi^{\frac{1}{v}}\left(Q_{t}^{I, H}\right)^{\frac{v-1}{v}}+(1-\varpi)^{\frac{1}{v}}\left(Q_{t}^{I, F}\right)^{\frac{v-1}{v}}\right]^{\frac{v}{v-1}} \\
P_{I, t} & =\left[\gamma_{i}\left(P_{t}^{T}\right)^{1-e}+\left(1-\gamma_{i}\right)\left(P_{t}^{N}\right)^{1-e}\right]^{\frac{1}{1-e}}
\end{aligned}
$$

Profits maximization leads to the following demand functions:

$$
\begin{aligned}
C_{t}^{N} & =\left(1-\gamma_{c}\right)\left(\frac{P_{t}^{N}}{P_{C, t}}\right)^{-e} C_{t} \\
C_{t}^{H} & =\varpi \gamma_{c}\left(\frac{P_{t}^{H}}{P_{t}^{T}}\right)^{-v}\left(\frac{P_{t}^{T}}{P_{C, t}}\right)^{-e} C_{t} \\
C_{t}^{F} & =(1-\varpi) \gamma_{c}\left(\frac{P_{t}^{F}}{P_{t}^{T}}\right)^{-v}\left(\frac{P_{t}^{T}}{P_{C, t}}\right)^{-e} C_{t} \\
Q_{t}^{I, N} & =\left(1-\gamma_{i}\right)\left(\frac{P_{t}^{N}}{P_{I, t}}\right)^{-e} Q_{t}^{I} \\
Q_{t}^{I, H} & =\varpi \gamma_{i}\left(\frac{P_{t}^{H}}{P_{t}^{T}}\right)^{-v}\left(\frac{P_{t}^{T}}{P_{I, t}}\right)^{-e} Q_{t}^{I} \\
Q_{t}^{I, F} & =(1-\varpi) \gamma_{i}\left(\frac{P_{t}^{F}}{P_{t}^{T}}\right)^{-v}\left(\frac{P_{t}^{T}}{P_{I, t}}\right)^{-e} Q_{t}^{I}
\end{aligned}
$$

Total demand for domestically produced intermediate goods is

$$
\begin{aligned}
Y_{t}^{H} & =C_{t}^{H}+Q_{t}^{I, H}+\frac{1-s}{s}\left(C_{t}^{H^{*}}+Q_{t}^{I, H^{*}}\right) \\
Y_{t}^{N} & =C_{t}^{N}+Q_{t}^{I, N}+G_{t}
\end{aligned}
$$

where $\left(C_{t}^{H^{*}}+Q_{t}^{I, H^{*}}\right)$ defines foreign demand for home tradables and $G_{t}$ is public consumption demand which is assumed to fall entirely on nontradables. ${ }^{4}$

\footnotetext{
${ }^{3}$ The home country investment price index $P_{I, t}$ differs from its consumption counterpart $P_{C, t}$ because $\gamma_{i} \neq \gamma_{c}$.

${ }^{4}$ We also make the standard assumption that $G_{t}$ and $C_{t}^{N}$ are identically distributed on individual non tradable goods.
} 


\subsubsection{Intermediate goods}

The representative firm uses the following production technology:

$$
Y_{t}^{i n t}=\varepsilon_{t}^{a, i n t}\left[u_{t}^{i n t} K_{t}^{i n t}\right]^{\alpha_{i n t}}\left[z_{t} h_{t}^{i n t}\right]^{1-\alpha_{i n t}}-z_{t} \Phi_{i n t}
$$

where $i n t=h, f, n, n^{*}$, $\Phi_{\text {int }}$ defines fixed costs of production, $u_{t}^{\text {int }}$ is the degree of capacity utilization, $K_{t}^{i n t}$ is the capital stock, $\varepsilon_{t}^{a, i n t}$ and $z_{t}=z_{t-1} g_{z, t}$ incorporate temporary and permanent technology shocks respectively, modelled as $\mathrm{AR}(1)$ processes with i.i.d. Normal innovation terms, $\eta_{t}^{i n t}, \eta_{t}^{g_{z}}:$

$$
\begin{gathered}
\log \left(\varepsilon_{t}^{a, i n t}\right)=\left(1-\rho_{\text {int }}\right) \log \left(\varepsilon^{a, i n t}\right)+\rho_{\text {int }} \log \left(\varepsilon_{t-1}^{a, i n t}\right)+\eta_{t}^{\text {int }} \\
\log \left(g_{z, t}\right)=\left(1-\rho_{g_{z}}\right) \log \left(g_{z}\right)+\rho_{g_{z}} \log \left(g_{z, t-1}\right)+\eta_{t}^{g_{z}}
\end{gathered}
$$

Firms profits are defined as

$$
P_{t}^{i n t} Y_{t}^{i n t}-R_{t}^{k} u_{t}^{i n t} K_{t}^{i n t}-\left(1+\tau^{w f}\right) W_{t} h_{t}^{i n t}
$$

where $\tau^{w f}$ is a payroll tax. The nominal marginal cost is:

$$
M C_{t}^{i n t}=\alpha_{i n t}^{-\alpha_{i n t}}\left(1-\alpha_{i n t}\right)^{-\left(1-\alpha_{i n t}\right)}\left(\varepsilon_{t}^{a, i n t}\right)^{-1} z_{t}^{-\left(1-\alpha_{i n t}\right)}\left(R_{t}^{k}\right)^{\alpha_{i n t}}\left[\left(1+\tau^{w f}\right) W_{t}\right]^{1-\alpha_{i n t}}
$$

Price setting Prices are sticky à la Calvo (1983). Firms optimally reset their price with probability $\left(1-\xi_{p}^{\text {int }}\right)$. Non-optimizing firms adopt the standard indexation scheme:

$$
P_{t}^{i n t}=\pi_{i n t, t-1}^{\chi_{p}^{i n t}} \bar{\pi}_{t}^{1-\chi_{p}^{i n t}} P_{t-1}^{i n t}
$$

where $\bar{\pi}_{t}$ is the monetary union trend inflation rate and $\pi_{i n t, t}=\frac{P_{t}^{\text {int }}}{P_{t-1}^{\text {int }}}$ is the sectorial inflation rate.

The first order condition for the optimizing firm is:

$$
E_{t} \sum_{k=0}^{\infty}\left(\xi_{p}^{i n t}\right)^{s} \Xi_{t, t+k} Y_{t+k}^{i n t}\left[\frac{\tilde{P}_{t}^{i n t} \pi_{N, t, t+k-1}^{\chi_{p}^{i n t}} \bar{\pi}_{t, t+k}^{1-\chi_{p}^{i n t}}}{P_{C, t+k}}-\left(1+\lambda_{t+k}^{p, i n t}\right) \frac{M C_{t+k}^{i n t}}{P_{C, t+k}}\right]=0
$$

where $Y_{t+k}^{\text {int }}$ defines total demand for goods produced in the sector, $\Xi_{t, t+s}$ is the stochastic discount factor to be defined below and

$$
\begin{aligned}
\pi_{i n t, t, t+k-1} & =\left\{\begin{array}{cc}
1 & \text { for } k=0 \\
\pi_{i n t, t} \cdot \pi_{i n t, t+1} \cdot \ldots \cdot \pi_{i n t, t+k-1} & \text { for } k=1,2 \ldots
\end{array}\right. \\
\bar{\pi}_{t, t+k} & =\left\{\begin{array}{cc}
1 & \text { for } k=0 \\
\bar{\pi}_{t} \cdot \bar{\pi}_{t+1} \cdot \ldots \cdot \bar{\pi}_{t+k} & \text { for } k=1,2 \ldots
\end{array}\right.
\end{aligned}
$$

The sectorial price index is:

$$
P_{t}^{i n t}=\left[\left(1-\xi_{p}^{i n t}\right)\left(\tilde{P}_{t}^{i n t}\right)^{\frac{1}{\lambda_{t}^{p, i n t}}}+\xi_{p}^{i n t}\left(\pi_{i n t, t-1}^{\chi_{p}^{i n t}} \bar{\pi}_{t}^{1-\chi_{p}^{i n t}} P_{t-1}^{i n t}\right)^{\frac{1}{\lambda_{t}^{p, i n t}}}\right]^{\lambda_{t}^{p, i n t}}
$$


Note that price-setting decisions are affected by shocks to the elasticity of substitution across goods, that we characterize as net markup shocks, assumed to follow an AR(1) process with i.i.d. Normal error term:

$$
\log \left(\lambda_{t}^{p, i n t}\right)=\left(1-\rho_{p, i n t}\right) \log \left(\lambda^{p, i n t}\right)+\rho_{p, i n t} \log \left(\lambda_{t-1}^{p, i n t}\right)+\eta_{t}^{p, i n t}
$$

\subsection{Labor market}

In the country-specific labor market $j$, a monopolistic union sets the nominal wage $W_{t}^{j}$, taking as given firms' demand labor input $j$. At the given nominal wage, households supply the amount of labor that firms demand. This, in turn, is uniformly split across households, who supply an identical amount of labor services, $h_{t}=h_{t}^{i}$ as in Colciago (2011).

Wages are staggered à la Calvo (1983). Union $j$ receives permission to optimally reset the nominal wage with probability $\left(1-\xi_{w}\right)$. Non-optimizing unions adjust the wage according to the following scheme:

$$
W_{t}^{j}=g_{z, t} \pi_{C, t-1}^{\chi_{w}} \bar{\pi}_{t}^{1-\chi_{w}} W_{t-1}^{j}
$$

where $\pi_{t}=\frac{P_{C, t}}{P_{C, t-1}}$ is the gross rate of consumer price inflation in the region.

Following Colciago (2011), we assume that optimizing unions maximize a weighted average $(1-\theta, \theta)$ of the two households types' utility functions: ${ }^{5}$

$$
\max _{\tilde{W}_{t}^{j}} E_{t} \sum_{k=0}^{\infty}\left(\xi_{w} \beta\right)^{k}\left\{(1-\theta) U_{t}^{o}\left(c_{t+k}^{o}, h_{t+k}^{o}\right)+\theta U_{t}^{r t}\left(c_{t+k}^{r t}, h_{t+k}^{r t}\right)\right\}
$$

subject to the budget constraints 47,48 (to be defined below) and to

$$
h_{t+k}^{i}=\frac{1}{s} h_{t+k}^{d} \int_{0}^{s}\left(\frac{\tilde{W}_{t}^{j} g_{z, t, t+k} \pi_{C, t, t+k-1}^{\chi_{w}} \bar{\pi}_{t, t+k}^{1-\chi_{w}}}{W_{t+k}}\right)^{-\frac{1+\lambda_{t+k}^{w}}{\lambda_{t+k}^{w}}} d j
$$

where:

$$
\pi_{C, t, t+k-1}=\left\{\begin{array}{cr}
1 & \text { for } k=0 \\
\pi_{C, t} \pi_{C, t+1} \ldots \pi_{C, t+k-1} & \text { for } k=1,2 \ldots
\end{array}\right.
$$

$\bar{\pi}_{t, t+k}$ is defined by $(36)$ and $g_{z, t, t+k}=\prod_{k=1}^{k} g_{z, t+k}$.

Then, the first order condition of union is:

$$
\begin{aligned}
0= & E_{t} \sum_{s=0}^{\infty}\left(\xi_{w} \beta\right)^{s} \varepsilon_{t}^{c} c_{t+s-1}^{\zeta(\sigma-1)} \exp \left(\frac{\sigma-1}{1+\phi_{l}}\left(h_{t+s}\right)^{1+\phi_{l}}\right) h_{t+s}^{j} \\
& \cdot\left\{\begin{array}{c}
\tilde{W}_{t}^{j} \frac{\left(1-\tau^{l}-\tau^{w h}\right) g_{z, t, t+s} \pi_{C, t, t+s-1}^{\chi_{w}} \bar{\pi}_{t, t+s}^{1-\chi_{w}}}{\left(1+\tau^{c}\right) P_{C, t+s} z_{t+s}}\left(1-\frac{1+\lambda_{t+s}^{w}}{\lambda_{t+s}^{w}}\right)\left[(1-\theta)\left(c_{t+s}^{o}\right)^{-\sigma}+\theta\left(c_{t+s}^{r t}\right)^{-\sigma}\right] \\
+\frac{1+\lambda_{t+s}^{w}}{\lambda_{t+s}^{w}}\left[(1-\theta)\left(c_{t+s}^{o}\right)^{-\sigma} M R S_{t+s}^{o}+\theta\left(c_{t+s}^{r t}\right)^{-\sigma} M R S_{t+s}^{r t}\right]
\end{array}\right\}
\end{aligned}
$$

\footnotetext{
${ }^{5} U_{t}^{o}, U_{t}^{r t}$ are characterized in (3)
} 
where

$$
M R S_{t}^{i}=c_{t}^{i} h_{t}^{\phi_{l}} ; i=o, r t
$$

The aggregate wage index is

$$
W_{t}=\left[\xi_{w}\left(g_{z, t} \pi_{C, t-1}^{\chi_{w}} \bar{\pi}_{t}^{1-\chi_{w}} W_{t-1}\right)^{\frac{1}{\lambda_{t}^{w}}}+\left(1-\xi_{w}\right)\left(\tilde{W}_{t}\right)^{\frac{1}{\lambda_{t}^{w}}}\right]^{\lambda_{t}^{w}}
$$

Note that we incorporate wage markup shocks, because $\lambda_{t}^{w}$ is assumed to follow an $\operatorname{AR}(1)$ process with i.i.d. Normal error term:

$$
\log \left(\lambda_{t}^{w}\right)=\left(1-\rho_{w}\right) \log \left(\lambda^{w}\right)+\rho_{w} \log \left(\lambda_{t-1}^{w}\right)+\eta_{t}^{w}
$$

\subsection{Non-Ricardian households}

Non-Ricardian households consume their current disposable income

$$
\left(1+\tau^{c}\right) P_{C, t} C_{t}^{r t}=\left(1-\tau^{l}-\tau^{w h}\right) W_{t} h_{t}+T R_{t}^{r t}-T_{t}^{r t}
$$

where $\tau^{c}, \tau^{l}, \tau^{w h}, T R_{t}^{r t}, T_{t}^{r t}$ respectively denote consumption and labor income tax rates, social contributions levied on labor incomes, public transfers and lump-sum taxes.

\subsection{Ricardian households}

Ricardian households allocate their resources between consumption $C_{t}^{o}$, investment in physical capital $I_{t}^{o}$, in public bonds $B_{t+1}^{o}$ and in a portfolio of financial assets $A_{t}$. Their budget constraint is:

$$
\begin{aligned}
\left(1+\tau^{c}\right) P_{C, t} C_{t}^{o}+P_{I, t} I_{t}^{o}+A_{t}+B_{t+1}^{o}= & A_{t-1}+R_{t-1} B_{t}^{o}+\left(1-\tau^{l}-\tau^{w h}\right) W_{t}^{o} h_{t}^{o}+D_{t}^{o} \\
& +\left(1-\tau^{k}\right)\left[\frac{R_{t}^{k}}{\varepsilon_{t-1}^{b}} u_{t}^{o}-a\left(u_{t}^{o}\right) P_{I, t}\right] K_{t}^{o}+\tau^{k} \delta P_{I, t} K_{t}^{o}+T R_{t}^{o}-T_{t}^{o}
\end{aligned}
$$

where $P_{I, t}$ is the price of investment, $K_{t}^{o}$ is the physical capital stock, $D_{t}^{o}$ are dividends and $u_{t}^{o}$ defines capacity utilization. $T R_{t}^{o}$ are transfers of Ricardian households and $T_{t}^{o}$ are lump-sum taxes. $\varepsilon_{t}^{b}$ is a risk premium shock that creates a wedge between the return on capital accruing to the households and the price of capital paid by firms. ${ }^{6}$ It is assumed to follow a first-order autoregressive process with an i.i.d. Normal error term:

$$
\log \left(\varepsilon_{t}^{b}\right)=\left(1-\rho_{b}\right) \log \left(\varepsilon^{b}\right)+\rho_{b} \log \left(\varepsilon_{t-1}^{b}\right)+\eta_{t}^{b}
$$

The capital accumulation equation is:

$$
K_{t+1}^{o}=(1-\delta) K_{t}^{o}+\varepsilon_{t}^{i}\left[1-S\left(\frac{I_{t}^{o}}{I_{t-1}^{o}}\right)\right] I_{t}^{o}
$$

where $\delta$ is the depreciation rate and $\varepsilon_{t}^{i}$ denotes an investment-specific technology shock that affects the real price of investment. It is assumed to evolve as an $\operatorname{AR}(1)$ process with i.i.d. Normal innovation term:

$$
\log \left(\varepsilon_{t}^{i}\right)=\left(1-\rho_{i}\right) \log \left(\varepsilon^{i}\right)+\rho_{i} \log \left(\varepsilon_{t-1}^{i}\right)+\eta_{t}^{i}
$$

\footnotetext{
${ }^{6}$ A similar kind of shock is introduced in Ratto et al. (2008) and Amano and Shukayev (2012).
} 
The term $S\left(\frac{I_{t}^{o}}{I_{t-1}^{o}}\right)$ represents investment adjustment costs. The standard adjustment costs function is:

$$
S\left(\frac{I_{t}^{o}}{I_{t-1}^{o}}\right)=\frac{\gamma_{I}}{2}\left(\frac{I_{t}^{o}}{I_{t-1}^{o}}-g_{z}\right)^{2}
$$

Capital utilization costs are defined as in Christiano et al. (2005):

$$
a\left(u_{t}^{o}\right)=\gamma_{u 1}\left(u_{t}^{o}-1\right)+\frac{\gamma_{u 2}}{2}\left(u_{t}^{o}-1\right)^{2}
$$

The Ricardian households maximize

$$
E_{t} \sum_{k=0}^{\infty} \beta^{t} \varepsilon_{t+k}^{c} U_{k}^{o}\left(c_{t+k}^{o}, h_{t+k}^{o}\right)
$$

with respect to $C_{t}^{o}, B_{t+1}, I_{t}^{o}, K_{t+1}^{o}, u_{t}^{o}$, subject to (48), (50), (52) and (53). We define the Lagrange multipliers associated with (48) and (50) respectively as $\Lambda_{t}^{o} / P_{C, t}$ and $\Lambda_{t}^{o} Q_{t}^{o}$. The first order conditions are:

$$
\begin{gathered}
\varepsilon_{t}^{c}\left(c_{t}^{o}\right)^{-\sigma} c_{t-1}^{\zeta(\sigma-1)} \exp \left(\frac{\sigma-1}{1+\phi_{l}}\left(h_{t}^{o}\right)^{1+\phi_{l}}\right) \frac{1}{z_{t}}=\Lambda_{t}^{o}\left(1+\tau^{c}\right) \\
R_{t}=\pi_{C, t+1} \frac{\Lambda_{t}^{o}}{\beta \Lambda_{t+1}^{o}} \\
\frac{P_{I, t}}{P_{C, t}}=Q_{t}^{o} \varepsilon_{t}^{i}\left\{1-\gamma_{I}\left(\frac{I_{t}}{I_{t-1}}-g_{z}\right) \frac{I_{t}}{I_{t-1}}-\frac{\gamma_{I}}{2}\left(\frac{I_{t}}{I_{t-1}}-g_{z}\right)^{2}\right\} \\
+\Xi_{t, t+1} Q_{t+1}^{o} \varepsilon_{t+1}^{i} \gamma_{I}\left(\frac{I_{t+1}}{I_{t}}-g_{z}\right)\left(\frac{I_{t+1}}{I_{t}}\right)^{2} \\
\Xi_{t, t+1}\left\{\left(1-\tau^{k}\right)\left[\frac{R_{t+1}^{k}}{\varepsilon_{t}^{b} P_{C, t+1}} u_{t+1}^{o}-\frac{P_{I, t+1}}{P_{C, t+1}} a\left(u_{t+1}^{o}\right)\right]+\tau^{k} \frac{P_{I, t+1}}{P_{C, t+1}} \delta+Q_{t+1}^{o}(1-\delta)\right\}=Q_{t}^{o} \\
\frac{R_{t}^{k}}{\varepsilon_{t-1}^{b} P_{C, t}}=\frac{P_{I, t}}{P_{C, t}}\left[\gamma_{u 1}+\gamma_{u 2}\left(u_{t}^{o}-1\right)\right]
\end{gathered}
$$

$\Lambda_{t}^{o}$ represents the shadow price of a unit of consumption good, thus equation (55) shows the marginal utility of consumption out of income. $Q_{t}^{o}$ measures the shadow price of a unit of investment good and $\Xi_{t, t+1}=\beta \frac{\Lambda_{t+1}^{o}}{\Lambda_{t}^{o}}$ is the stochastic discount factor. $\varepsilon_{t}^{c}$ is a preference shock affecting the subjective discount factor and evolving according to:

$$
\log \left(\varepsilon_{t}^{c}\right)=\left(1-\rho_{c}\right) \log \left(\varepsilon^{c}\right)+\rho_{c} \log \left(\varepsilon_{t-1}^{c}\right)+\eta_{t}^{c}
$$

with $\eta_{t}^{c} \sim N\left(0, \sigma_{c}^{2}\right)$.

Equations (57) and (58) are the first order conditions for investment and capital respectively. Equation (59) equals the return from capital utilization to its cost. The latter equation implies that $u_{t}^{o}$ is identical across Ricardian households, so that $u_{t}^{o}=u_{t}$. Further, the sectorial degree of capital utilization is uniform.

To complete the set of first order conditions we need to spell out our assumptions about the functioning of the monetary union financial markets. 


\subsubsection{Integrated financial markets}

If the monetary union financial market are fully integrated, the portfolio $A_{t}$ is composed of statecontingent securities that allow Ricardian households in the two regions to engage in mutual risk sharing, and of nominally riskless bonds that yield the unique rate of return $R_{t}^{E C B}$. This nominal rate is in fact controlled by the central bank, see condition (85) below. In each region the standard Euler equation holds

$$
R_{t}^{E C B}=\pi_{C, t+1} \frac{\Lambda_{t}^{o}}{\beta \Lambda_{t+1}^{o}}=\pi_{C^{*}, t+1} \frac{\Lambda_{t}^{o, *}}{\beta \Lambda_{t+1}^{o, *}}
$$

With integrated markets, combining the Euler equations in the two countries and iterating backward, we obtain the usual risk sharing condition (see Chari, Kehoe and Mc Grattan (2002)):

$$
\frac{P_{C, t}^{*}}{P_{C, t}}=\frac{P_{C, 0}^{*}}{P_{C, 0}} \frac{\Lambda_{0}^{o}}{\Lambda_{0}^{o, *}} \frac{\Lambda_{t}^{o, *}}{\Lambda_{t}^{o}}
$$

Then, defining the real effective exchange rate as $R E R_{t} \equiv \frac{P_{C, t}^{*}}{P_{C, t}}$ we obtain:

$$
R E R_{t}=\varepsilon_{t}^{r s h} \kappa \frac{\Lambda_{t}^{o, *}}{\Lambda_{t}^{o}}
$$

where $\kappa$ defines initial conditions. Condition (63) implies that Ricardian households in the two region, by trading state-contingent assets $A_{t}$, commit themselves to international transfer schemes that allow to smooth relative consumption levels unless a variation occurs in their relative price $R E R_{t}$. The additional term $\varepsilon_{t}^{r s h}$ is a shock meant to capture temporary disruptions in the Euro area financial market, which impair risk sharing.

$$
\log \left(\varepsilon_{t}^{r s h}\right)=\left(1-\rho_{r s h}\right) \log \left(\varepsilon^{r s h}\right)+\rho_{r s h} \log \left(\varepsilon_{t-1}^{r s h}\right)+\eta_{t}^{r s h}
$$

Note that our characterization implies that the deviations from full risk sharing affect the relative growth rate of Ricardian households consumption in the two countries, as in Kalemli-Ozcan et al. (2014).

\subsubsection{Segmented financial markets}

In this case we treat EMU financial markets as if they were segmented, assuming that domestic residents can only trade in domestic bonds whose prices are discounted differently relative to bonds issued in the foreign region, in analogy with a case discussed in Schmitt-Grohé and Uribe (2003). The domestic premium is an increasing function of the region foreign debt holdings, $N W_{t}$. Foreign resident trade in both domestic and foreign issued bonds. In this case, the Euler equation for domestic residents is

$$
R_{t}=\pi_{C, t+1} \frac{\Lambda_{t}^{o}}{\beta \Lambda_{t+1}^{o}}
$$

where:

$$
R_{t}=\frac{R_{t}^{E C B}}{\Gamma\left(N W_{t}, \varepsilon_{t}^{r p}\right)}
$$

and 


$$
\Gamma\left(N W_{t}, \varepsilon_{t}^{r p}\right)=\exp \left\{\Gamma^{b}\left(\frac{N W_{t}}{P_{C, t} Y_{t}}-\frac{N W}{P_{C} Y}\right)-\varepsilon_{t}^{r p}\right\}
$$

Note that $\varepsilon_{t}^{r p}$ defines a "confidence" shock following an AR (1) process with a i.i.d. Normal .

$$
\log \left(\varepsilon_{t}^{r p}\right)=\left(1-\rho_{r p}\right) \log \left(\varepsilon^{r p}\right)+\rho_{r p} \log \left(\varepsilon_{t-1}^{r p}\right)+\eta_{t}^{r p}
$$

The law of motion of foreign debt is:

$$
\frac{N W_{t}}{P_{C, t}}=R_{t-1} \frac{N W_{t-1}}{P_{C, t-1}}+N X_{t}
$$

where $N X_{t}$ stands for domestic net exports (trade balance). As a matter of fact, this characterization differs from the one presented in 2.5.1 because, in addition to shocks, deviations from full risk sharing are determined by an endogenous mechanism of foreign debt accumulation.

\subsection{Aggregation}

$$
\begin{gathered}
C_{t}=\theta C_{t}^{r t}+(1-\theta) C_{t}^{o} \\
K_{t}=(1-\theta) K_{t}^{o} \\
I_{t}=(1-\theta) I_{t}^{o} \\
B_{t}=(1-\theta) B_{t}^{o} \\
D_{t}=(1-\theta) D_{t}^{o} \\
T R_{t}=\theta T R_{t}^{r t}+(1-\theta) T R_{t}^{o} \\
T_{t}=\theta T_{t}^{r t}+(1-\theta) T_{t}^{o}
\end{gathered}
$$

\subsection{Market clearing}

The following market clearing conditions obtain. Domestic aggregate GDP in terms of consumption prices:

$$
Y_{t}=\frac{P_{t}^{H}}{P_{C, t}} Y_{t}^{H}+\frac{P_{t}^{N}}{P_{C, t}} Y_{t}^{N}
$$

Capital services:

$$
u_{t} K_{t}=u_{t}^{N} K_{t}^{N}+u_{t}^{H} K_{t}^{H}
$$

Labor input:

$$
h_{t}^{d}=h_{t}^{N}+h_{t}^{H}
$$


Labor market:

$$
\begin{gathered}
h_{t}=s_{W, t} h_{t}^{d} \\
s_{W, t}=\frac{1}{s} \int_{0}^{s}\left(\frac{W_{t}^{j}}{W_{t}}\right)^{-\frac{1+\lambda_{t}^{w}}{\lambda_{t}^{w}}} d j
\end{gathered}
$$

Investment goods:

$$
Q_{t}^{I}=I_{t}+a\left(u_{t}\right) K_{t}
$$

\subsection{Government}

The domestic government budget constraint is:

$$
P_{N, t} G_{t}+R_{t-1} B_{t}+T R_{t}=\left\{\begin{array}{c}
B_{t+1}+T_{t}+\tau^{c} P_{C, t} C_{t}+\left(\tau^{l}+\tau^{w h}+\tau^{w f}\right) W_{t} h_{t}+ \\
+\tau^{k}\left[R_{t}^{k} u_{t}-\left(a\left(u_{t}\right)+\delta\right) P_{I, t}\right] K_{t}
\end{array}\right\}
$$

where tax variables and public transfers are held constant at their steady state values, public consumption is driven by the stochastic process

$$
\log \left(\frac{g_{t}-g}{y}\right)=\rho_{G} \log \left(\frac{g_{t-1}-g}{y}\right)+\eta_{t}^{G}
$$

where lower case letters stand for variables adjusted for growth, i.e. $y_{t}=Y_{t} / Z_{t}$.

\section{$2.9 \quad$ ECB policy}

As in Christoffel et al. (2008), the common monetary authority sets the nominal interest rate according to the following log-linear Taylor rule:

$$
\begin{aligned}
\hat{R}_{t}^{E C B}= & \phi_{R} \hat{R}_{t-1}^{E C B}+\left(1-\phi_{R}\right)\left(\hat{\pi}_{t}^{E A}+\phi_{\pi}\left(\hat{\pi}_{t-1}^{E A}-\hat{\bar{\pi}}_{t}\right)+\phi_{y} \hat{y}_{t}^{E A}\right) \\
& +\phi_{\Delta \pi}\left(\hat{\pi}_{t}^{E A}-\hat{\pi}_{t-1}^{E A}\right)+\phi_{\Delta y}\left(\hat{y}_{t}^{E A}-\hat{y}_{t-1}^{E A}\right)+\hat{\varepsilon}_{t}^{r}
\end{aligned}
$$

where "^, denotes log deviations from steady state. $\pi_{t}^{E A}=P_{t}^{E A} / P_{t-1}^{E A}$ is Euro area gross inflation

rate, which is obtained from $P_{t}^{E A}=P_{C, t}^{s}\left(P_{C, t}^{*}\right)^{1-s}$, and $y_{t}^{E A}=s y_{t}+(1-s) y_{t}^{*}$ is the Euro area aggregate output, where the inflation target $\widehat{\bar{\pi}}_{t}$ is stochastic shock:

$$
\widehat{\bar{\pi}}_{t}=\rho_{\bar{\pi}} \widehat{\bar{\pi}}_{t-1}+\eta_{t}^{\bar{\pi}}
$$

\section{$3 \quad$ Estimation strategy}

The model is log-linearized around its steady state and then estimated with Bayesian estimation techniques. We use 19 time series characterizing PIIGS economies and the rest of the Euro area countries. In particular, for both groups, we use: real GDP, real private consumption, consumer price inflation, real investments, real compensation per employee, total employment, government 
spending, nontradables inflation and nontradables GDP. ${ }^{7}$ The Euro area short-term nominal interest rate completes the set of observables. ${ }^{8}$ Inflation has been computed as the log difference in the price index (overall HICP index for consumer price inflation and services HICP index for nontradables inflation). Output, consumption, investments, wages and government spending are transformed in log differences; total employment has been detrended with a linear trend. The data sample is 1996Q2-2013Q3, due to data availability.

Following Christoffel et al. (2008), the auxiliary equation

$$
\hat{e}_{t}=\frac{\beta}{1+\beta} E_{t} \hat{e}_{t+1}+\frac{1}{1+\beta} \hat{e}_{t-1}+\frac{\left(1-\xi_{e}\right)\left(1-\beta \xi_{e}\right)}{(1+\beta) \xi_{e}}\left(\hat{h}_{t}-\hat{e}_{t}\right)
$$

relates the employment variable, $e_{t}$, to the unobserved hours worked variable, $h_{t} \cdot{ }^{9}$

We include 19 structural shocks. In all our experiments we consider an interest rate shock and the following country-specific shocks: two transitory sectorial TFP shocks (eq.29), a risk premium shock (eq.49), an investment-specific shock (eq.51), a preference shock (eq.60), price and wage markup shocks (eq.38, 46), and a government spending shock (eq.84). Model A is then closed assuming a permanent labor-augmenting technology shock common to the Euro area (eq. 30) and a Central Bank inflation objective shock (eq.86). In models $\mathrm{B}$ and $\mathrm{C}$ we remove the inflation objective shock and introduce shocks that generate segmentation in the Eurozone financial markets (eq. 63 and 68, respectively). Finally, in model D we remove the inflation objective shock and allow for two country-specific shocks to the common productivity trend identified in eq. 30 .

For non stationary variables we assume a measurement equation of the type:

$$
\Delta \ln Y_{t}=\hat{y}_{t}-\hat{y}_{t-1}+\bar{\gamma}+\hat{g}_{z, t}
$$

where $\bar{\gamma}=100\left(g_{z}-1\right)$ denotes a deterministic growth trend common to the real variables while $\hat{g}_{z, t}$ is the stochastic trend component. ${ }^{10}$

For inflation variables, the observation equation is the following:

$$
\Delta \ln P_{t}=\pi_{t}+\bar{\pi}_{*}
$$

where $\bar{\pi}_{*}=100(\bar{\pi}-1)$ is the quarterly steady-state inflation rate.

With regard to employment variables, we have the following measurement equation:

$$
\ln e_{t}=\hat{e}_{t}+\bar{e}
$$

with $\bar{e}$ being a constant normalized at zero.

Finally, the nominal interest rate is defined as:

$$
\ln R_{t}^{*}=\hat{R}_{t}^{*}+\bar{R}
$$

with $\bar{R}=100\left(\beta^{-1} g_{z} \bar{\pi}-1\right)$, corresponding to the steady state nominal interest rate.

\footnotetext{
${ }^{7}$ Following Kolasa (2009), nontradables inflation is obtained by services HICP. Following Rabanal (2009), we use services GDP as a proxy for nontradables GDP.

${ }^{8}$ We use quarterly data from the Eurostat database. The group series are based on the authors' computations.

${ }^{9}$ Parameter $\xi_{e}$ determines the sensitivity of employment with respect to worked hours.

${ }^{10} \mathrm{We}$ allow for a measurement error in nontradables GDP equations.
} 


\subsection{Calibration and priors}

We calibrate a number of parameters (Table 1). The common discount factor $\beta$ is fixed at 0.9988 , which is consistent with a steady state growth rate of $2 \%$ per year (as in Christoffel et al. 2008) and a $2.5 \%$ real interest rate. Some parameters are calibrated to be equal across countries. In particular, the steady-state depreciation rate $\delta$ is 0.025 , corresponding to a $10 \%$ depreciation rate per year. The capital shares in each sector of production and country is set at 0.3 . The steady state net price markup is fixed ad $35 \%$ in both countries and sectors as well as the steady state wage markup which is set at $30 \%$. We assume that redistributive transfers between the two households groups determine a steady state consumption ratio $c^{r t} / c^{o}=0.8$.

The remaining parameters are calibrated using average data over the sample. The size of PIIGS countries, $s$, is $35 \%$, as measured by the HICP weights. The share of tradable consumption goods for the PIIGS $\left(\gamma_{c}\right)$ and the rest of the Euro area $\left(\gamma_{c}^{*}\right)$ is set to 0.624 and 0.597 respectively. These correspond to sample-average shares of goods in the HICP basket. The shares of investment goods $\left(\gamma_{i}, \gamma_{i}^{*}\right)$ are measured by the share of non-construction investments over total investment expenditures and are set to 0.43 for PIIGS and 0.49 for the rest of the Euro area. We set the share of home produced goods in the tradable index $\varpi$ equal to 0.91 for the PIIGS. This is obtained by subtracting the average ratio between total bilateral imports and GDP from 1 . The rest of the Euro area counterpart, $\varpi^{*}$, is obtained endogenously through the steady state (and gives a value of 0.96 , which is in line with the data).

The constant tax rates are obtained again from sample average. In particular, $\tau^{c}, \tau^{c, *}$ are the result of the ratio between total indirect tax revenues and consumption expenditures. Similarly, $\tau^{l}$, $\tau^{l, *}$ correspond to the ratio between total direct taxes of households over total households' wages and salaries. The capital tax rates $\tau^{k}, \tau^{k, *}$ are computed as the ratio between corporate tax revenues and corporations income. Social security contributions tax rates are obtained from the ratio of total social security contributions over wages and salaries. As a proxy for employees and employers social security contributions we suppose that $1 / 3$ of contributions are paid by the households while $2 / 3$ of contributions are paid by firms. We use average ratios for calculating government spending to GDP and debt to GDP ratios. We derive the difference between aggregate transfers and taxes to GDP ratios $(t r / y-t / y)$ as a residual from the steady state government budget constraint.

The remaining parameters are estimated with Bayesian techniques. Priors, reported in Table 2, are set in line with the literature on Euro area models (see Christoffel et al. (2008), Smets and Wouters (2003, 2005), Rabanal (2009), Kolasa (2009)). All the parameters priors are set symmetrically for the two countries, so that the data can tell about possible asymmetries. In particular, parameters measuring the persistence of the shocks are set to be Beta distributed, with mean 0.5 and standard deviation 0.1 and the standard errors of the innovations are assumed to follow Gamma distributions, similarly to Rabanal (2009). The parameters governing price and wage setting, habits, utilization elasticity, interest rate smoothing and the steady state fraction of LAMP are also Beta distributed. The fraction of LAMP $\theta, \theta^{*}$ are assumed to be Beta distributed with mean 0.4 and standard deviation 0.1 , in line with the recent results obtained for the Euro area by Albonico et al. (2014). We estimate the monetary authority's long-run (net) quarterly inflation objective $100(\bar{\pi}-1)$ assuming a prior mean of $0.5 \%$ ( $2 \%$ in annual terms), consistent with the ECB's quantitative definition of price stability. Also the trend growth rate of the economy is estimated with a Normal distribution with mean 0.6 (corresponding to $2.4 \%$ in annual terms) and 0.1 standard deviation. The priors for the elasticity of substitutions in the consumption indices $(e, v)$ are set in line with Rabanal (2009) as Normal(1, 0.5) distributions.

Risk aversion, the inverse of Frisch elasticity and the parameters of the Taylor rule are Normally 
Table 1: Calibration of parameters

\begin{tabular}{cc}
\hline \hline parameter & value \\
\hline \hline$\beta$ & 0.9988 \\
$\alpha_{N}, \alpha_{H}, \alpha_{N, *} \alpha_{F}$ & 0.025 \\
$\lambda_{p}, \lambda_{p}^{*}$ & 0.3 \\
$\lambda_{w}, \lambda_{w}^{*}$ & 0.35 \\
$\frac{c^{r t}}{c^{o}}, \frac{c^{r t, *}}{c^{o, *}}$ & 0.8 \\
$s$ & 0.35 \\
$\gamma_{c}$ & 0.624 \\
$\gamma_{c}^{*}$ & 0.597 \\
$\gamma_{i}$ & 0.43 \\
$\gamma_{i}^{*}$ & 0.49 \\
$\varpi$ & 0.91 \\
$\tau_{c}$ & 0.215 \\
$\tau_{c}^{*}$ & 0.23 \\
$\tau_{l}$ & 0.303 \\
$\tau_{l}^{*}$ & 0.229 \\
$\tau_{k}$ & 0.206 \\
$\tau_{k}^{*}$ & 0.159 \\
$\tau_{w h}$ & 0.127 \\
$\tau_{w h}^{*}$ & 0.131 \\
$\tau_{w f}$ & 0.254 \\
$\tau_{w f}^{*}$ & 0.262 \\
$\frac{b}{y}$ & $0.912^{*} 4$ \\
$\frac{b^{*}}{y^{*}}$ & $0.669 * 4$ \\
$\frac{g}{y}$ & 0.186 \\
$\frac{g^{*}}{y^{*}}$ & 0.207 \\
\hline \hline
\end{tabular}


distributed, whereas the parameter defining investment adjustment costs is Gamma distributed.

Table 2: Prior distributions of parameters

\begin{tabular}{|c|c|c|c|}
\hline parameters & shape & mean & std dev \\
\hline $\bar{\gamma}$ & norm & 0.6 & 0.1 \\
\hline$\overline{\pi_{*}}$ & norm & 0.5 & 0.1 \\
\hline$e, v$ & gamma & 1 & 0.5 \\
\hline$\sigma, \sigma^{*}$ & norm & 2.5 & 0.375 \\
\hline$\zeta, \zeta^{*}$ & beta & 0.6 & 0.1 \\
\hline$\phi_{l}, \phi_{l}^{*}$ & norm & 2.5 & 0.4 \\
\hline$\theta, \theta^{*}$ & beta & 0.4 & 0.1 \\
\hline$\gamma_{I}, \gamma_{I}^{*}$ & gamma & 4 & 0.5 \\
\hline$\sigma_{u}, \sigma_{u}^{*}$ & beta & 0.5 & 0.15 \\
\hline$\chi_{n}^{N}, \chi_{p}^{N, *}, \chi_{n}^{H}, \chi_{n}^{F}$ & beta & 0.75 & 0.1 \\
\hline$\xi_{n}^{N}, \xi_{n}^{N, *}, \xi_{n}^{H}, \xi_{n}^{F}$ & beta & 0.75 & 0.1 \\
\hline$\chi_{w}, \chi_{w}^{*}$ & beta & 0.75 & 0.1 \\
\hline$\xi_{w}, \xi_{w}^{*}$ & beta & 0.75 & 0.1 \\
\hline$\xi_{e}, \xi_{e}^{*}$ & beta & 0.5 & 0.15 \\
\hline$\phi_{r}$ & beta & 0.9 & 0.05 \\
\hline$\phi_{\pi}$ & norm & 1.7 & 0.1 \\
\hline$\phi_{y}$ & norm & 0.12 & 0.05 \\
\hline$\phi_{\Delta y}$ & norm & 0.063 & 0.05 \\
\hline$\phi_{\Delta \pi}$ & norm & 0.3 & 0.1 \\
\hline shocks persistences $(\rho)$ & beta & 0.5 & 0.1 \\
\hline$\sigma^{g z}, \sigma^{g z, *}, \sigma^{a, N}, \sigma^{a, H}, \sigma^{a, N, *}, \sigma^{a, F}$ & gamma & 0.7 & 0.3 \\
\hline$\sigma^{b}, \sigma^{b, *}, \sigma^{r}, \sigma^{\pi}, \sigma^{r s h}$ & gamma & 0.4 & 0.2 \\
\hline$\sigma^{c}, \sigma^{c, *}, \sigma^{i}, \sigma^{i, *}, \sigma^{w}, \sigma^{w, *}, \sigma^{p}, \sigma^{p, *}, \sigma^{g}, \sigma^{g, *}$ & gamma & 1 & 0.5 \\
\hline
\end{tabular}

\section{Results}

\subsection{Posterior estimates}

Tables 3 and 4 show the posterior mean estimates of structural parameters and shocks under the different specifications of the model. The four specifications yield fairly similar posterior estimates for the common parameters, which appear to be well identified. ${ }^{11}$ Model D is strongly preferred on the grounds of the marginal data density (-870), followed by model A (-915).

All models yield a larger posterior estimate for the share of non-Ricardian households in the core countries region than in the PIIGS region. This result survives also if we estimate the model for a shorter sample which excludes the financial crisis (1996q2-2007q3). Under specification D, in the PIIGS the fraction is $25 \%$ (29.7\% with the full sample) while in the core region is $30.6 \%$ (increasing to $41.6 \%$ considering the crisis period). This latter result is also in line with previous findings for the Euro area in Albonico et al. (2014), where the authors show how this fraction has increased due to the financial retrenchment during the recent crisis. The finding that the share

\footnotetext{
${ }^{11}$ Visual diagnostics of the estimation results are available upon request. The posterior distributions are computed considering 4 Monte Carlo Markov chains of 250,000 draws each, with $20 \%$ draws being discarded as burn-in draws. The average acceptance rate is comprised between 23 and 35 percent.
} 
of non-Ricardian households is larger in the core region is not entirely new in the literature. Di Bartolomeo et. al. (2011) estimate a larger fraction of LAMP consumers in France (44\%) than in Italy $(9 \%)$. These authors argue that it could be due to differences in savings rates and/or to different structures of the financial markets. We checked the average savings rates for the two group of countries and we could not find such a significant difference between the two regions, indeed the savings rate is higher in the core countries. More recently, Kaplan et al. (2014) estimated the fraction of LAMP using survey data. Their theoretical approach is a bit different from ours. In fact, they allow for the possibility that the total fraction of LAMP is composed by "poor hand-tomouth" consumers, who do not hold any type of assets, and "wealthy hand-to-mouth" consumers, i.e. consumers holding illiquid assets, such as housing, but whose consumption is still strongly correlated with their income. They show that the presence of these "wealthy hand-to-mouth" consumers can significantly influence the estimates of the total LAMP fraction. In particular, for a cross-section of 2010 they find that, although the fraction of "poor hand-to-mouth" consumers in Germany and Italy is not very different $\left(7.4 \%\right.$ versus $8.3 \%$ respectively $\left.^{12}\right)$, the gap between the two countries is reversed and increases considerably if "wealthy hand-to-mouth" consumers are taken into account. In this case, in fact, Germany's total fraction of LAMP is found to be $32.2 \%$, while being only $23.8 \%$ in Italy and $19.6 \%$ in Spain. Our results appear then in line with this finding.

In Table 5 we report the variance decomposition obtained under model D. The first striking result is that technology and demand shocks have different importance in the two regions. In the PIIGS region demand shocks play a lesser role than in the rest of the Euro area. The second striking result is that shocks originating in one region have a minimal impact onto the rest of the Eurozone.

In Table 6 in the Appendix we check the variance decomposition of model $\mathrm{B}$, to get some intuition about the importance of the risk sharing shock in explaining macro variables volatilities. The role of the risk sharing is negligible.

\subsection{Output growth determinants during the post-2007 crises}

In this section, we present the historical decomposition of output growth to gain intuition about which shocks caused the recent crises in the Euro area. ${ }^{13}$ This analysis is also useful to detect possible spillover effects and transmission of shocks across the two regions.

Figure 1 shows that in the CORE countries the 2008-2009 global crisis has been mainly characterized by adverse demand shocks. In this model the demand shocks include investment-specific and risk premium shocks. A contractionary investment-specific shock entails a drop in investment and consumption (the latter effect being due to the presence of LAMP consumers, as discussed in Furlanetto et al., 2013). Similarly, in case of a negative risk premium shock the wedge between the return on capital accruing to households and the price of capital paid by firms causes a decrease in capital demand and thus investment. The weaker demand pushes the economic system into recession. Differently, in the PIIGS region (Figure 2) the financial crisis has been determined by a combination of demand and technology shocks. The contribution of the interest rate policy was contractionary in both regions.

Asymmetries between the two region become more important after the onset of the Greek crisis in 2010. In the core region the initial faint recovery has been due to favorable demand shocks and to the ECB accommodative interest rate policy. The subsequent slowdown has been determined

\footnotetext{
${ }^{12}$ Note that the value for Spain is even lower (4.4\%), although also for France a value of $3.2 \%$ is found.

${ }^{13}$ We show the results obtained under model D. However, the other specifications give similar results.
} 
Table 3: Posterior mean estimates of parameters

\begin{tabular}{|c|c|c|c|c|}
\hline \multirow[t]{2}{*}{ parameters } & \multicolumn{4}{|c|}{ MODEL } \\
\hline & A & $\mathrm{B}$ & $\mathrm{C}$ & $\mathrm{D}$ \\
\hline $\bar{\gamma}$ & 0.369 & 0.366 & $\overline{0.342}$ & 0.349 \\
\hline $\bar{\pi}_{*}$ & 0.392 & 0.470 & 0.438 & 0.395 \\
\hline$e$ & 0.565 & 0.565 & 0.497 & 0.564 \\
\hline$v$ & 1.404 & 2.205 & 1.404 & 1.966 \\
\hline$\sigma$ & 2.287 & 2.339 & 2.572 & 2.436 \\
\hline$\sigma^{*}$ & 2.548 & 2.405 & 2.442 & 2.623 \\
\hline$b$ & 0.673 & 0.660 & 0.705 & 0.621 \\
\hline$b^{*}$ & 0.597 & 0.598 & 0.581 & 0.645 \\
\hline$\phi_{l}$ & 2.741 & 2.744 & 2.752 & 2.879 \\
\hline$\phi_{l}^{*}$ & 2.730 & 2.795 & 2.807 & 2.763 \\
\hline$\theta$ & 0.311 & 0.302 & 0.323 & 0.297 \\
\hline$\theta^{*}$ & 0.488 & 0.511 & 0.508 & 0.416 \\
\hline$\gamma_{I}$ & 4.804 & 4.353 & 4.629 & 4.615 \\
\hline$\gamma_{I}^{*}$ & 4.415 & 4.472 & 4.304 & 4.697 \\
\hline$\sigma_{u}$ & 0.354 & 0.395 & 0.338 & 0.183 \\
\hline$\sigma_{u}^{*}$ & 0.463 & 0.414 & 0.403 & 0.467 \\
\hline$\chi_{p}^{N}$ & 0.961 & 0.817 & 0.816 & 0.883 \\
\hline$\chi_{p}^{N, *}$ & 0.894 & 0.848 & 0.846 & 0.859 \\
\hline$\chi_{p}^{H}$ & 0.282 & 0.462 & 0.512 & 0.255 \\
\hline$\chi_{p}^{F}$ & 0.433 & 0.352 & 0.369 & 0.345 \\
\hline$\xi_{p}^{N}$ & 0.892 & 0.889 & 0.892 & 0.663 \\
\hline$\xi_{p}^{N, *}$ & 0.547 & 0.531 & 0.536 & 0.557 \\
\hline$\xi_{p}^{H}$ & 0.888 & 0.539 & 0.499 & 0.613 \\
\hline$\xi_{p}^{F}$ & 0.493 & 0.478 & 0.483 & 0.502 \\
\hline$\chi_{w}$ & 0.712 & 0.745 & 0.740 & 0.717 \\
\hline$\chi_{w}^{*}$ & 0.738 & 0.678 & 0.759 & 0.641 \\
\hline$\xi_{w}$ & 0.840 & 0.866 & 0.875 & 0.770 \\
\hline$\xi_{w}^{*}$ & 0.832 & 0.831 & 0.829 & 0.849 \\
\hline$\xi_{e}$ & 0.658 & 0.682 & 0.672 & 0.619 \\
\hline$\xi_{e}^{*}$ & 0.549 & 0.534 & 0.538 & 0.563 \\
\hline$\phi_{r}$ & 0.872 & 0.874 & 0.898 & 0.879 \\
\hline$\phi_{\pi}$ & 1.602 & 1.640 & 1.612 & 1.682 \\
\hline$\phi_{y}$ & 0.034 & 0.030 & 0.029 & 0.023 \\
\hline$\phi_{\Delta y}$ & 0.163 & 0.164 & 0.149 & 0.167 \\
\hline$\phi_{\Delta \pi}$ & 0.249 & 0.206 & 0.171 & 0.216 \\
\hline$\Gamma_{b}$ & & & 0.018 & \\
\hline MDD & -914.5 & -946.2 & -985.3 & -869.7 \\
\hline
\end{tabular}


Table 4: Posterior mean estimates of shocks

\begin{tabular}{c|cccc}
\hline \hline parameters & \multicolumn{4}{|c}{ MODEL } \\
\hline \hline & $\mathrm{A}$ & $\mathrm{B}$ & $\mathrm{C}$ & $\mathrm{D}$ \\
\hline$\rho_{a, H}$ & 0.888 & 0.864 & 0.873 & 0.636 \\
$\rho_{a, F}$ & 0.575 & 0.621 & 0.618 & 0.636 \\
$\rho_{a, N}$ & 0.722 & 0.894 & 0.920 & 0.621 \\
$\rho_{a, N, *}$ & 0.596 & 0.594 & 0.607 & 0.584 \\
$\rho_{c}$ & 0.935 & 0.924 & 0.879 & 0.512 \\
$\rho_{c, *}$ & 0.437 & 0.489 & 0.409 & 0.591 \\
$\rho_{b}$ & 0.836 & 0.838 & 0.809 & 0.795 \\
$\rho_{b, *}$ & 0.820 & 0.809 & 0.802 & 0.836 \\
$\rho_{i}$ & 0.519 & 0.547 & 0.579 & 0.476 \\
$\rho_{i, *}$ & 0.627 & 0.676 & 0.832 & 0.555 \\
$\rho_{p}$ & 0.494 & 0.839 & 0.875 & 0.939 \\
$\rho_{p, *}$ & 0.949 & 0.948 & 0.944 & 0.948 \\
$\rho_{w}$ & 0.633 & 0.516 & 0.466 & 0.729 \\
$\rho_{w, *}$ & 0.781 & 0.732 & 0.685 & 0.721 \\
$\rho_{g}$ & 0.919 & 0.917 & 0.908 & 0.442 \\
$\rho_{g, *}$ & 0.880 & 0.856 & 0.877 & 0.789 \\
$\rho_{g z}$ & 0.483 & 0.515 & 0.480 & 0.544 \\
$\rho_{g z, *}$ & & & & 0.485 \\
$\rho_{s}(\mathrm{~A}), \rho_{r p}(\mathrm{C})$ & & 0.491 & 0.668 & \\
$\sigma_{a, H}$ & 1.547 & 1.447 & 1.384 & 1.325 \\
$\sigma_{a, F}$ & 1.003 & 0.975 & 0.950 & 1.046 \\
$\sigma_{a, N}$ & 0.807 & 1.710 & 1.487 & 1.123 \\
$\sigma_{a, N, *}$ & 0.697 & 0.669 & 0.694 & 0.739 \\
$\sigma_{c}$ & 2.302 & 2.383 & 2.696 & 1.053 \\
$\sigma_{c, *}$ & 1.425 & 1.318 & 1.481 & 1.656 \\
$\sigma_{b}$ & 1.919 & 2.055 & 1.908 & 1.715 \\
$\sigma_{b, *}$ & 2.183 & 2.045 & 2.072 & 2.261 \\
$\sigma_{i}$ & 0.178 & 0.186 & 0.174 & 0.186 \\
$\sigma_{i, *}$ & 0.179 & 0.175 & 0.147 & 0.193 \\
$\sigma_{p}$ & 0.168 & 0.092 & 0.085 & 0.270 \\
$\sigma_{p, *}$ & 0.298 & 0.326 & 0.319 & 0.285 \\
$\sigma_{w}$ & 0.274 & 0.302 & 0.300 & 0.299 \\
$\sigma_{w, *}$ & 0.099 & 0.123 & 0.135 & 0.115 \\
$\sigma_{g}$ & 0.238 & 0.242 & 0.248 & 0.142 \\
$\sigma_{g, *}$ & 0.108 & 0.102 & 0.103 & 0.097 \\
$\sigma_{g z}$ & 0.318 & 0.294 & 0.297 & 0.604 \\
$\sigma_{g z, *}$ & & & & 0.274 \\
$\sigma_{r}$ & 0.107 & 0.095 & 0.076 & 0.104 \\
$\sigma_{p i}(\mathrm{~A}), \sigma_{s}(\mathrm{~B}), \sigma_{r p}(\mathrm{C})$ & 0.656 & 0.435 & 0.050 & \\
$\sigma_{m e}$ & 0.533 & 0.535 & 0.539 & 0.519 \\
$\sigma_{m e, *}$ & 0.437 & 0.433 & 0.431 & 0.433 \\
\hline \hline & & & & \\
\hline
\end{tabular}




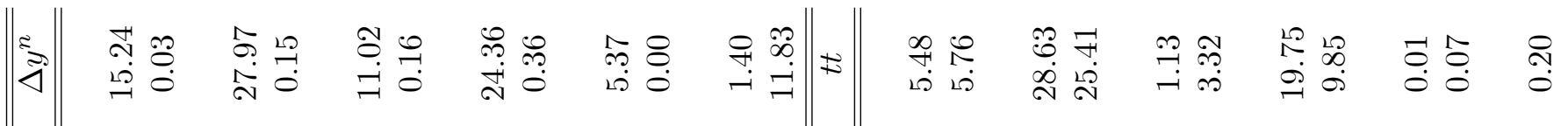

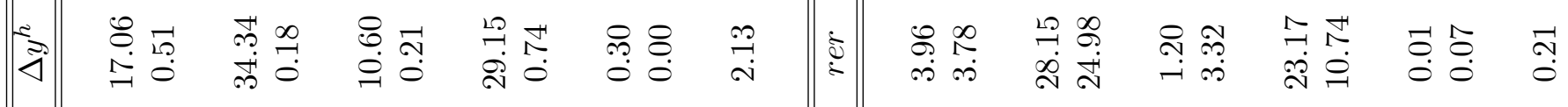

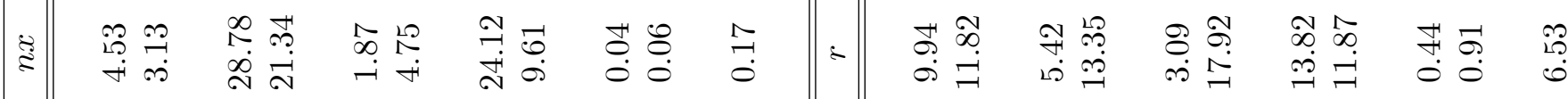

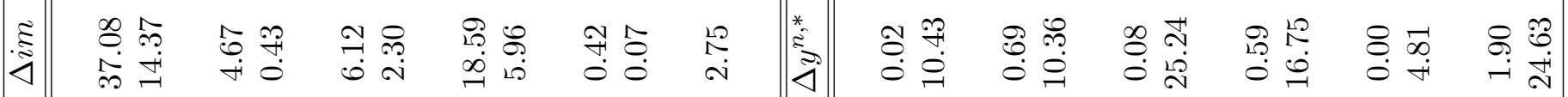

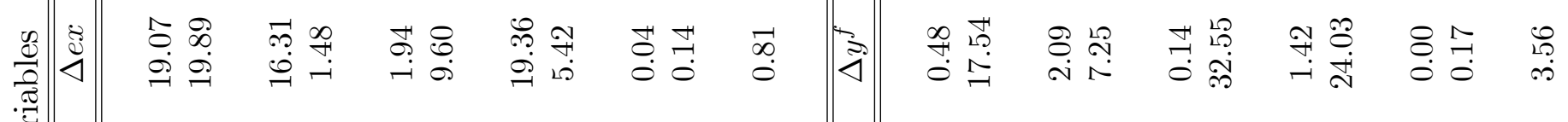

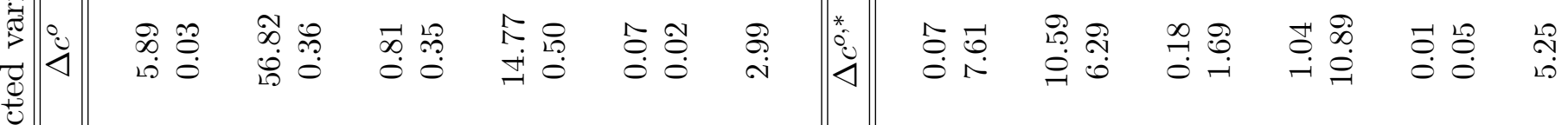

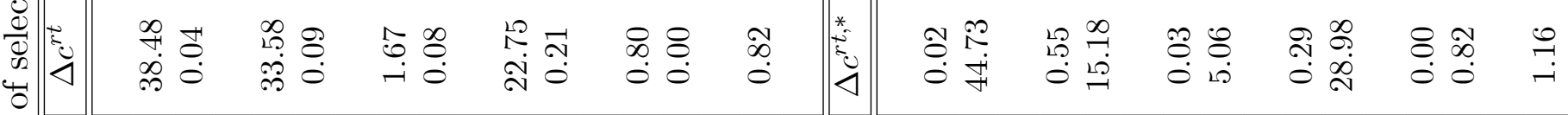

:

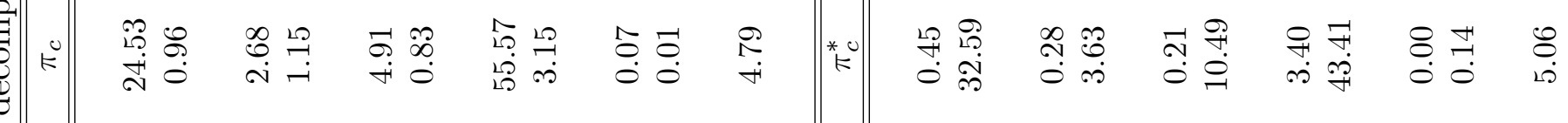

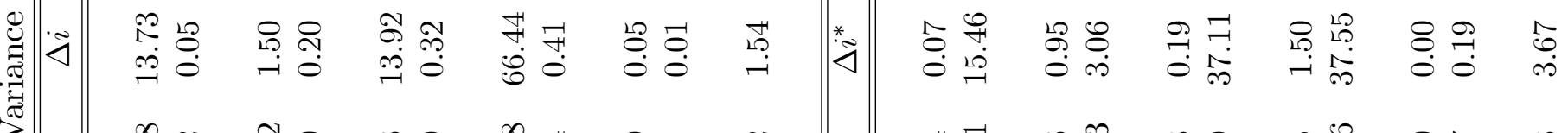

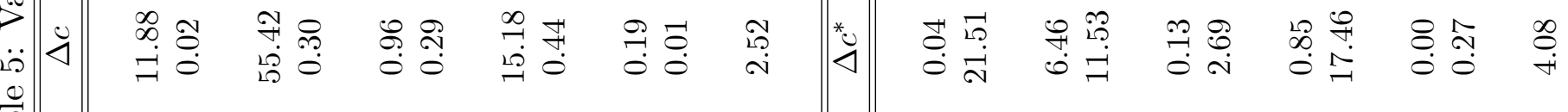

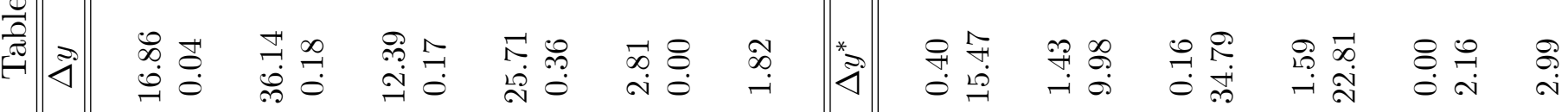

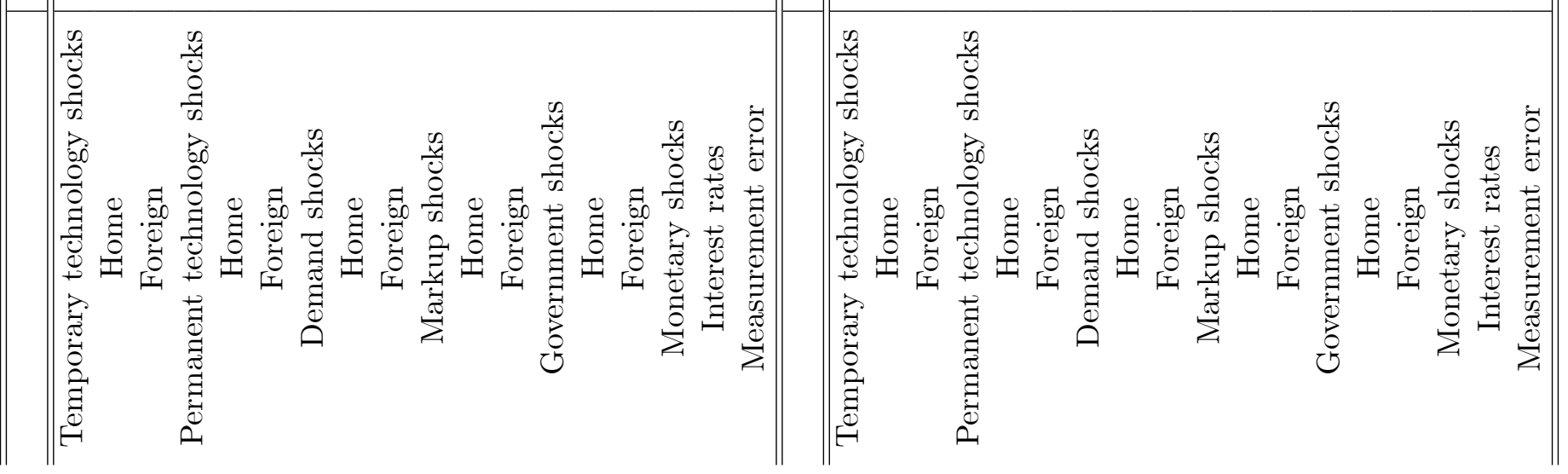


by negative demand shocks, partly offset by favorable markup shocks. Differently, the largest part of the double dip in the PIIGS is explained by adverse permanent technology shocks.

Figures 3 and 4 show that each region country-specific shocks drove output growth volatility. Each region is only marginally affected by shocks originating in the other group. All in all, permanent technology shocks seem to have played a key role in explaining growth differentials in the Eurozone.

Finally, in Figures 5 and 6 we present the historical decompositions of the growth in the PublicConsumption-to-GDP ratios. We have already shown that public consumption shocks were not particularly important to explain output growth volatility. Here we observe important differences in the post-2007 drivers of the two ratios. In the CORE region the ratio almost exclusively reacted to domestic shocks, implying that public consumption had a stabilizing effect. By contrast, in the PIIGS region the ratio is more responsive to fiscal shocks. However, it is difficult to identify a pattern in these discretionary actions.

Figure 1: Rest of EA output growth historical decomposition by nature of shocks.

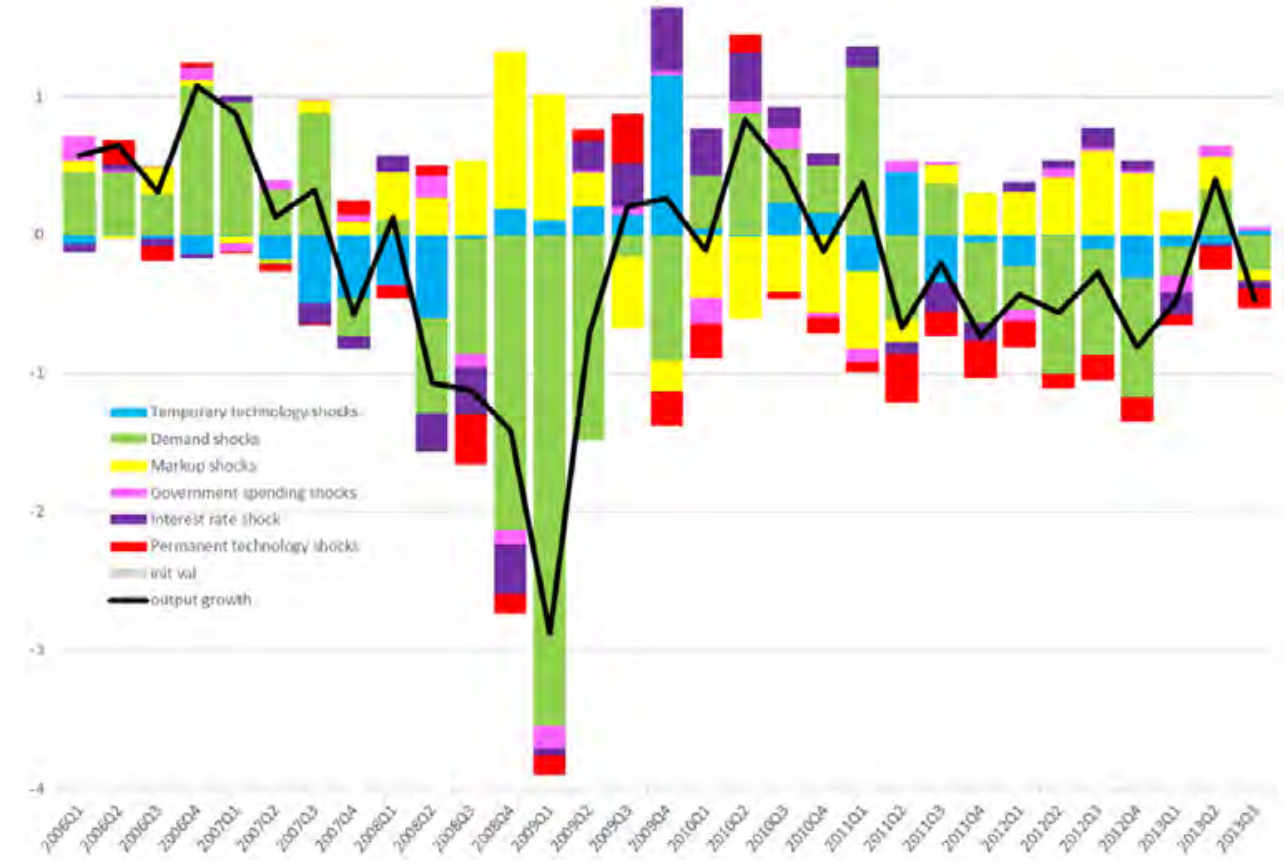

\subsubsection{Inspecting the black box: the transmission mechanism and the possible inter- pretations of shocks to PIIGS productivity growth rate}

The analysis of the historical decomposition of output growth stresses the importance of permanent technology shocks in the PIIGS region. This section aims at better understanding the effects of this shock. A temporary slowdown in productivity growth has a widespread contractionary effect in the PIIGS region. All households reduce consumption, investment output and hours worked fall, along with the real wage and inflation. There are two key differences with respect to a temporary technology shock: the first is that Ricardian consumers now react to the permanent income reduction and do not smooth consumption, the second is that the effects of the permanent shock accumulate in the long run. On impact, we observe a limited positive transmission to output, consumption and hours worked in the CORE region (Figure 8). The permanent shock to PIIGS 
Figure 2: PIIGS output growth historical decomposition by nature of shocks.

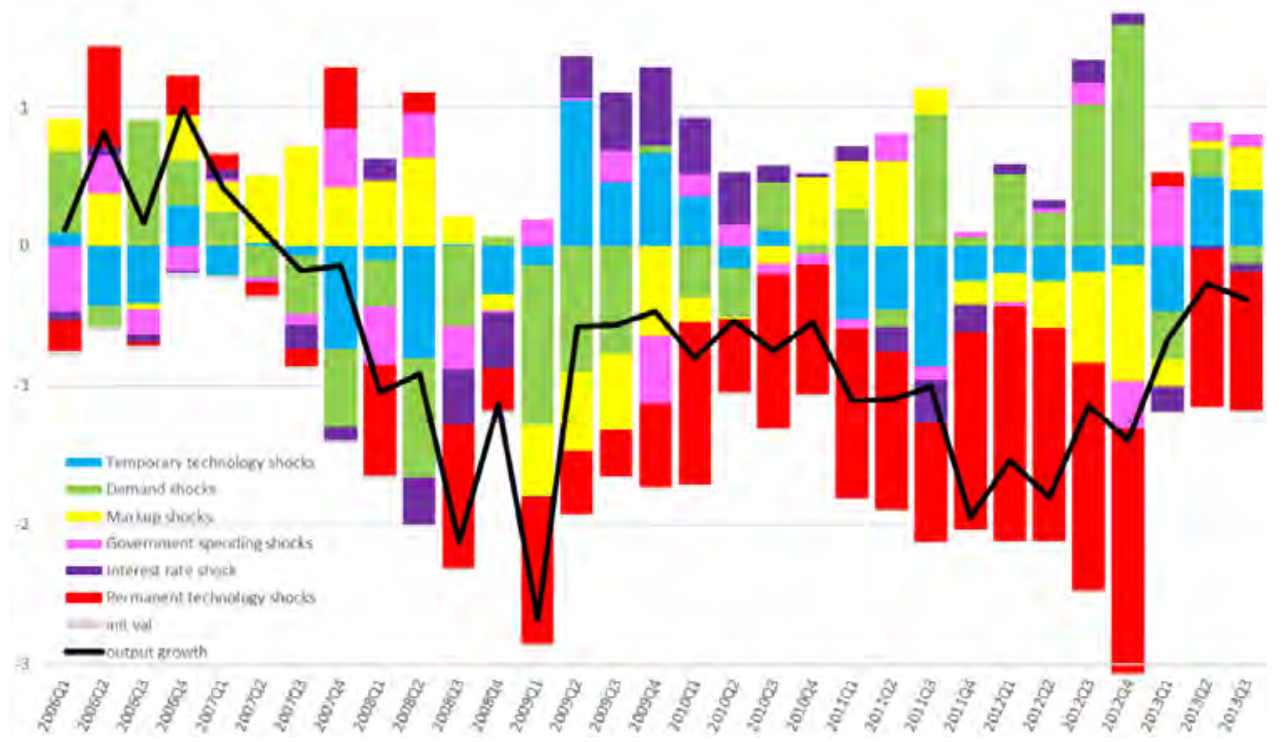

Figure 3: Rest of EA output growth historical decomposition by country origin of shocks.

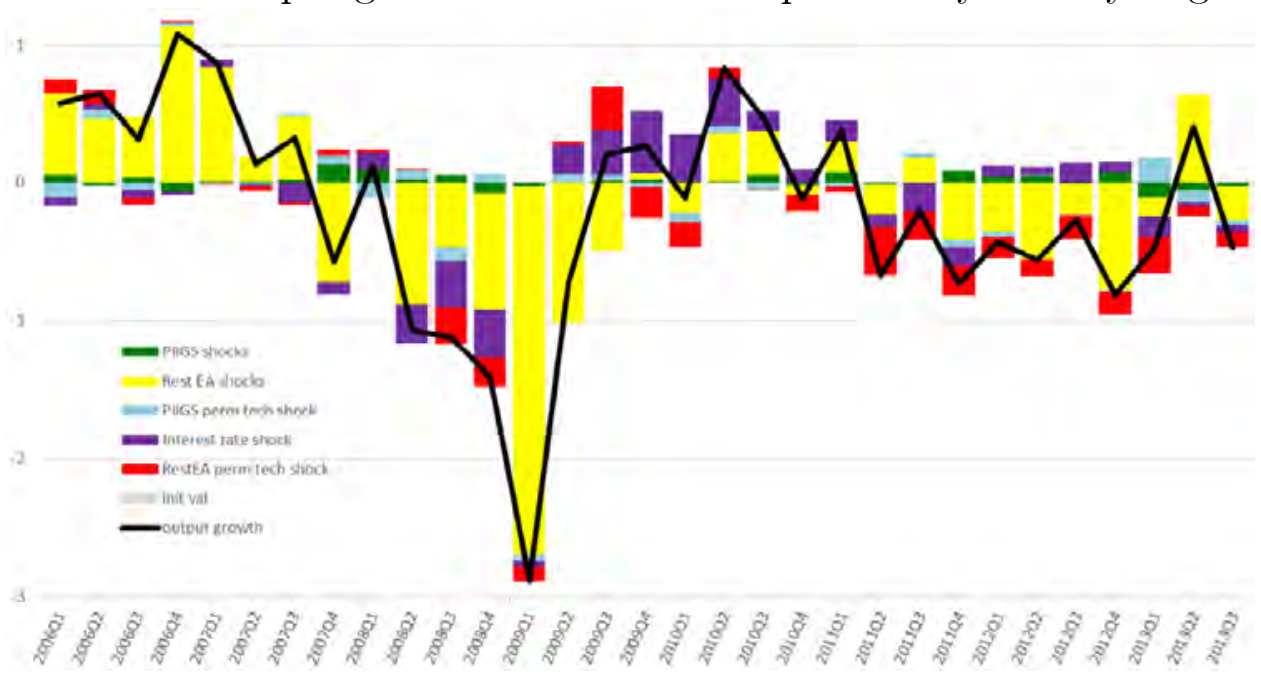


Figure 4: PIIGS output growth historical decomposition by country origin of shocks.

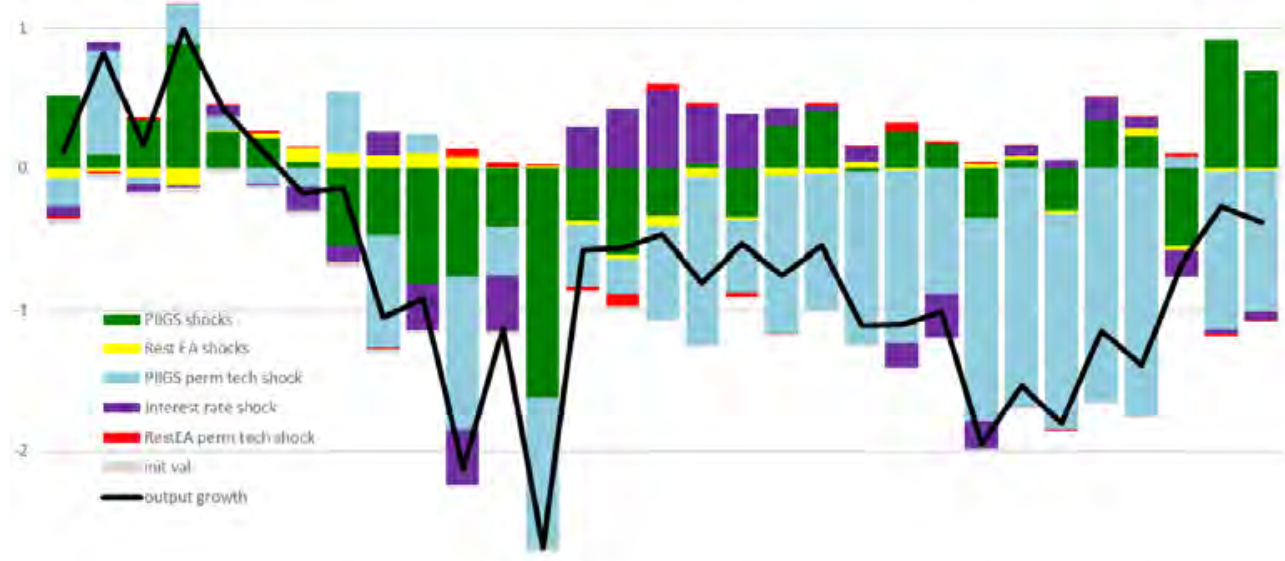

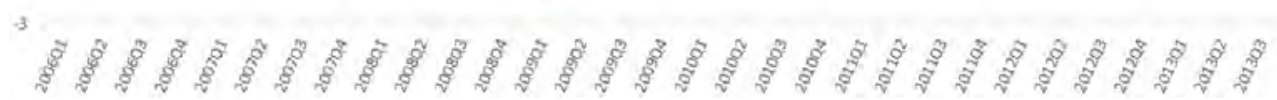

Figure 5: PIIGS G/Y growth historical decomposition.

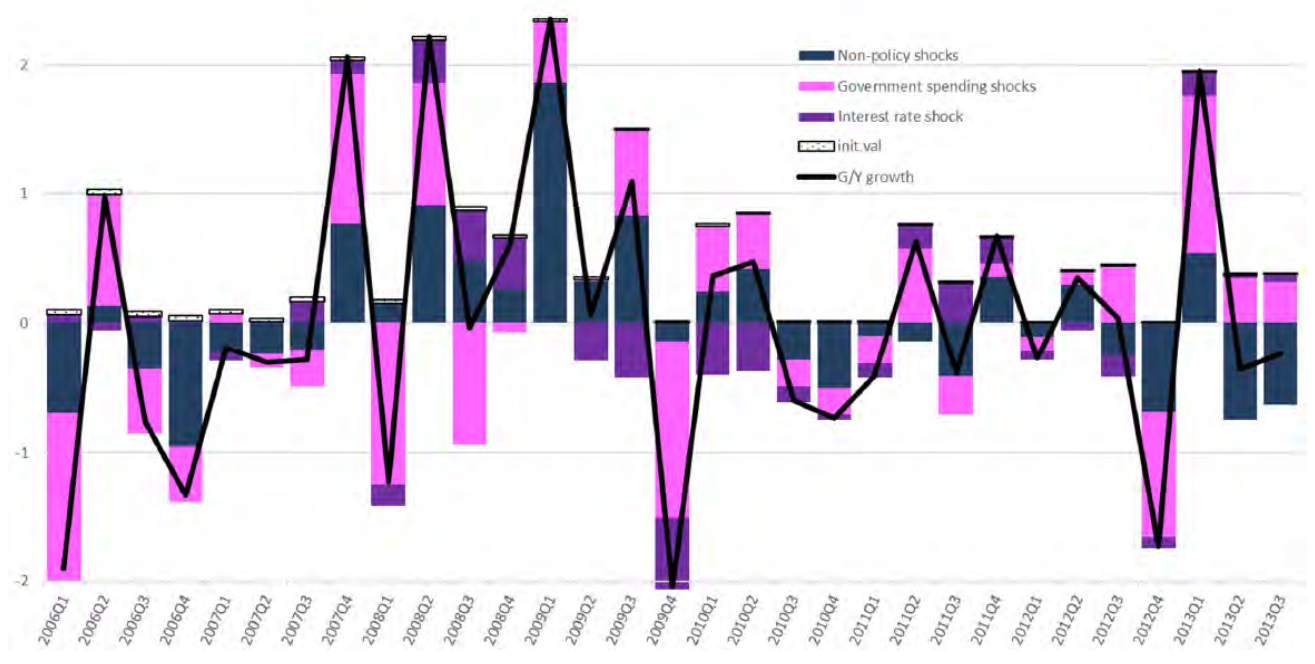


Figure 6: Rest of thr EA G/Y growth historical decomposition.

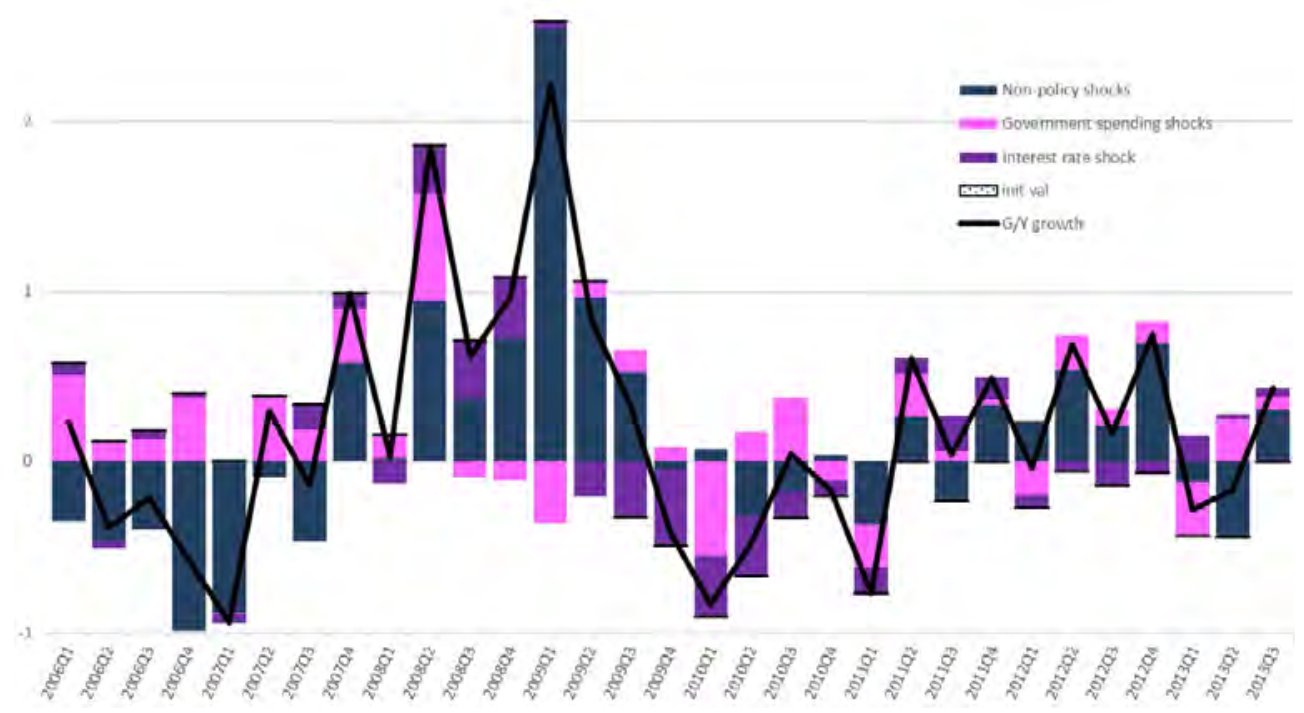

productivity level has no statistically significant long-run effects in the CORE region. Considering the aggregate Euro area, we observe a temporary fall in inflation and a permanent output loss.

Figure 7: PIIGS IRFs to a negative growth rate shock in the PIIGS under model D.
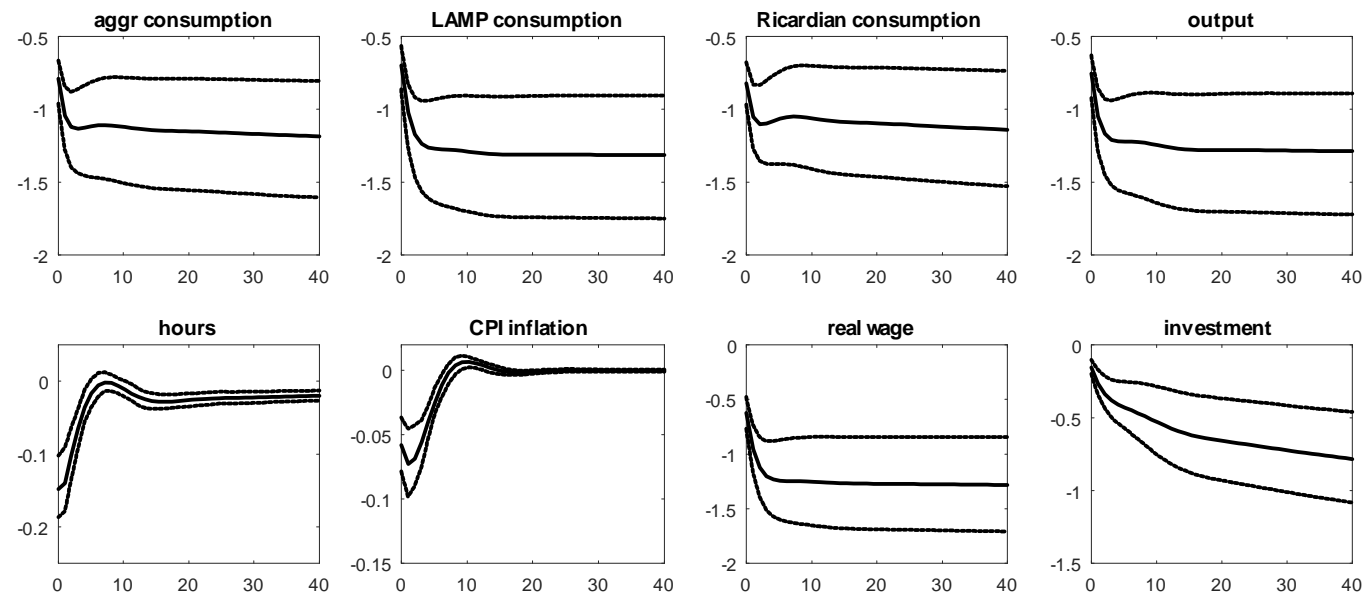

But how can we interpret the sequence of adverse permanent technology shocks that started in 2008 and persisted until the end of our sample? According to a popular view (Shambaugh, 2012), the financial shocks and the weak growth rate are distinct and mutually reinforcing factors in the Eurozone crisis. Our estimates suggest that neither the risk sharing shock nor the "confidence" shock in (67) seem to have played any role during the crises, ${ }^{14}$ nor the PIIGS growth slowdown was caused by standard domestic shocks such as the risk premium and the investment-specific shocks. ${ }^{15}$

\footnotetext{
${ }^{14}$ Note that these shocks typically impact on Ricardian households demand and saving decisions but have no direct effect on the supply side.

${ }^{15}$ According to Justiniano et al. (2011), an adverse investment-specific shock might be interpreted as a loss of efficiency in the financial intermediation process that allows to transform savings into future capital inputs.
} 
Figure 8: Core countries IRFs to a negative growth rate shock in the PIIGS under model D.
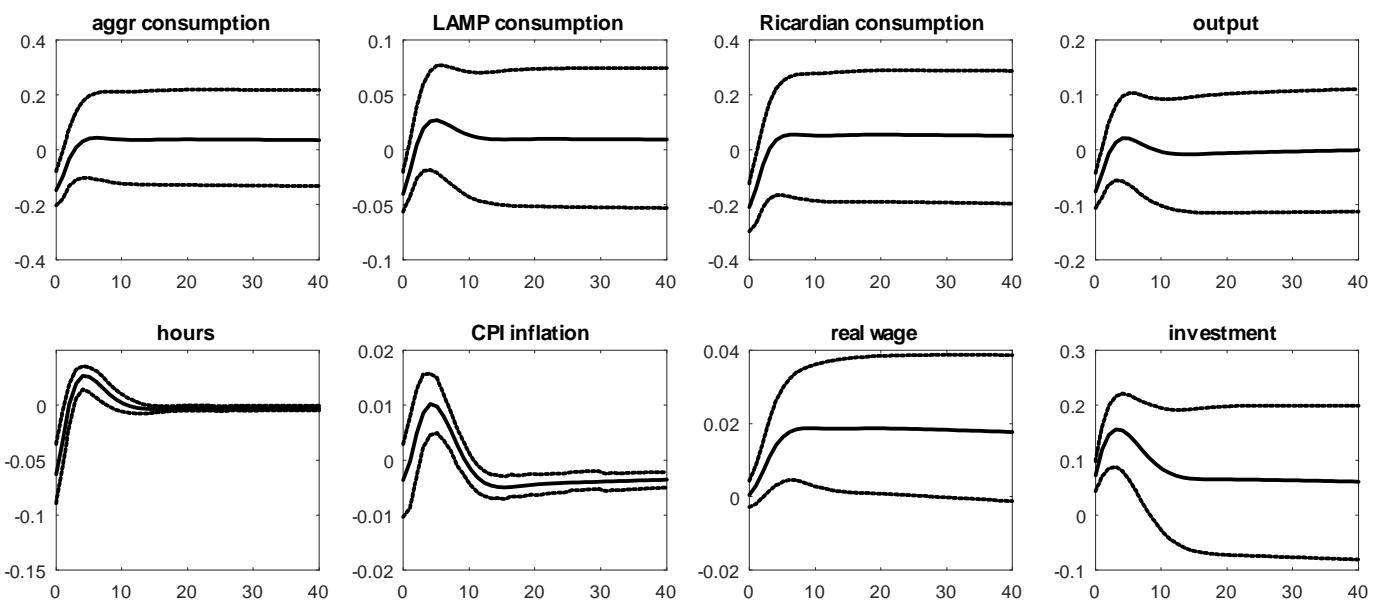

Figure 9: Other variables IRFs to a negative growth rate shock in the PIIGS under model D.
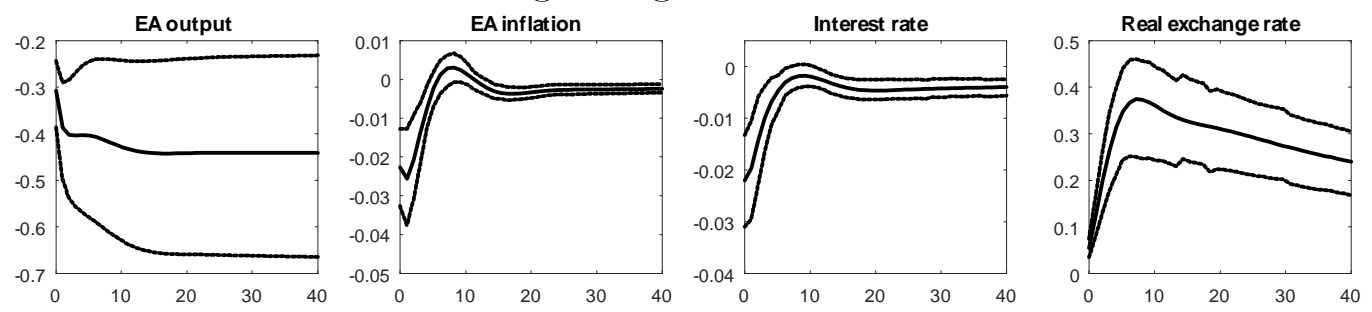
In fact, the shocks to productivity growth are crucial to characterize PIIGS performance. Bearing in mind that we cannot find evidence of adverse productivity shocks in the rest of the Eurozone during the same period, it is tempting to interpret them as a consequence of specific features of the financial crises in the Eurozone periphery.

The Post 2007 financial crisis in the PIIGS region is a multifaceted event. Figure 10 shows that a reversal in total capital flows took place only after 2011, and was compensated by an increase in public capital inflows. However, commercial banks channel the bulk of firms credit in these countries and Figure 11 documents the post-2008 reversal in the external funds accruing to banks in the PIIGS region. Bonds spreads (Figure 12) also document that in the region the relative cost of credit strongly increased since $2010 .^{16}$ If one takes the ratio of non-performing to total gross loans as a proxy for the availability of bank credit (Nkusu, 2011), there is little doubt that the situation in the PIIGS region was certainly worse than in the rest of the Eurozone (see Figure 13).

Khan and Thomas (2013) provide a theoretical explanation of the reason why a credit crunch may adversely affect productivity. In their model collateralized borrowing constraints and partial investment irreversibilities imply that firms net worth, as opposed to productivity, drives external finance flows and firms capital accumulation. Adverse financial shocks cause large and persistent disruptions to the cross-sectional distribution of capital, penalizing firms characterized by relatively high productivity but relatively low net worth. This, in turn, implies large and persistent reductions in aggregate total factor productivity. A growing body of empirical evidence provides support for this view. Furceri and Mourougane (2012) find that the occurrence of a financial crisis hits negatively and permanently potential output in a panel of OECD countries. Benigno et al. (2015) identify 155 episodes of large capital inflows and find that larger inflows of foreign capital are associated with a deeper fall in TFP, measured by the Solow residual, at the end of the episode. Gopinath et al. (2015) provide microeconometric evidence on manufacturing firms total factor productivity in a number of Eurozone countries. They find that after 2008 an increase in the dispersion in firm-specific productivity shocks was associated to a downward trend in TFP in manufacturing sectors in Spain and Italy. These phenomena were not observed for Germany and France. Identifying TFP with the Solow residual without controlling for varying factor utilization, as these studies do, is open to criticism (Basu et al. 2006), but our results seem to provide further indirect support for the Khan and Thomas (2013) argument. Finally, it is interesting to note that Acharya et al. (2016) document a substantial credit misallocation in the Eurozone periphery, where undercapitalized banks continued to lend to their distressed borrowers in order to avoid losses on outstanding loans, at the expenses of more creditworthy and productive firms.

\footnotetext{
${ }^{16}$ Gunn and Johri (2013) identify the transmission channel from severeign to bank loans spreads.
} 
Figure 10: PIIGS: public and private capital flows (blue and red line repectively). Source: Gros and Alcidi (2013).

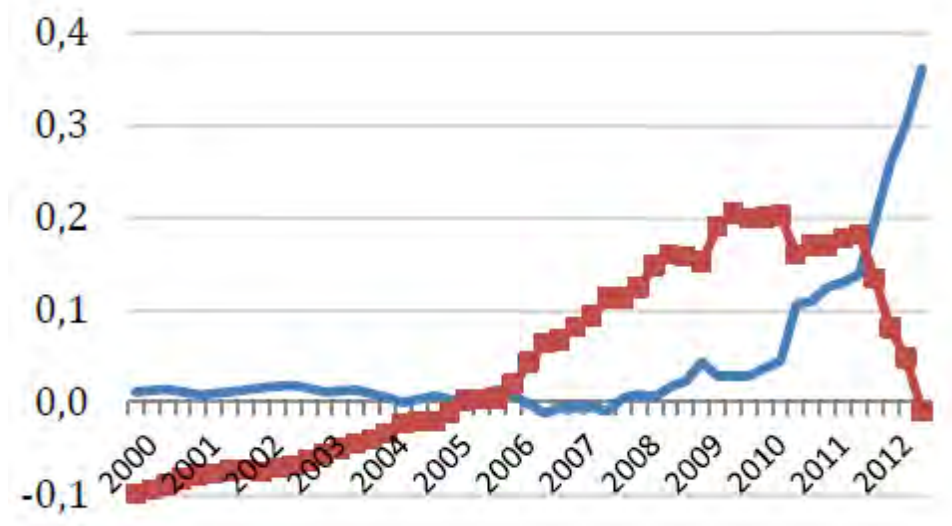

Figure 11: BIS-reporting banks external claims vis-à-vis PIIGS countries (Index, base year Dec. 1999=100). Source: Gros and Alcidi (2013).

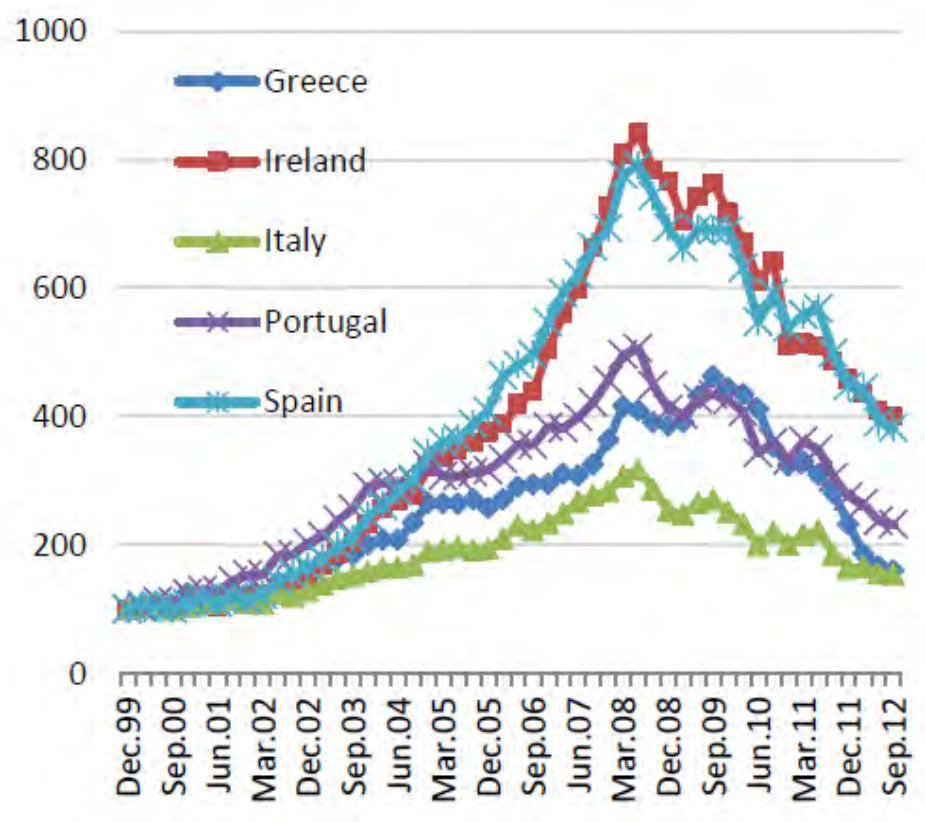


Figure 12: Spreads 10-year government bond rates eurozone.

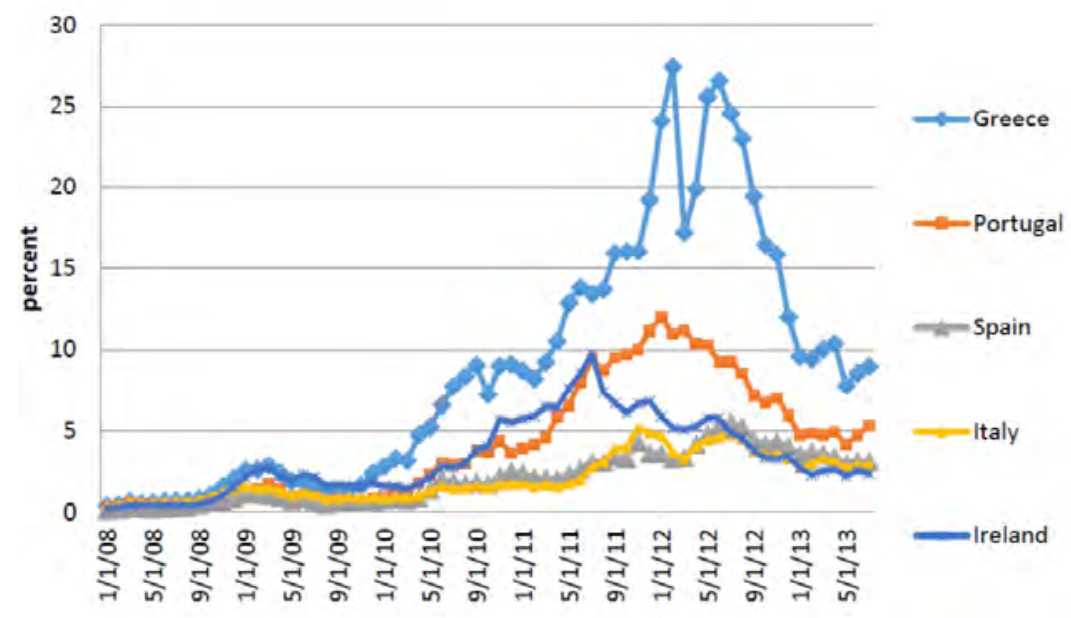

Figure 13: Bank nonperforming loans to total gross loans (\%) Source: World Bank.

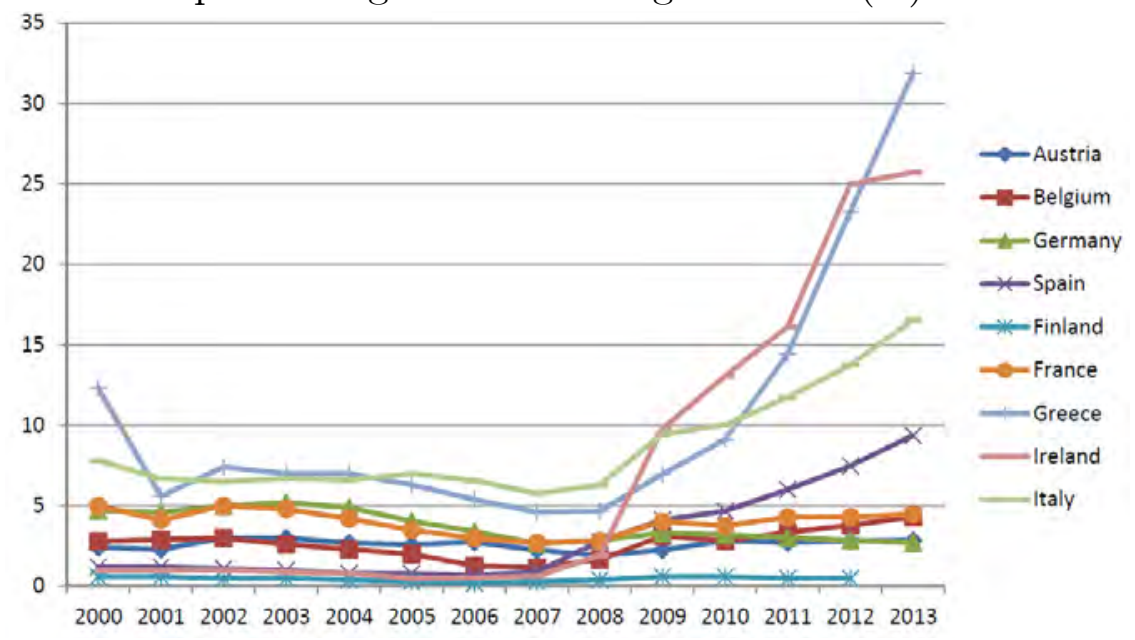




\section{Conclusions}

In this paper we build a medium-scale two country model for the European monetary union. The aim is in fact to understand the interactions between the PIIGS and the CORE regions of the Eurozone.

We consider different specifications of the model, concerning the structure of shocks and segmentation of financial markets. We obtain similar estimates for structural parameters in the two regions, but the shocks that caused the post-2007 crises appear to be quite different. Permanent adverse productivity shocks explain the worse performance of the PIIGS region.

Our analysis has also shown that in both regions public consumption did not particularly contribute to output growth volatility either before or after 2007. We do observe, however, important differences in the post-2007 drivers of the public consumption-to-GDP ratios. In the CORE region the ratio almost exclusively reacted to domestic shocks, implying that relative public consumption stability had a stabilizing effect. By contrast, in the PIIGS region the ratio is more responsive to fiscal shocks. However, it is difficult to interpret such shocks as attempts to stabilize the economy in bad times or, to the contrary, as the consequence of austerity imposed by EMU institutions. This latter result questions the effectiveness of EMU institutions and PIIGS governments in designing consistent national fiscal policies.

Our results suggest that achieving cyclical recovery will not be sufficient to restore the relative income level that PIIGS had achieved before 2007, and productivity-enhancing reforms should be at the forefront of political debate. To the extent that the slow down in productivity growth in the PIIGS region was caused by the capital flows reversal and by the ensuing credit crunch, macroeconomic policies should target credit availability and external financing conditions for innovative firms.

\section{References}

[1] Acharya V., T. Eisert, C. Eufinger, and C.Hirsch, 2016. Whatever It Takes: The Real Effects of Unconventional Monetary Policy. Available at SSRN: https://ssrn.com/abstract=2740338 or http://dx.doi.org/10.2139/ssrn.2740338

[2] Albonico A., A. Paccagnini and P. Tirelli, 2014. Estimating a DSGE model with Limited Asset Market Participation for the Euro Area, Working Papers 286, University of MilanoBicocca, Department of Economics, Management and Statistics.

[3] Albonico A., A. Paccagnini and P. Tirelli, 2016. In search of the Euro Area Fiscal Stance, Working Paper 324, University of Milan Bicocca Department of Economics, Management and Statistics.

[4] Amano R. and M. Shukayev, 2012. Risk Premium Shocks and the Zero Bound on Nominal Interest Rates, Journal of Money, Credit and Banking, Blackwell Publishing, vol. 44(8), pages 1475-1505, December.

[5] Basu S., J.G. Fernald and M.S. Kimball, 2006. Are Technology Improvements Contractionary?, American Economic Review, 96(5): 1418-1448.

[6] Benigno G., N. Converse, and L. Fornaro, 2015. Large capital inflows, sectoral allocation, and economic performance, Journal of International Money and Finance. Volume 55, Pages 60-87 
[7] Blanchard O. and F. Giavazzi, 2002. Current Account Deficits in the Euro Area: The End of the Feldstein Horioka Puzzle?, Brookings Papers on Economic Activity, Economic Studies Program, The Brookings Institution, vol. 33(2), pages 147-210.

[8] Brzoza-Brzezina M. and M. Kolasa, 2013. Bayesian evaluation of DSGE models with financial frictions. Journal of Money, Credit and Banking, 45(8), pp.1451-1476.

[9] Calvo G.A., 1983. Staggered prices in a utility-maximizing framework, Journal of Monetary Economics, Elsevier, vol. 12(3), pages 383-398, September.

[10] Chari V.V., P.J. Kehoe and E.R. McGrattan, 2002. Can Sticky Price Models Generate Volatile and Persistent Real Exchange Rates?, Review of Economic Studies, Oxford University Press, vol. 69(3), pages 533-563.

[11] Christiano L.J., M. Eichenbaum and C.L. Evans, 2005. Nominal Rigidities and the Dynamic Effects of a Shock to Monetary Policy, Journal of Political Economy, University of Chicago Press, vol. 113(1), pages 1-45, February.

[12] Christoffel K., G. Coenen and A. Warne, 2008. The New Area-Wide Model of the Euro area: a micro-founded open-economy model for forecasting and policy analysis, Working Paper Series 0944, European Central Bank.

[13] Colciago A., 2011. Rule-of-thumb consumers meet sticky wages. Journal of Money, Credit and Banking 43, 325-353.

[14] Christiansen C., 2014. Integration of European bond markets, Journal of Banking and Finance, Volume 42, May, Pages 191-198.

[15] De Grauwe P. and Y. Ji, 2013. Self-fulfilling crises in the Eurozone: an empirical test, Journal of International Money and Finance, vol. e-pub no. 34, pp. 15-36.

[16] Di Bartolomeo G., L. Rossi and M. Tancioni, 2011. Monetary policy, rule-of-thumb consumers and external habits: a G7 comparison, Applied Economics, Taylor \& Francis Journals, vol. 43(21), pages 2721-2738.

[17] Eggertsson G., A. Ferrero and A. Raffo, 2014. Can structural reforms help Europe?, Journal of Monetary Economics, Volume 61, January 2014, Pages 2-22.

[18] Furceri D., and A. Mourougane, 2012. The effect of financial crises on potential output: New empirical evidence from OECD countries, Journal of Macroeconomics, Elsevier, vol. 34(3), pages $822-832$.

[19] Furlanetto F., G.J. Natvik and M. Seneca, 2013. Investment shocks and macroeconomic comovement, Journal of Macroeconomics, Elsevier, vol. 37(C), pages 208-216.

[20] Gerali A., Neri, S., Sessa, L., and Signoretti, F., (2010) "Credit andBanking in a DSGE Model of the Euro Area." Journal of Money, Credit and Banking, 42, 107-41.

[21] Giavazzi F. and L. Spaventa, 2011. Why the current account may matter in a monetary union: Lessons from the financial crisis in the Euro area, in D. Cobham (ed.), The Euro Area and the Financial Crisis, Cambridge University Press, 2011 Cambridge University Press.

[22] Gopinath G., S. Kalemli-Ozcan, L. Karabarbounis and C. Villegas-Sanchez, 2015. Capital Allocation and Productivity in South Europe, NBER Working Paper No 21453.

[23] Gunn C.M. and A. Johri, 2013. Fear of Sovereign Default, Banks, and Expectations-driven Business Cycles. McMaster University Department of Economics Working Paper, 8. 
[24] Justiniano A.,Primiceri G., Tambalotti A., 2011. Investment Shocks and the Relative Price of Investment Review of Economic Dynamics, Elsevier for the Society for Economic Dynamics, vol. 14(1), pages 101-121, January.

[25] Kalemli-Ozcan S., E. Luttini and B. Sørensen, 2014. Debt Crises and Risk-Sharing: The Role of Markets versus Sovereigns, Scandinavian Journal of Economics, Wiley Blackwell, vol. 116(1), pages 253-276, 01.

[26] Khan A. and J. Thomas, 2013. Credit Shocks and Aggregate Fluctuations in an Economy with Production Heterogeneity, Journal of Political Economy, University of Chicago Press, vol. 121(6), pages 1055 - 1107

[27] Kaplan G., G. Violante and J. Weidner, 2014. The Wealthy Hand-to-Mouth, Brookings Papers on Economic Activity, Spring 2014 Conference.

[28] Kolasa M., 2009. Structural heterogeneity or asymmetric shocks? Poland and the euro area through the lens of a two-country DSGE model, Economic Modelling, Elsevier, vol. 26(6), pages 1245-1269, November.

[29] Kollmann, R., Pataracchia, B., Ratto, M., Roeger, W., and Vogel, L., 2016. The Post-Crisis Slump in the Euro Area and the US: Evidence from an Estimated Three-Region DSGE Model. European Economic Review, Elsevier, vol. 88(C), pages 21-41.

[30] Kuvshinov D., G.J. Müller and M. Wolf, 2016. Deleveraging, deflation and depreciation in the euro area. European Economic Review, vol. 88 pages 42-66.

[31] Lane P.R., 2012. The European sovereign debt crisis, The Journal of Economic Perspectives, 26(3), 49-67.

[32] Nkusu M., 2011. Nonperforming loans and macrofinancial vulnerabilities in advanced economies. IMF Working Papers, 1-27

[33] Rabanal P., 2009. Inflation Differentials between Spain and the EMU: A DSGE Perspective, Journal of Money, Credit and Banking, Blackwell Publishing, vol. 41(6), pages 1141-1166, 09.

[34] Ratto M., W. Roeger and J. Veld, 2009. QUEST III: An estimated open-economy DSGE model of the euro area with fiscal and monetary policy, Economic Modelling, Elsevier, vol. 26(1), pages 222-233, January.

[35] Sensoy A., E. Hacihasanoglu and A. Rostom, 2015. European economic and monetary union sovereign debt markets, Policy Research working paper 7149, The World Bank.

[36] Schmitt-Grohé S. and M. Uribe, 2003. Closing small open economy models, Journal of International Economics, Elsevier, vol. 61(1), pages 163-185, October.

[37] Shambaugh J.C., 2012. The Euro's Three Crises, Brookings Papers on Economic Activity, Economic Studies Program, The Brookings Institution, vol. 44(1 (Spring), pages 157-231.

[38] Smets F. and R. Wouters, 2003. An Estimated Dynamic Stochastic General Equilibrium Model of the Euro Area, Journal of the European Economic Association, MIT Press, vol. 1(5), pp. 1123-1175.

[39] Smets F. and R. Wouters, 2005. Comparing shocks and frictions in US and Euro area business cycles: a Bayesian DSGE Approach, Journal of Applied Econometrics, vol. 20(2), pp. 161183. 
[40] Lindé J., F. Smets and R. Wouters, 2016. Challenges for Central Banks' macro models. Handbook of Macroeconomics, 2, pp.2185-2262.

[41] Smets F. and R. Wouters, 2007. Shocks and Frictions in US Business Cycles: A Bayesian DSGE Approach, American Economic Review, American Economic Association, vol. 97(3), pp. 586-606.

[42] Suh H. and T.B. Walker, 2016. Taking financial frictions to the data. Journal of Economic Dynamics and Control, 64, pp.39-65. 


\section{A Appendix}

\section{A.1 Variance decomposition under model B}

Table 6: Variance decomposition of selected variables

\begin{tabular}{|c|c|c|c|c|c|c|c|c|c|c|c|c|}
\hline & $\Delta y$ & $\Delta c$ & $\Delta i$ & $\pi_{c}$ & $\pi^{N}$ & $\Delta c^{r t}$ & $\Delta c^{O}$ & $\Delta e x$ & $\Delta i m$ & $n x$ & $\Delta y^{h}$ & $\Delta y^{n}$ \\
\hline \multicolumn{13}{|l|}{ Technology shocks } \\
\hline Home & 35.99 & 25.10 & 33.02 & 53.12 & 21.91 & 63.64 & 13.83 & 45.34 & 36.71 & 31.99 & 42.36 & 23.00 \\
\hline Foreign & 0.54 & 0.11 & 0.10 & 0.75 & 0.19 & 0.23 & 0.08 & 14.79 & 14.35 & 2.65 & 2.33 & 0.19 \\
\hline aggregate & 4.50 & 5.26 & 0.40 & 1.39 & 1.02 & 5.20 & 4.23 & 1.00 & 0.60 & 0.52 & 3.48 & 3.55 \\
\hline \multicolumn{13}{|l|}{ Demand shocks } \\
\hline Home & 17.95 & 0.72 & 14.87 & 3.13 & 0.84 & 1.89 & 0.50 & 1.99 & 2.50 & 1.79 & 13.41 & 12.64 \\
\hline Foreign & 0.45 & 0.48 & 0.59 & 0.70 & 0.33 & 0.19 & 0.51 & 2.42 & 1.66 & 1.40 & 0.58 & 0.41 \\
\hline Risk sharing & 0.00 & 0.00 & 0.00 & 0.00 & 0.00 & 0.00 & 0.00 & 0.06 & 0.00 & 0.00 & 0.00 & 0.00 \\
\hline \multicolumn{13}{|l|}{ Markup shocks } \\
\hline Home & 17.20 & 8.60 & 40.59 & 25.64 & 66.78 & 20.88 & 7.01 & 20.97 & 20.18 & 21.98 & 15.52 & 27.30 \\
\hline Foreign & 1.79 & 0.83 & 2.12 & 6.13 & 3.06 & 0.98 & 0.67 & 5.57 & 10.60 & 16.04 & 3.20 & 1.66 \\
\hline \multicolumn{13}{|l|}{ Government shocks } \\
\hline Home & 4.22 & 0.18 & 0.36 & 0.32 & 0.18 & 1.13 & 0.06 & 0.37 & 0.29 & 0.63 & 0.28 & 8.73 \\
\hline Foreign & 0.02 & 0.04 & 0.02 & 0.02 & 0.01 & 0.01 & 0.05 & 0.05 & 0.06 & 0.13 & 0.01 & 0.02 \\
\hline \multicolumn{13}{|l|}{ Monetary shocks } \\
\hline \multirow{3}{*}{$\begin{array}{c}\text { Interest rates } \\
\text { Measurement error }\end{array}$} & 3.34 & 3.83 & 3.44 & 3.86 & 2.56 & 1.26 & 4.16 & 0.53 & 1.23 & 0.20 & 3.20 & 2.61 \\
\hline & & & & & & & & & & & & 11.64 \\
\hline & $\Delta y^{*}$ & $\Delta c^{*}$ & $\Delta i^{*}$ & $\pi_{c}^{*}$ & $\pi^{N, *}$ & $\Delta c^{r t, *}$ & $\Delta c^{O, *}$ & $\Delta y^{f}$ & $\Delta y^{n, *}$ & $r$ & rer & $t t$ \\
\hline \multicolumn{13}{|l|}{ Technology shocks } \\
\hline Home & 1.35 & 0.15 & 0.33 & 2.81 & 2.15 & 0.16 & 0.29 & 2.15 & 0.09 & 19.49 & 29.72 & 38.70 \\
\hline Foreign & 13.09 & 16.78 & 9.12 & 21.82 & 15.23 & 40.63 & 5.07 & 14.87 & 8.45 & 5.74 & 2.75 & 3.33 \\
\hline \multirow{2}{*}{\multicolumn{13}{|c|}{ Demand shocks }} \\
\hline & & & & & & & & & & & & \\
\hline Home & 0.46 & 0.41 & 0.54 & 0.45 & 0.38 & 0.16 & 0.50 & 0.47 & 0.28 & 3.51 & 1.81 & 1.94 \\
\hline Foreign & 25.67 & 2.95 & 22.22 & 7.15 & 6.91 & 5.57 & 1.87 & 23.24 & 20.18 & 9.40 & 2.14 & 1.58 \\
\hline Risk sharing & 0.22 & 1.09 & 0.00 & 0.00 & 0.00 & 0.11 & 1.76 & 0.26 & 0.13 & 0.04 & 0.00 & 0.00 \\
\hline \multicolumn{13}{|l|}{ Markup shocks } \\
\hline Home & 0.96 & 0.45 & 2.00 & 1.33 & 1.18 & 0.28 & 0.46 & 1.22 & 0.55 & 11.31 & 12.12 & 15.21 \\
\hline Foreign & 40.57 & 27.29 & 60.45 & 60.59 & 68.79 & 36.07 & 18.92 & 41.28 & 30.93 & 19.15 & 32.11 & 22.26 \\
\hline \multicolumn{13}{|l|}{ Government shocks } \\
\hline Home & 0.04 & 0.13 & 0.08 & 0.03 & 0.03 & 0.03 & 0.18 & 0.04 & 0.05 & 1.00 & 0.74 & 0.67 \\
\hline Foreign & 1.25 & 0.10 & 0.13 & 0.08 & 0.08 & 0.60 & 0.01 & 0.08 & 3.40 & 0.61 & 0.16 & 0.13 \\
\hline \multicolumn{13}{|l|}{ Monetary shocks } \\
\hline $\begin{array}{c}\text { Interest rates } \\
\text { Measurement error }\end{array}$ & 3.47 & 5.30 & 3.34 & 3.27 & 2.98 & 1.63 & 6.76 & 3.85 & $\begin{array}{c}2.44 \\
22.54\end{array}$ & 7.56 & 0.05 & 0.14 \\
\hline
\end{tabular}




\section{A.2 Non linear equations}

The model is adjusted for growth, to obtain a balanced growth equilibrium. Thus, all growing variables are divided by the level of technology. Lower case letters stand for detrended variables, for example, $y_{t}=\frac{Y_{t}}{z_{t}}$. We define $\lambda_{t}^{o}=\Lambda_{t}^{o} z_{t}$ (see Christoffel, Coenen and Warne (2008)). $c_{t}^{o}$ and $c_{t}$ are already expressed as stationary variables. We also define $r_{t}^{k}=\frac{R_{t}^{k}}{P_{C, t}}, w_{t}=\frac{W_{t}}{z_{t} P_{C, t}}, t r_{t}^{r t}=\frac{T R_{t}^{r t}}{z_{t} P_{C, t}}$, $t_{t}^{r t}=\frac{T_{t}^{r t}}{z_{t} P_{C, t}}$. In this way it is also possible to compute the steady state of the model. For each country, lower letters price variables with a tilde " $\sim$ " stand for the optimal price relative to aggregate price of the sector, for example: $\frac{\tilde{P}_{t}^{n}}{P_{t}^{N}}=\tilde{p}_{t}^{n}$.

Moreover, it is possible to express all the equilibrium equations as functions of relative prices. In particular, we will adopt the following definitions.

Terms of trade:

$$
t t_{t}=\frac{P_{t}^{F}}{P_{t}^{H}}=\frac{P_{t}^{F, *}}{P_{t}^{H, *}}
$$

where the second equality comes from the law of one price assumption.

"Internal" exchange rates:

$$
\begin{gathered}
x_{t}=\frac{P_{t}^{N}}{P_{t}^{T}} \\
x_{t}^{*}=\frac{P_{t}^{N^{*}}}{P_{t}^{T^{*}}}
\end{gathered}
$$

All prices are expressed in terms of $t t_{t}, x_{t}$ and $x_{t}^{*}$.

\section{A.2.1 Relative prices}

Relative investment prices Home country:

$$
\frac{P_{I, t}}{P_{C, t}}=\left[\frac{\gamma_{i}+\left(1-\gamma_{i}\right)\left(x_{t}\right)^{1-e}}{\gamma_{c}+\left(1-\gamma_{c}\right)\left(x_{t}\right)^{1-e}}\right]^{\frac{1}{1-e}}
$$

Foreign country:

$$
\frac{P_{I, t}^{*}}{P_{C, t}^{*}}=\left[\frac{\gamma_{i}^{*}+\left(1-\gamma_{i}^{*}\right)\left(x_{t}^{*}\right)^{1-e}}{\gamma_{c}^{*}+\left(1-\gamma_{c}^{*}\right)\left(x_{t}^{*}\right)^{1-e}}\right]^{\frac{1}{1-e}}
$$

Relative non tradable prices Home country:

$$
\frac{P_{t}^{N}}{P_{C, t}}=\frac{x_{t}}{\left[\gamma_{c}+\left(1-\gamma_{c}\right)\left(x_{t}\right)^{1-e}\right]^{\frac{1}{1-e}}}
$$

Foreign country:

$$
\frac{P_{t}^{N, *}}{P_{C, t}^{*}}=\frac{x_{t}^{*}}{\left[\gamma_{c}^{*}+\left(1-\gamma_{c}^{*}\right)\left(x_{t}^{*}\right)^{1-e}\right]^{\frac{1}{1-e}}}
$$


Relative tradables prices Home country:

$$
\begin{gathered}
\frac{P_{t}^{H}}{P_{C, t}}=\left\{\left[\varpi+(1-\varpi)\left(t t_{t}\right)^{1-v}\right]^{\frac{1}{1-v}}\left[\gamma_{c}+\left(1-\gamma_{c}\right)\left(x_{t}\right)^{1-e}\right]^{\frac{1}{1-e}}\right\}^{-1} \\
\frac{P_{t}^{H}}{P_{t}^{T}}=\left[\varpi+(1-\varpi)\left(t t_{t}\right)^{1-v}\right]^{-\frac{1}{1-v}} \\
\frac{P_{t}^{F}}{P_{t}^{T}}=\left[\varpi\left(\frac{1}{t t_{t}}\right)^{1-v}+(1-\varpi)\right]^{-\frac{1}{1-v}} \\
\frac{P_{t}^{T}}{P_{C, t}}=\left[\gamma_{c}+\left(1-\gamma_{c}\right)\left(x_{t}\right)^{1-e}\right]^{-\frac{1}{1-e}}
\end{gathered}
$$

Foreign country:

$$
\begin{gathered}
\frac{P_{t}^{F, *}}{P_{C, t}^{*}}=\left\{\left[\left(1-\varpi^{*}\right)\left(\frac{1}{t t_{t}}\right)^{1-v}+\varpi^{*}\right]^{\frac{1}{1-v}}\left[\gamma_{c}^{*}+\left(1-\gamma_{c}^{*}\right)\left(x_{t}^{*}\right)^{1-e}\right]^{\frac{1}{1-e}}\right\}^{-1} \\
\frac{P_{t}^{H, *}}{P_{t}^{T, *}}=\left[\left(1-\varpi^{*}\right)+\varpi^{*}\left(t t_{t}\right)^{1-v}\right]^{-\frac{1}{1-v}} \\
\frac{P_{t}^{F, *}}{P_{t}^{T, *}}=\left[\left(1-\varpi^{*}\right)\left(\frac{1}{t t_{t}}\right)^{1-v}+\varpi^{*}\right]^{-\frac{1}{1-v}} \\
\frac{P_{t}^{T, *}}{P_{C, t}^{*}}=\left[\gamma_{c}^{*}+\left(1-\gamma_{c}^{*}\right)\left(x_{t}^{*}\right)^{1-e}\right]^{-\frac{1}{1-e}}
\end{gathered}
$$

\section{A.2.2 Households}

Home country:

$$
\begin{gathered}
\varepsilon_{t}^{c}\left(c_{t}^{o}\right)^{-\sigma} c_{t-1}^{\zeta(\sigma-1)} \exp \left(\frac{(\sigma-1)}{1+\phi_{l}}\left(h_{t}\right)^{1+\phi_{l}}\right)=\lambda_{t}^{o}\left(1+\tau^{c}\right) \\
R_{t}=\pi_{C, t+1} g_{z, t+1} \frac{\lambda_{t}^{o}}{\beta \lambda_{t+1}^{o}} \\
{\left[\frac{\gamma_{i}+\left(1-\gamma_{i}\right)\left(x_{t}\right)^{1-e}}{\gamma_{c}+\left(1-\gamma_{c}\right)\left(x_{t}\right)^{1-e}}\right]^{\frac{1}{1-e}}=Q_{t}^{o} \varepsilon_{t}^{i}\left\{1-\gamma_{I}\left(g_{z, t} \frac{i_{t}}{i_{t-1}}-g_{z}\right) g_{z, t} \frac{i_{t}}{i_{t-1}}-\frac{\gamma_{I}}{2}\left(g_{z, t} \frac{i_{t}}{i_{t-1}}-g_{z}\right)^{2}\right\}} \\
+\frac{1}{g_{z, t+1}} \frac{\lambda_{t+1}^{o}}{\lambda_{t}^{o}} Q_{t+1}^{o} \varepsilon_{t+1}^{i} \beta \gamma_{I}\left(g_{z, t+1} \frac{i_{t+1}}{i_{t}}-g_{z}\right)\left(g_{z, t+1} \frac{i_{t+1}}{i_{t}}\right)^{2} \\
\frac{1}{g_{z, t+1}} \frac{\lambda_{t+1}^{o} \beta}{\lambda_{t}^{o}} \beta\left\{\begin{array}{c}
\left(1-\tau^{k}\right)\left[\frac{r_{t+1}^{k}}{\varepsilon_{t}^{b}} u_{t+1}-\left[\frac{\gamma_{i}+\left(1-\gamma_{i}\right)\left(x_{t+1}\right)^{1-e}}{\gamma_{c}+\left(1-\gamma_{c}\right)\left(x_{t+1}\right)^{1-e}}\right]^{\frac{1}{1-e}} a\left(u_{t+1}\right)\right] \\
+\tau^{k} \delta\left[\frac{\gamma_{i}+\left(1-\gamma_{i}\right)\left(x_{t+1}\right)^{1-e}}{\gamma_{c}+\left(1-\gamma_{c}\right)\left(x_{t+1}\right)^{1-e}}\right]
\end{array}\right\}=Q_{t}^{\frac{1}{1-e}}+Q_{t+1}^{o}(1-\delta)
\end{gathered}
$$




$$
\begin{gathered}
\frac{r_{t}^{k}}{\varepsilon_{t-1}^{b}}=\left[\frac{\gamma_{i}+\left(1-\gamma_{i}\right)\left(x_{t}\right)^{1-e}}{\gamma_{c}+\left(1-\gamma_{c}\right)\left(x_{t}\right)^{1-e}}\right]^{\frac{1}{1-e}}\left[\gamma_{u 1}+\gamma_{u 2}\left(u_{t}-1\right)\right] \\
k_{t+1}=(1-\delta) \frac{k_{t}}{g_{z, t}}+\varepsilon_{t}^{i}\left[1-\frac{\gamma_{I}}{2}\left(g_{z, t} \frac{i_{t}}{i_{t-1}}-g_{z}\right)^{2}\right] i_{t} \\
\left(1+\tau^{c}\right) c_{t}^{r t}=\left(1-\tau^{l}-\tau^{w h}\right) w_{t} h_{t}+t r_{t}^{r t}-t_{t}^{r t} \\
c_{t}=\theta c_{t}^{r t}+(1-\theta) c_{t}^{o} \\
t r_{t}=\theta t r_{t}^{r t}+(1-\theta) t r_{t}^{o} \\
t_{t}=\theta t_{t}^{r t}+(1-\theta) t_{t}^{o} \\
M R S_{t}^{o}=c_{t}^{o} \varepsilon_{t}^{l}\left(h_{t}\right)^{\phi_{l}} \\
M R S_{t}^{r t}=c_{t}^{r t} \varepsilon_{t}^{l}\left(h_{t}\right)^{\phi_{l}}
\end{gathered}
$$

Foreign country:

$$
\begin{aligned}
& \varepsilon_{t}^{c, *}\left(c_{t}^{o, *}\right)^{-\sigma}\left(c_{t-1}^{*}\right)^{\zeta^{*}\left(\sigma^{*}-1\right)} \exp \left(\frac{\left(\sigma^{*}-1\right)}{1+\phi_{l}^{*}}\left(h_{t}^{*}\right)^{1+\phi_{l}^{*}}\right)=\lambda_{t}^{o, *}\left(1+\tau^{c, *}\right) \\
& \left.\left[\frac{\gamma_{i}^{*}+\left(1-\gamma_{i}^{*}\right)\left(x_{t}^{*}\right)^{1-e}}{\gamma_{c}^{*}+\left(1-\gamma_{c}^{*}\right)\left(x_{t}^{*}\right)^{1-e}}\right]^{\frac{1}{1-e}}=Q_{t}^{o, *} \varepsilon_{t}^{i, *}\left\{1-\gamma_{I}^{*}\left(g_{z, t} \frac{i_{t}^{*}}{i_{t-1}^{*}}-g_{z}\right) g_{z, t} \frac{i_{t}^{*}}{i_{t-1}^{*}}-\frac{\gamma_{I}^{*}}{2}\left(g_{z, t} \frac{i_{t}^{*}}{i_{t-1}^{*}}-g_{z}\right)^{2}\right)^{105}\right) \\
& +\frac{1}{g_{z, t+1}} \frac{\lambda_{t+1}^{o, *}}{\lambda_{t}^{o, *}} Q_{t+1}^{o, *} \varepsilon_{t+1}^{i, *} \beta \gamma_{I}^{*}\left(g_{z, t+1} \frac{i_{t+1}^{*}}{i_{t}^{*}}-g_{z}\right)\left(g_{z, t+1} \frac{i_{t+1}^{*}}{i_{t}^{*}}\right)^{2} \\
& \frac{1}{g_{z, t+1}} \frac{\lambda_{t+1}^{o, *}}{\lambda_{t}^{o, *}} \beta\left\{\begin{array}{c}
\left(1-\tau^{k, *}\right)\left[\gamma_{t+1}^{k, *} u_{t+1}^{*}-\left[\frac{\gamma_{i}^{*}+\left(1-\gamma_{i}^{*}\right)\left(x_{t}^{*}\right)^{1-e}}{\gamma_{c}^{*}+\left(1-\gamma_{c}^{*}\right)\left(x_{t}^{*}\right)^{1-e}}\right]^{\frac{1}{1-e}} a\left(u_{t+1}^{*}\right)\right] \\
+\tau^{k, *} \delta^{*}\left[\frac{\gamma_{i}^{*}+\left(1-\gamma_{i}^{*}\right)\left(x_{t}^{*}\right)^{1-e}}{\gamma_{c}^{*}+\left(1-\gamma_{c}^{*}\right)\left(x_{t}^{*}\right)^{1-e}}\right]^{\frac{1}{1-e}}+Q_{t+1}^{o, *}\left(1-\delta^{*}\right)
\end{array}\right\}=Q_{t}^{o, *} \\
& r_{t}^{k, *}=\left[\frac{\gamma_{i}^{*}+\left(1-\gamma_{i}^{*}\right)\left(x_{t}^{*}\right)^{1-e}}{\gamma_{c}^{*}+\left(1-\gamma_{c}^{*}\right)\left(x_{t}^{*}\right)^{1-e}}\right]^{\frac{1}{1-e}}\left[\gamma_{u 1}^{*}+\gamma_{u 2}^{*}\left(u_{t}^{*}-1\right)\right] \\
& k_{t+1}^{*}=\left(1-\delta^{*}\right) \frac{k_{t}^{*}}{g_{z, t}}+\varepsilon_{t}^{i, *}\left[1-\frac{\gamma_{I}^{*}}{2}\left(g_{z, t} \frac{i_{t}^{*}}{i_{t-1}^{*}}-g_{z}\right)^{2}\right] i_{t}^{*} \\
& \left(1+\tau^{c, *}\right) c_{t}^{r t, *}=\left(1-\tau^{l, *}-\tau^{w h, *}\right) w_{t}^{*} h_{t}^{*}+t r_{t}^{r t, *}-t_{t}^{r t, *}
\end{aligned}
$$




$$
\begin{gathered}
c_{t}^{*}=\theta^{*} c_{t}^{r t, *}+\left(1-\theta^{*}\right) c_{t}^{o, *} \\
t r_{t}^{*}=\theta^{*} t r_{t}^{r t, *}+\left(1-\theta^{*}\right) t r_{t}^{o, *} \\
t_{t}^{*}=\theta^{*} t_{t}^{r t, *}+\left(1-\theta^{*}\right) t_{t}^{o, *} \\
M R S_{t}^{o, *}=c_{t}^{o, *} \varepsilon_{t}^{l, *}\left(h_{t}^{*}\right)^{\phi_{l}^{*}} \\
M R S_{t}^{r t, *}=c_{t}^{r t, *} \varepsilon_{t}^{l, *}\left(h_{t}^{*}\right)^{\phi_{l}^{*}}
\end{gathered}
$$

\section{A.2.3 Risk sharing condition}

$$
R E R_{t}=\kappa \frac{\lambda_{t}^{o, *}}{\lambda_{t}^{o}}
$$

\section{A.2.4 Wages}

$$
\begin{aligned}
0= & E_{t} \sum_{s=0}^{\infty}\left(\xi_{w} \beta\right)^{s} \varepsilon_{t}^{c} c_{t+s-1}^{\zeta(\sigma-1)} \exp \left(\frac{(\sigma-1)}{1+\phi_{l}}\left(h_{t+s}\right)^{1+\phi_{l}}\right)\left(\frac{\pi_{C, t, t+s-1}^{\chi_{w}} \bar{\pi}_{t, t+s}^{1-\chi_{w}}}{w_{t+s} \pi_{C, t, t+s}}\right)^{-\frac{1+\lambda_{t+s}^{w}}{\lambda_{t+s}^{w}}} h_{t+s}^{d} . \\
& \cdot\left\{\begin{array}{c}
\tilde{w}_{t} \frac{\left(1-\tau^{l}-\tau^{w h}\right) \pi_{C, t, t+s-1}^{\chi_{w}} \bar{\pi}_{t, t+s}^{1-\chi_{w}}}{\left(1+\tau^{c}\right) \pi_{C, t, t+s}}\left[(1-\theta)\left(c_{t+s}^{o}\right)^{-\sigma}+\theta\left(c_{t+s}^{r t}\right)^{-\sigma}\right] \\
-\left(1+\lambda_{t+s}^{w}\right)\left[(1-\theta)\left(c_{t+s}^{o}\right)^{-\sigma} M R S_{t+s}^{o}+\theta\left(c_{t+s}^{r t}\right)^{-\sigma} M R S_{t+s}^{r t}\right]
\end{array}\right\}
\end{aligned}
$$

$$
\begin{gathered}
0=E_{t} \sum_{s=0}^{\infty}\left(\xi_{w}^{*} \beta\right)^{s} \varepsilon_{t}^{c, *}\left(c_{t+s-1}^{*}\right)^{\zeta(\sigma-1)} \exp \left(\frac{\left(\sigma^{*}-1\right)}{1+\phi_{l}}\left(h_{t+s}^{*}\right)^{1+\phi_{l}}\right) h_{t+s}^{d, *}\left(\frac{\left(\pi_{C, t, t+s-1}^{*}\right)^{\chi_{w}^{*}} \bar{\pi}_{t, t+s}^{1-\chi_{w}^{*}}}{w_{t+s}^{*} \pi_{C, t, t+s}^{*}}\right)^{-\frac{1+\lambda_{t+s}^{w, *}}{\lambda_{t+s}^{w * *}}} \\
\left\{\begin{array}{l}
\tilde{w}_{t}^{*} \frac{\left(1-\tau^{l}-\tau^{w h}\right)\left(\pi_{C, t, t+s-1}^{*}\right)^{\chi_{w}^{*}} \bar{\pi}_{t, t+s}^{1-\chi_{w}^{*}}}{\left(1+\tau^{c} \pi_{C, t, t+s}^{*}\right.}\left[\left(1-\theta^{*}\right)\left(c_{t+s}^{o, *}\right)^{-\sigma^{*}}+\theta^{*}\left(c_{t+s}^{r t, *}\right)^{-\sigma^{*}}\right] \\
-\left(1+\lambda_{t+s}^{w, *}\right)\left[\left(1-\theta^{*}\right)\left(c_{t+s}^{o, *}\right)^{-\sigma^{*}} M R S_{t+s}^{o, *}+\theta^{*}\left(c_{t+s}^{r t, *}\right)^{-\sigma^{*}} M R S_{t+s}^{r t, *}\right]
\end{array}\right\} \\
1=\xi_{w}\left(\frac{\pi_{C, t-1}^{\chi_{w}} \bar{\pi}_{t}^{1-\chi_{w}}}{\pi_{C, t}} \frac{w_{t-1}}{w_{t}}\right)^{\frac{1}{\lambda_{t}^{w}}}+\left(1-\xi_{w}\right)\left(\frac{\tilde{w}_{t}}{w_{t}}\right)^{\frac{1}{\lambda_{t}^{w}}} \\
1=\xi_{w}^{*}\left(\frac{\left(\pi_{C, t-1}^{*}\right)^{\chi_{w}^{*}} \bar{\pi}_{t}^{1-\chi_{w}^{*}} w_{t-1}^{*}}{\pi_{C, t}^{*}}\right)^{\frac{1}{\lambda_{t}^{w, * *}}}+\left(1-\xi_{w}^{*}\right)\left(\frac{\tilde{w}_{t}^{*}}{w_{t}^{*}}\right)^{\frac{1}{\lambda_{t}^{w, *}}}
\end{gathered}
$$




\section{A.2.5 Production}

Non-tradable goods Home country:

$$
\begin{aligned}
& \frac{u_{t} k_{t}^{N}}{h_{t}^{N} g_{z, t}}=\frac{\alpha_{N}}{\left(1-\alpha_{N}\right)} \frac{\left(1+\tau_{t}^{w f}\right) w_{t}}{r_{t}^{k}} \\
& m c_{t}^{N}=\alpha_{N}^{-\alpha_{N}}\left(1-\alpha_{N}\right)^{-\left(1-\alpha_{N}\right)}\left(\varepsilon_{t}^{a, N}\right)^{-1}\left(r_{t}^{k}\right)^{\alpha_{N}}\left[\left(1+\tau^{w f}\right) w_{t}\right]^{1-\alpha_{N}} \\
& s_{P, t}^{N} y_{t}^{N}=\varepsilon_{t}^{a, N}\left(\frac{u_{t}^{N} k_{t}^{N}}{g_{z, t}}\right)^{\alpha_{N}}\left(h_{t}^{N}\right)^{1-\alpha_{N}}-\Phi_{N} \\
& s_{P, t}^{N}=\frac{1}{s} \int_{0}^{s}\left(\frac{P_{t}^{n}}{P_{t}^{N}}\right)^{-\frac{1+\lambda_{t}^{p, N}}{\lambda_{t}^{p, N}}} d n \\
& 0=E_{t} \sum_{s=0}^{\infty}\left(\beta \xi_{p}^{N}\right)^{s} \lambda_{t+s}^{o} y_{t+s}^{N}\left(\frac{\pi_{N, t, t+s-1}^{\chi_{N}^{N}} \bar{\pi}_{t, t+s}^{1-\chi_{p}^{N}}}{\pi_{N, t, t+s}}\right)^{-\frac{1+\lambda_{t+s}^{p, N}}{\lambda_{t+s}^{p, N}}} \\
& \cdot\left[\tilde{p}_{t}^{n} \frac{\pi_{N, t, t+s-1}^{\chi_{p}^{N}} \bar{\pi}_{t, t+s}^{1-\chi_{p}^{N}}}{\pi_{N, t, t+s}} \frac{x_{t+s}}{\left[\gamma_{c}+\left(1-\gamma_{c}\right)\left(x_{t+s}\right)^{1-e}\right]^{\frac{1}{1-e}}}-\left(1+\lambda_{t+s}^{p, N}\right) m c_{t+s}^{N}\right] \\
& 1=\left(1-\xi_{p}^{N}\right)\left(\tilde{p}_{t}^{n}\right)^{\frac{1}{\lambda_{t}^{p, N}}}+\xi_{p}^{N}\left(\frac{\pi_{N, t-1}^{\chi_{p}^{N}} \bar{\pi}_{t}^{1-\chi_{p}^{N}}}{\pi_{N, t}}\right)^{\frac{1}{\lambda_{t}^{p, N}}}
\end{aligned}
$$

Foreign country:

$$
\begin{aligned}
& \frac{u_{t} k_{t}^{N, *}}{h_{t}^{N, *} g_{z, t}}=\frac{\alpha_{N}^{*}}{\left(1-\alpha_{N}^{*}\right)} \frac{\left(1+\tau^{w f, *}\right) w_{t}^{*}}{r_{t}^{k, *}} \\
& m c_{t}^{N, *}=\left(\alpha_{N}^{*}\right)^{-\alpha_{N}^{*}}\left(1-\alpha_{N}^{*}\right)^{-\left(1-\alpha_{N}^{*}\right)}\left(\varepsilon_{t}^{a, N *}\right)^{-1}\left(r_{t}^{k, *}\right)^{\alpha_{N}^{*}}\left[\left(1+\tau^{w f, *}\right) w_{t}^{*}\right]^{1-\alpha_{N}^{*}} \\
& s_{P, t}^{N, *} y_{t}^{N, *}=\varepsilon_{t}^{a, N *}\left(\frac{u_{t}^{N, *} k_{t}^{N, *}}{g_{z, t}}\right)^{\alpha_{N}^{*}}\left(h_{t}^{N, *}\right)^{1-\alpha_{N}^{*}}-\Phi_{N}^{*} \\
& s_{P, t}^{N, *}=\frac{1}{1-s} \int_{s}^{1}\left(\frac{P_{t}^{n, *}}{P_{t}^{N, *}}\right)^{-\frac{1+\lambda_{t}^{p, N *}}{\lambda_{t}^{p, N *}}} d n \\
& 0=E_{t} \sum_{s=0}^{\infty}\left(\beta \xi_{p}^{N, *}\right)^{s} \lambda_{t, t+s}^{o, *} y_{t+s}^{N}\left(\frac{\left(\pi_{N, t, t+s-1}^{*}\right)^{\chi_{p}^{N, *}} \bar{\pi}_{t, t+s}^{1-\chi_{p}^{N, *}}}{\pi_{N, t, t+s}^{*}}\right)^{-\frac{1+\lambda_{t+s}^{p, N *}}{\lambda_{t+s}^{p, N *}}} \\
& \cdot\left[\tilde{p}_{t}^{n, *} \frac{\left(\pi_{N, t, t+s-1}^{*}\right)^{\chi_{p}^{N, *}} \bar{\pi}_{t, t+s}^{1-\chi_{p}^{N, *}}}{\pi_{N, t, t+s}^{*}} \frac{x_{t+s}^{*}}{\left[\gamma_{c}^{*}+\left(1-\gamma_{c}^{*}\right)\left(x_{t+s}^{*}\right)^{1-e}\right]^{\frac{1}{1-e}}}-\left(1+\lambda_{t+s}^{p, N *}\right) m c_{t+s}^{N, *}\right]
\end{aligned}
$$




$$
1=\left(1-\xi_{p}^{N, *}\right)\left(\tilde{p}_{t}^{n, *}\right)^{\frac{1}{\lambda_{t}^{, N *}}}+\xi_{p}^{N, *}\left(\frac{\left(\pi_{N, t-1}^{*}\right)^{\chi_{p}^{N, *}} \bar{\pi}_{t}^{1-\chi_{p}^{N, *}}}{\pi_{N, t}^{*}}\right)^{\frac{1,1}{\lambda_{t}^{p, N *}}}
$$

Tradable goods Home country:

$$
\begin{aligned}
& \frac{u_{t} k_{t}^{H}}{h_{t}^{H} g_{z, t}}=\frac{\alpha_{H}}{\left(1-\alpha_{H}\right)} \frac{\left(1+\tau^{w f}\right) w_{t}}{r_{t}^{k}} \\
& m c_{t}^{H}=\alpha_{H}^{-\alpha_{H}}\left(1-\alpha_{H}\right)^{-\left(1-\alpha_{H}\right)}\left(\varepsilon_{t}^{a, H}\right)^{-1}\left(r_{t}^{k}\right)^{\alpha_{H}}\left[\left(1+\tau^{w f}\right) w_{t}\right]^{1-\alpha_{H}} \\
& s_{P, t}^{H} y_{t}^{H}=\varepsilon_{t}^{a, H}\left(\frac{u_{t}^{H} k_{t}^{H}}{g_{z, t}}\right)^{\alpha_{H}}\left(h_{t}^{H}\right)^{1-\alpha_{H}}-\Phi_{H} \\
& s_{P, t}^{H}=\frac{1}{s} \int_{0}^{s}\left(\frac{P_{t}^{h}}{P_{t}^{H}}\right)^{-\frac{1+\lambda_{t}^{p, H}}{\lambda_{t}^{p, H}}} d h \\
& 0=E_{t} \sum_{s=0}^{\infty}\left(\beta \xi_{p}^{H}\right)^{s} \lambda_{t, t+s}^{o} y_{t+s}^{H}\left(\frac{\pi_{H, t, t+s-1}^{\chi_{p}^{H}} \bar{\pi}_{t, t+s}^{1-\chi_{p}^{H}}}{\pi_{H, t, t+s}}\right)^{-\frac{c_{1+\lambda_{t+s}^{p, H}}^{\lambda_{t+s}^{p, H}}}{t_{t+s}}} . \\
& \cdot\left[\begin{array}{c}
\tilde{p}_{t}^{h} \frac{\pi_{H, t, t+s-1}^{\chi_{H}^{H}} \bar{\pi}_{t, t+s}^{1-\chi_{H}^{H}}}{\pi_{H, t, t+s}}\left\{\left[\varpi+(1-\varpi)\left(t t_{t+s}\right)^{1-v}\right]^{\frac{1}{1-v}}\left[\gamma_{c}+\left(1-\gamma_{c}\right)\left(x_{t+s}\right)^{1-e}\right]^{\frac{1}{1-e}}\right\}^{-1} \\
-\left(1+\lambda_{t+s}^{p, H}\right) m c_{t+s}^{H}
\end{array}\right] \\
& 1=\left(1-\xi_{p}^{H}\right)\left(\tilde{p}_{t}^{h}\right)^{\frac{1}{\lambda_{t}^{p, H}}}+\xi_{p}^{H}\left(\frac{\pi_{H, t-1}^{\chi_{H}^{H}} \bar{\pi}_{t}^{1-\chi_{p}^{H}}}{\pi_{H, t}}\right)^{\frac{1}{\lambda_{t}^{p, H}}}
\end{aligned}
$$

Foreign country:

$$
\begin{gathered}
\frac{u_{t} k_{t}^{F}}{h_{t}^{F} g_{z, t}}=\frac{\alpha_{F}}{\left(1-\alpha_{F}\right)} \frac{\left(1+\tau^{w f, *}\right) w_{t}^{*}}{r_{t}^{k, *}} \\
m c_{t}^{F}=\alpha_{F}^{-\alpha_{F}}\left(1-\alpha_{F}\right)^{-\left(1-\alpha_{F}\right)}\left(\varepsilon_{t}^{a, F}\right)^{-1}\left(r_{t}^{k, *}\right)^{\alpha_{F}}\left[\left(1+\tau^{w f, *}\right) w_{t}^{*}\right]^{1-\alpha_{F}} \\
s_{P, t}^{F} y_{t}^{F}=\varepsilon_{t}^{a, F}\left(\frac{u_{t}^{F} k_{t}^{F}}{g_{z, t}}\right)^{\alpha_{F}}\left(h_{t}^{F}\right)^{1-\alpha_{F}}-\Phi_{F} \\
s_{P, t}^{F}=\frac{1}{1-s} \int_{s}^{1}\left(\frac{P_{t}^{f}}{P_{t}^{F}}\right)^{-\frac{1+\lambda_{t, F}^{p, F}}{\lambda_{t}^{p, F}}} d f
\end{gathered}
$$




$$
\begin{aligned}
& 0=E_{t} \sum_{s=0}^{\infty}\left(\beta \xi_{p}^{F}\right)^{s} \lambda_{t, t+s}^{o, *} y_{t+s}^{F}\left(\frac{\pi_{F, t, t+s-1}^{\chi_{p}^{F}} \bar{\pi}_{t, t+s}^{1-\chi_{p}^{F}}}{\pi_{F, t, t+s}}\right)^{-\frac{1+\lambda_{t+s}^{p, F}}{\lambda_{t+s}^{p, F}}} \\
& \cdot\left[\begin{array}{c}
\left.\tilde{p}_{t}^{f} \frac{\pi_{F, t, t+s-1}^{\chi_{p}^{F}} \bar{\pi}_{t, t+s}^{1-\chi_{p}^{F}}}{\pi_{F, t, t+s}}\left\{\left[\left(1-\varpi^{*}\right)\left(\frac{1}{t t_{t+s}}\right)^{1-v}+\varpi^{*}\right]^{\frac{1}{1-v}}\left[\gamma_{c}^{*}+\left(1-\gamma_{c}^{*}\right)\left(x_{t+s}^{*}\right)^{1-e}\right]^{\frac{1}{1-e}}\right\}^{-1}\right] \\
-\left(1+\lambda_{t+s}^{p, F}\right) m c_{t+s}^{f}
\end{array}\right] \\
& 1=\left(1-\xi_{p}^{F}\right)\left(\tilde{p}_{t}^{f}\right)^{\frac{1}{\lambda_{t}^{p, F}}}+\xi_{p}^{F}\left(\frac{\pi_{F, t-1}^{\chi_{p}^{F}} \bar{\pi}_{t}^{1-\chi_{p}^{F}}}{\pi_{F, t}}\right)^{\frac{1}{\lambda_{t}^{p, F}}}
\end{aligned}
$$

\section{A.2.6 Demand functions}

Home country:

$$
\begin{gathered}
c_{t}^{N}=\left(1-\gamma_{c}\right)\left(x_{t}\right)^{-e}\left[\gamma_{c}+\left(1-\gamma_{c}\right)\left(x_{t}\right)^{1-e}\right]^{\frac{e}{1-e}} c_{t} \\
c_{t}^{H}=\varpi \gamma_{c}\left[\varpi+(1-\varpi)\left(t t_{t}\right)^{1-v}\right]^{\frac{v}{1-v}}\left[\gamma_{c}+\left(1-\gamma_{c}\right)\left(x_{t}\right)^{1-e}\right]^{\frac{e}{1-e}} c_{t} \\
c_{t}^{F}=(1-\varpi) \gamma_{c}\left[\varpi\left(\frac{1}{t t_{t}}\right)^{1-v}+(1-\varpi)\right]^{\frac{v}{1-v}}\left[\gamma_{c}+\left(1-\gamma_{c}\right)\left(x_{t}\right)^{1-e}\right]^{\frac{e}{1-e}} c_{t} \\
q_{t}^{I, N}=\left(1-\gamma_{i}\right)\left(x_{t}\right)^{-e}\left[\gamma_{i}+\left(1-\gamma_{i}\right)\left(x_{t}\right)^{1-e}\right]^{\frac{e}{1-e}} q_{t}^{I} \\
q_{t}^{I, H}=\varpi \gamma_{i}\left[\varpi+(1-\varpi)\left(t t_{t}\right)^{1-v}\right]^{\frac{v}{1-v}}\left[\gamma_{i}+\left(1-\gamma_{i}\right)\left(x_{t}\right)^{1-e}\right]^{\frac{e}{1-e}} q_{t}^{I} \\
q_{t}^{I, F}=(1-\varpi) \gamma_{i}\left[\varpi\left(\frac{1}{t t_{t}}\right)^{1-v}+(1-\varpi)\right]^{\frac{v}{1-v}}\left[\gamma_{i}+\left(1-\gamma_{i}\right)\left(x_{t}\right)^{1-e}\right]^{\frac{e}{1-e}} q_{t}^{I}
\end{gathered}
$$

Foreign country:

$$
\begin{gathered}
c_{t}^{N *}=\left(1-\gamma_{c}^{*}\right)\left(x_{t}^{*}\right)^{-e}\left[\gamma_{c}^{*}+\left(1-\gamma_{c}^{*}\right)\left(x_{t}^{*}\right)^{1-e}\right]^{\frac{e}{1-e}} c_{t}^{*} \\
c_{t}^{H *}=\left(1-\varpi^{*}\right) \gamma_{c}^{*}\left[\left(1-\varpi^{*}\right)+\varpi^{*}\left(t t_{t}\right)^{1-v}\right]^{\frac{v}{1-v}}\left[\gamma_{c}^{*}+\left(1-\gamma_{c}^{*}\right)\left(x_{t}^{*}\right)^{1-e}\right]^{\frac{e}{1-e}} c_{t}^{*} \\
c_{t}^{F *}=\varpi^{*} \gamma_{c}^{*}\left[\left(1-\varpi^{*}\right)\left(\frac{1}{t t_{t}}\right)^{1-v}+\varpi^{*}\right]^{\frac{v}{1-v}}\left[\gamma_{c}^{*}+\left(1-\gamma_{c}^{*}\right)\left(x_{t}^{*}\right)^{1-e}\right]^{\frac{e}{1-e}} c_{t}^{*} \\
q_{t}^{I, N *}=\left(1-\gamma_{i}^{*}\right)\left(x_{t}^{*}\right)^{-e}\left[\gamma_{i}^{*}+\left(1-\gamma_{i}^{*}\right)\left(x_{t}^{*}\right)^{1-e}\right]^{\frac{e}{1-e}} q_{t}^{I, *} \\
q_{t}^{I, H *}=\left(1-\varpi^{*}\right) \gamma_{i}^{*}\left[\left(1-\varpi^{*}\right)+\varpi^{*}\left(t t_{t}\right)^{1-v}\right]^{\frac{v}{1-v}}\left[\gamma_{i}^{*}+\left(1-\gamma_{i}^{*}\right)\left(x_{t}^{*}\right)^{1-e}\right]^{\frac{e}{1-e}} q_{t}^{I, *}
\end{gathered}
$$




$$
q_{t}^{I, F *}=\varpi^{*} \gamma_{i}^{*}\left[\left(1-\varpi^{*}\right)\left(\frac{1}{t t_{t}}\right)^{1-v}+\varpi^{*}\right]^{\frac{v}{1-v}}\left[\gamma_{i}^{*}+\left(1-\gamma_{i}^{*}\right)\left(x_{t}^{*}\right)^{1-e}\right]^{\frac{e}{1-e}} q_{t}^{I, *}
$$

\section{A.2.7 Relative price of non tradable goods}

$$
\begin{aligned}
\frac{x_{t}}{x_{t-1}} & =\frac{\pi_{t}^{N}}{\pi_{t}^{T}} \\
\frac{x_{t}^{*}}{x_{t-1}^{*}} & =\frac{\pi_{t}^{N, *}}{\pi_{t}^{T, *}}
\end{aligned}
$$

\section{A.2.8 Tradables inflation}

Home country:

$$
\pi_{t}^{T}=\left[\varpi+(1-\varpi)\left(t t_{t}\right)^{1-v}\right]^{\frac{1}{1-v}}\left[\varpi+(1-\varpi)\left(t t_{t-1}\right)^{1-v}\right]^{-\frac{1}{1-v}} \pi_{t}^{H}
$$

Foreign country:

$$
\pi_{t}^{T}=\left[\left(1-\varpi^{*}\right)\left(\frac{1}{t t_{t}}\right)^{1-v}+\varpi^{*}\right]^{\frac{1}{1-v}}\left[\left(1-\varpi^{*}\right)\left(\frac{1}{t t_{t-1}}\right)^{1-v}+\varpi^{*}\right]^{-\frac{1}{1-v}} \pi_{t}^{F}
$$

\section{A.2.9 Market clearing}

Home country:

$$
\begin{gathered}
y_{t}^{N}=c_{t}^{N}+q_{t}^{I, N}+g_{t} \\
y_{t}^{H}=c_{t}^{H}+\frac{1-s}{s} c_{t}^{H^{*}}+q_{t}^{I, H}+\frac{1-s}{s} q_{t}^{I, H^{*}} \\
y_{t}=\frac{\left[\varpi+(1-\varpi)\left(t t_{t}\right)^{1-v}\right]^{-\frac{1}{1-v}} y_{t}^{H}+x_{t} y_{t}^{N}}{\left[\gamma_{c}+\left(1-\gamma_{c}\right)\left(x_{t}\right)^{1-e}\right]^{\frac{1}{1-e}}} \\
k_{t}=k_{t}^{N}+k_{t}^{H} \\
h_{t}^{d}=h_{t}^{N}+h_{t}^{H} \\
h_{t}=s_{W, t} h_{t}^{d} \\
s_{W, t}=\frac{1}{s} \int_{0}^{s}\left(\frac{W_{t}^{j}}{W_{t}}\right)^{-\frac{1+\lambda_{t}^{w}}{\lambda_{t}^{w}}} d j \\
q_{t}^{I}=i_{t}+a\left(u_{t}\right) \frac{k_{t}}{g_{z, t}}
\end{gathered}
$$


Foreign country:

$$
\begin{gathered}
y_{t}^{N *}=c_{t}^{N *}+q_{t}^{I, N, *}+g_{t}^{*} \\
y_{t}^{F}=\frac{s}{1-s} c_{t}^{F}+c_{t}^{F^{*}}+\frac{s}{1-s} q_{t}^{I, F}+q_{t}^{I, F^{*}} \\
y_{t}^{*}=\frac{\left[\left(1-\varpi^{*}\right)\left(\frac{1}{t t_{t}}\right)^{1-v}+\varpi^{*}\right]^{-\frac{1}{1-v}} y_{t}^{F}+x_{t}^{*} y_{t}^{N *}}{\left[\gamma_{c}^{*}+\left(1-\gamma_{c}^{*}\right)\left(x_{t}^{*}\right)^{1-e}\right]^{\frac{1}{1-e}}} \\
k_{t}^{*}=k_{t}^{N, *}+k_{t}^{F} \\
h_{t}^{d, *}=h_{t}^{N, *}+h_{t}^{F} \\
h_{t}^{*}=s_{W, t}^{*} h_{t}^{d, *} \\
\frac{1}{1-s} \int_{s}^{1}\left(\frac{W_{t}^{j, *}}{W_{t}^{*}}\right)^{-\frac{1+\lambda_{t}^{w *}}{\lambda_{t}^{u *}}} d j \\
q_{t}^{I, *}=i_{t}^{*}+a\left(u_{t}^{*}\right) \frac{k_{t}^{*}}{g_{z, t}}
\end{gathered}
$$

\section{A.2.10 CPI Inflation}

Home country:

$$
\pi_{C, t}=\left[\frac{\gamma_{c}\left(\pi_{t}^{T}\right)^{1-e}+\left(1-\gamma_{c}\right)\left(\pi_{t}^{N}\right)^{1-e}\left(x_{t-1}\right)^{1-e}}{\gamma_{c}+\left(1-\gamma_{c}\right)\left(x_{t-1}\right)^{1-e}}\right]^{\frac{1}{1-e}}
$$

Foreign country:

$$
\pi_{C, t}^{*}=\left[\frac{\gamma_{c}^{*}\left(\pi_{t}^{T, *}\right)^{1-e}+\left(1-\gamma_{c}^{*}\right)\left(\pi_{t}^{N, *}\right)^{1-e}\left(x_{t-1}^{*}\right)^{1-e}}{\gamma_{c}^{*}+\left(1-\gamma_{c}^{*}\right)\left(x_{t-1}^{*}\right)^{1-e}}\right]^{\frac{1}{1-e}}
$$

\section{A.2.11 Real exchange rate}

$$
\begin{gathered}
R E R_{t}=\frac{\left[\gamma_{c}^{*}+\left(1-\gamma_{c}^{*}\right)\left(x_{t}^{*}\right)^{1-e}\right]^{\frac{1}{1-e}}}{\left[\gamma_{c}+\left(1-\gamma_{c}\right)\left(x_{t}\right)^{1-e}\right]^{\frac{1}{1-e}}} \frac{\left[\left(1-\varpi^{*}\right)+\varpi^{*}\left(t t_{t}\right)^{1-v}\right]^{\frac{1}{1-v}}}{\left[\varpi+(1-\varpi)\left(t t_{t}\right)^{1-v}\right]^{\frac{1}{1-v}}} \\
\frac{R E R_{t}}{R E R_{t-1}}=\frac{\frac{P_{C, t}^{*}}{P_{C, t}}}{\frac{P_{C, t-1}^{*}}{P_{C, t-1}}}=\frac{\pi_{C, t}^{*}}{\pi_{C, t}}
\end{gathered}
$$




\section{A.2.12 Resource constraints}

$$
\begin{aligned}
y_{t} & =c_{t}+\frac{P_{I, t}}{P_{C, t}} q_{t}^{I}+\frac{P_{t}^{N}}{P_{C, t}} g_{t}+\frac{P_{t}^{H}}{P_{C, t}} \frac{1-s}{s}\left(c_{t}^{H, *}+q_{t}^{I, H, *}\right)-\frac{P_{t}^{F}}{P_{C, t}}\left(c_{t}^{F}+q_{t}^{I, F}\right) \\
& =c_{t}+\frac{P_{I, t}}{P_{C, t}} q_{t}^{I}+\frac{P_{t}^{N}}{P_{C, t}} g_{t}+\frac{P_{t}^{H}}{P_{C, t}} \frac{1-s}{s} e x_{t}-\frac{P_{t}^{F}}{P_{C, t}} i m_{t}
\end{aligned}
$$

where $e x_{t}$ stands for exports and $i m_{t}$ for imports.

Similarly, for the foreign country we obtain:

$$
\begin{aligned}
y_{t}^{*} & =c_{t}^{*}+\frac{P_{I, t}^{*}}{P_{C, t}^{*}} q_{t}^{I, *}+\frac{P_{t}^{N, *}}{P_{C, t}^{*}} g_{t}^{*}+\frac{P_{t}^{F}}{P_{C, t}^{*}} \frac{s}{1-s}\left(c_{t}^{F}+q_{t}^{I, F}\right)-\frac{P_{t}^{H}}{P_{C, t}^{*}}\left(c_{t}^{H, *}+q_{t}^{I, H, *}\right) \\
& =c_{t}^{*}+\frac{P_{I, t}^{*}}{P_{C, t}^{*}} q_{t}^{I, *}+\frac{P_{t}^{N, *}}{P_{C, t}^{*}} g_{t}^{*}+\frac{P_{t}^{F}}{P_{C, t}^{*}} \frac{s}{1-s} e x_{t}^{*}-\frac{P_{t}^{H}}{P_{C, t}^{*}} i m_{t}^{*} \\
& =c_{t}^{*}+\frac{P_{I, t}^{*}}{P_{C, t}^{*}} q_{t}^{I, *}+\frac{P_{t}^{N, *}}{P_{C, t}^{*}} g_{t}^{*}+\frac{P_{t}^{F}}{P_{C, t}^{*}} \frac{s}{1-s} i m_{t}-\frac{P_{t}^{H}}{P_{C, t}^{*}} e x_{t}
\end{aligned}
$$

where $e x_{t}^{*}$ stands for the foreign country exports and $i m_{t}^{*}$ for the foreign country imports and $e x_{t}^{*}=i m_{t}, i m_{t}^{*}=e x_{t}$.

\section{Definition of exports and imports}

$$
\begin{gathered}
e x_{t}=c_{t}^{H, *}+q_{t}^{I, H, *} \\
i m_{t}=c_{t}^{F}+q_{t}^{I, F}
\end{gathered}
$$

\section{A.3 Steady state}

We assume that exogenous shocks are equal to one in steady state. For utilization, $u=1$ so that $a(u)=0$.

We make some simplifying assumptions, which enable us to find the steady state analytically.

In each country, we impose the same price markup $\left(\lambda^{p, H}=\lambda^{p, N}=\lambda_{p}, \lambda^{p, F}=\lambda^{p, N, *}=\lambda_{p}^{*}\right)$ and the same shares of capital in production $\left(\alpha_{H}=\alpha_{N}, \alpha_{F}=\alpha_{N, *}\right)$ in both sectors. This implies that $P^{H}=P^{N}$ and $P^{F}=P^{N, *}$ in steady state. We set the fixed costs so that steady state profits are zero, which implies also that $\frac{y^{N}+\Phi_{N}}{y^{N}}=\frac{y^{H}+\Phi_{H}}{y^{H}}=1+\lambda_{p}$.

Moreover, we impose that in steady state quantities of exports and imports correspond in steady state, so that home tradable prices are equal to foreign tradable prices $\left(P^{H}=P^{F}\right)$ and finally steady state net exports are equal to zero. Thus:

$$
\frac{\frac{1-s}{s}\left(c^{H, *}+q^{I, H, *}\right)}{\left(c^{F}+q^{I, F}\right)}=\frac{P^{F}}{P^{H}}=1
$$

This in turn implies that $P^{F}=P^{H}=P^{N}=P^{N, *}=P^{T}=P^{T, *}=P_{C}=P_{C}^{*}=P_{I}=P_{I}^{*}$, thus all relative prices are equal to 1 in steady state. Thus, also $t t_{t}, x_{t}, x_{t}^{*}$ are 1 in steady state. 


\section{A.4 Log-linearized equations}

\section{A.4.1 Households}

Home country:

$$
\begin{gathered}
\hat{c}_{t}^{o}=\hat{c}_{t+1}^{o}+\frac{(1-\sigma) \zeta}{\sigma}\left(\hat{c}_{t}-\hat{c}_{t-1}\right)-\frac{1}{\sigma}\left(\hat{R}_{t}-\hat{\pi}_{C, t+1}-\hat{g}_{z, t+1}+\hat{\varepsilon}_{t+1}^{c}-\hat{\varepsilon}_{t}^{c}\right) \\
+\frac{(1-\sigma) h^{1+\phi_{l}}}{\sigma}\left(\hat{h}_{t+1}-\hat{h}_{t}\right) \\
\hat{\imath}_{t}=\frac{1}{\gamma_{I} g_{z}^{2}(1+\beta)}\left(\hat{Q}_{t}^{o}+\hat{\varepsilon}_{t}^{i}\right)-\frac{1}{1+\beta} \hat{g}_{z, t}+\frac{1}{1+\beta} \hat{\imath}_{t-1} \\
\quad+\frac{\beta}{1+\beta} \hat{\imath}_{t+1}+\frac{\beta}{1+\beta} \hat{g}_{z, t+1}-\frac{\gamma_{c}-\gamma_{i}}{\gamma_{I} g_{z}^{2}(1+\beta)} \hat{x}_{t} \\
\hat{Q}_{t}^{o}=-\hat{R}_{t}+\hat{\pi}_{t+1}+\frac{\beta}{g_{z}}\left(1-\tau^{k}\right) \gamma_{u 1} \hat{r}_{t+1}^{k}+\frac{\beta}{g_{z}}(1-\delta) \hat{Q}_{t+1}^{o}+\frac{\beta}{g_{z}} \tau^{k} \delta\left(\gamma_{c}-\gamma_{i}\right) \hat{x}_{t+1} \\
\hat{r}_{t}^{k}=\frac{\sigma_{u}}{1-\sigma_{u}} \hat{u}_{t}+\left(\gamma_{c}-\gamma_{i}\right) \hat{x}_{t}
\end{gathered}
$$

where $\frac{\sigma_{u}}{1-\sigma_{u}} \equiv \frac{\gamma_{u 2}}{\gamma_{u 1}}=\frac{a^{\prime \prime}(u)}{a^{\prime}(u)}$.

$$
\begin{gathered}
\hat{k}_{t+1}=\frac{(1-\delta)}{g_{z}} \hat{k}_{t}+\frac{i}{k} \hat{\imath}_{t}-\frac{(1-\delta)}{g_{z}} \hat{g}_{z, t}+\frac{i}{k} \hat{\varepsilon}_{t}^{i} \\
\left(1+\tau^{c}\right) \frac{c^{r t}}{c} \hat{c}_{t}^{r t}=\left(1-\tau^{l}-\tau^{w h}\right) \frac{w h}{c}\left(\hat{w}_{t}+\hat{h}_{t}\right)+\frac{y}{c} \widehat{t r}_{t}^{r t}-\frac{y}{c} \hat{t}_{t}^{r t} \\
\hat{c}_{t}=\theta \frac{c^{r t}}{c} \hat{c}_{t}^{r t}+(1-\theta) \frac{c^{o}}{c} \hat{c}_{t}^{o} \\
\widehat{t r}_{t}=\theta \widehat{t r}_{t}^{r t}+(1-\theta) \widehat{t r}_{t}^{o} \\
\hat{t}_{t}=\theta \hat{t}_{t}^{r t}+(1-\theta) \hat{t}_{t}^{o} \\
\widehat{M R S}_{t}^{o}=\hat{c}_{t}^{o}+\phi_{l} \hat{h}_{t}+\hat{\varepsilon}_{t}^{l} \\
\widehat{M R S}_{t}^{r t}=\hat{c}_{t}^{r t}+\phi_{l} \hat{h}_{t}+\hat{\varepsilon}_{t}^{l}
\end{gathered}
$$

Foreign country:

$$
\begin{aligned}
\hat{\imath}_{t}^{*}= & \frac{1}{\gamma_{I}^{*} g_{z}^{2}(1+\beta)}\left(\hat{Q}_{t}^{o, *}+\hat{\varepsilon}_{t}^{i, *}\right)-\frac{1}{1+\beta} \hat{g}_{z, t}+\frac{1}{1+\beta} \hat{\imath}_{t-1}^{*} \\
& +\frac{\beta}{1+\beta} \hat{\imath}_{t+1}^{*}+\frac{\beta}{1+\beta} \hat{g}_{z, t+1}-\frac{\gamma_{c}^{*}-\gamma_{i}^{*}}{\gamma_{I} g_{z}^{2}(1+\beta)} \hat{x}_{t}
\end{aligned}
$$




$$
\begin{gathered}
-\hat{R}_{t}+\hat{\pi}_{C, t+1}^{*}+\frac{\beta}{g_{z}}\left(1-\tau^{k, *}\right) r^{k, *} \hat{r}_{t+1}^{k, *}+\frac{\beta}{g_{z}}\left(1-\delta^{*}\right) \hat{Q}_{t+1}^{o, *}+\frac{\beta}{g_{z}} \tau^{k} \delta\left(\gamma_{c}^{*}-\gamma_{i}^{*}\right) \hat{x}_{t+1}^{*}=\hat{Q}_{t}^{o, *} \\
\hat{r}_{t}^{k, *}=\frac{\sigma_{u}^{*}}{1-\sigma_{u}^{*}} \hat{u}_{t}^{*}+\left(\gamma_{c}^{*}-\gamma_{i}^{*}\right) \hat{x}_{t}
\end{gathered}
$$

where $\frac{\sigma_{u}^{*}}{1-\sigma_{u}^{*}} \equiv \frac{\gamma_{u 2}^{*}}{\gamma_{u 1}^{*}}=\frac{a^{\prime \prime}\left(u^{*}\right)}{a^{\prime}\left(u^{*}\right)}$.

$$
\begin{gathered}
\hat{k}_{t+1}^{*}=\frac{\left(1-\delta^{*}\right)}{g_{z}} \hat{k}_{t}^{*}+\frac{i^{*}}{k^{*}} \hat{\imath}_{t}^{*}-\frac{\left(1-\delta^{*}\right)}{g_{z}} \hat{g}_{z, t}+\frac{i^{*}}{k^{*}} \hat{\varepsilon}_{t}^{i, *} \\
\left(1+\tau^{c, *}\right) \frac{c^{r t, *}}{c^{*}} \hat{c}_{t}^{r t, *}=\left(1-\tau^{l, *}-\tau^{w h, *}\right) \frac{w^{*} h^{*}}{c^{*}}\left(\hat{w}_{t}^{*}+\hat{h}_{t}^{*}\right)+\frac{y^{*}}{c^{*}} \widehat{t r}_{t}^{r t, *}-\frac{y^{*}}{c^{*}} \hat{t}_{t}^{r t, *} \\
\hat{c}_{t}^{*}=\theta^{*} \frac{c^{r t, *}}{c^{*}} \hat{c}_{t}^{r t, *}+\left(1-\theta^{*}\right) \frac{c^{o, *}}{c^{*}} \hat{c}_{t}^{o, *} \\
\widehat{t r}_{t}^{*}=\theta^{*} \widehat{t r}_{t}^{r t, *}+\left(1-\theta^{*}\right) \widehat{t r}_{t}^{o, *} \\
\hat{t}_{t}^{*}=\theta^{*} \hat{t}_{t}^{r t, *}+\left(1-\theta^{*}\right) \hat{t}_{t}^{o, *} \\
\widehat{M R S}_{t}^{o, *}=\hat{c}_{t}^{o, *}+\phi_{l}^{*} \hat{h}_{t}^{*}+\hat{\varepsilon}_{t}^{l, *} \\
\widehat{M R S}_{t}^{r t, *}=\hat{c}_{t}^{r t, *}+\phi_{l}^{*} \hat{h}_{t}^{*}+\hat{\varepsilon}_{t}^{l, *}
\end{gathered}
$$

\section{A.4.2 Risk sharing condition}

$$
\begin{aligned}
\widehat{R E R}_{t}= & \hat{\varepsilon}_{t}^{c, *}-\hat{\varepsilon}_{t}^{c}+\sigma \hat{c}_{t}^{o}-\sigma^{*} \hat{c}_{t}^{o, *}+(1-\sigma) \zeta \hat{c}_{t-1}-\left(1-\sigma^{*}\right) \zeta^{*} \hat{c}_{t-1}^{*} \\
& +(1-\sigma) h^{1+\phi_{l}} \hat{h}_{t}-\left(1-\sigma^{*}\right)\left(h^{*}\right)^{1+\phi_{l}^{*}} \hat{h}_{t}^{*}
\end{aligned}
$$

\section{A.4.3 Wages}

Home country:

$$
\begin{aligned}
& \hat{w}_{t}=-\frac{\left(1-\xi_{w}\right)\left(1-\xi_{w} \beta\right)}{(1+\beta) \xi_{w}} \hat{w}_{t}+\frac{\left(1-\xi_{w}\right)\left(1-\xi_{w} \beta\right)}{(1+\beta) \xi_{w}} \frac{\lambda^{w}}{1+\lambda^{w}} \hat{\lambda}_{t}^{w} \\
& +\frac{\left(1-\xi_{w}\right)\left(1-\xi_{w} \beta\right)}{(1+\beta) \xi_{w}(\omega+1)}\left\{\left[\frac{\sigma \varrho\left(\frac{c^{r t}}{c^{o}}-1\right)}{(\varrho+1)}+1\right] \widehat{M R S}_{t}^{o}+\left[\omega-\frac{\sigma \varrho\left(\frac{c^{r t}}{c^{o}}-1\right)}{(\varrho+1)}\right] \widehat{M R S}_{t}^{r t}\right\} \\
& +\frac{\left(1-\chi_{w}\right)}{1+\beta} \widehat{\bar{\pi}}_{t}-\frac{\beta}{1+\beta}\left(1-\chi_{w}\right) \widehat{\bar{\pi}}_{t+1}+\frac{\beta}{1+\beta} \hat{w}_{t+1}+\frac{1}{1+\beta} \hat{w}_{t-1}+\frac{\chi_{w}}{1+\beta} \hat{\pi}_{C, t-1} \\
& -\frac{\left(1+\beta \chi_{w}\right)}{1+\beta} \hat{\pi}_{C, t}+\frac{\beta}{1+\beta} \hat{\pi}_{C, t+1}
\end{aligned}
$$




$$
\begin{aligned}
& \hat{w}_{t}^{*}=-\frac{\left(1-\xi_{w}^{*}\right)\left(1-\xi_{w}^{*} \beta\right)}{(1+\beta) \xi_{w}^{*}} \hat{w}_{t}^{*}+\frac{\left(1-\xi_{w}^{*}\right)\left(1-\xi_{w}^{*} \beta\right)}{(1+\beta) \xi_{w}^{*}} \frac{\lambda_{*}^{w}}{1+\lambda_{*}^{w}} \hat{\lambda}_{t}^{w, *} \\
& +\frac{\left(1-\xi_{w}^{*}\right)\left(1-\xi_{w}^{*} \beta\right)}{(1+\beta) \xi_{w}^{*}\left(\omega^{*}+1\right)}\left\{\left[\frac{\sigma^{*} \varrho^{*}\left(\frac{c^{r t, *}}{c^{o, *}}-1\right)}{\left(\varrho^{*}+1\right)}+1\right] \widehat{M R S}_{t}^{o, *}+\left[\omega^{*}-\frac{\sigma^{*} \varrho^{*}\left(\frac{c^{r t, *}}{c^{o, *}}-1\right)}{\left(\varrho^{*}+1\right)}\right] \widehat{M R S}_{t}^{r t, *}\right\} \\
& +\frac{\left(1-\chi_{w}^{*}\right)}{1+\beta} \widehat{\bar{\pi}}_{t}-\frac{\beta}{1+\beta}\left(1-\chi_{w}^{*}\right) \widehat{\bar{\pi}}_{t+1}+\frac{\beta}{1+\beta} \hat{w}_{t+1}^{*}+\frac{1}{1+\beta} \hat{w}_{t-1}^{*}+\frac{\chi_{w}^{*}}{1+\beta} \hat{\pi}_{C, t-1}^{*} \\
& -\frac{\left(1+\beta \chi_{w}^{*}\right)}{1+\beta} \hat{\pi}_{C, t}^{*}+\frac{\beta}{1+\beta} \hat{\pi}_{C, t+1}^{*}
\end{aligned}
$$

where $\varrho=\frac{\theta}{1-\theta}\left(\frac{c^{r t}}{c^{0}}\right)^{-\sigma}$ and $\omega=\frac{\theta}{1-\theta}\left(\frac{c^{r t}}{c^{o}}\right)^{1-\sigma}=\varrho \frac{c^{r t}}{c^{o}}$ and, simmetrically, $\varrho^{*}=\frac{\theta^{*}}{1-\theta^{*}}\left(\frac{c^{r t, *}}{c^{o, *}}\right)^{-\sigma^{*}}$ and $\omega^{*}=\frac{\theta^{*}}{1-\theta^{*}}\left(\frac{c^{r t, *}}{c^{o, *}}\right)^{1-\sigma^{*}}=\varrho^{*} \frac{c^{r t, *}}{c^{o, *}}$.

\section{A.4.4 Production}

Capital labor ratio Home country:

$$
\hat{u}_{t}+\hat{k}_{t}-\hat{h}_{t}-\hat{g}_{z, t}=\hat{w}_{t}-\hat{r}_{t}^{k}
$$

Foreign country:

$$
\hat{u}_{t}^{*}+\hat{k}_{t}^{*}-\hat{h}_{t}^{*}-\hat{g}_{z, t}=\hat{w}_{t}^{*}-\hat{r}_{t}^{k, *}
$$

Labor input Home country:

$$
\hat{h}_{t}=\alpha\left(\hat{r}_{t}^{k}-\hat{w}_{t}\right)+\frac{y^{N}}{y}\left(\frac{1}{\frac{y^{N}+\Phi_{N}}{y^{N}}} \hat{y}_{t}^{N}-\hat{\varepsilon}_{t}^{a, N}\right)+\frac{y^{H}}{y}\left(\frac{1}{\frac{y^{N}+\Phi_{N}}{y^{N}}} \hat{y}_{t}^{H}-\hat{\varepsilon}_{t}^{a, H}\right)
$$

Foreign country:

$$
\hat{h}_{t}^{*}=\alpha^{*}\left(\hat{r}_{t}^{k, *}-\hat{w}_{t}^{*}\right)+\frac{y^{N, *}}{y^{*}}\left(\frac{1}{\frac{y^{N, *}+\Phi_{N}^{*}}{y^{N, *}}} \hat{y}_{t}^{N, *}-\hat{\varepsilon}_{t}^{a, N, *}\right)+\frac{y^{F}}{y^{*}}\left(\frac{1}{\frac{y^{N, *}+\Phi_{N}^{*}}{y^{N, *}}} \hat{y}_{t}^{F}-\hat{\varepsilon}_{t}^{a, F}\right)
$$

Non-tradables Home country:

$$
\begin{aligned}
& \widehat{m c}_{t}^{N}=-\hat{\varepsilon}_{t}^{a, N}+\alpha_{N} \hat{r}_{t}^{k}+\left(1-\alpha_{N}\right) \hat{w}_{t} \\
\left(1+\beta \chi_{p}^{N}\right) \hat{\pi}_{N, t}= & \frac{\left(1-\xi_{p}^{N}\right)\left(1-\beta \xi_{p}^{N}\right)}{\xi_{p}^{N}}\left(\widehat{m c}_{t}^{N}-\gamma_{c} \hat{x}_{t}+\frac{\lambda^{p, N}}{1+\lambda^{p, N}} \hat{\lambda}_{t}^{p, N}\right) \\
& +\chi_{p}^{N} \hat{\pi}_{N, t-1}+\beta \hat{\pi}_{N, t+1}+\left(1-\chi_{p}^{N}\right) \widehat{\bar{\pi}}_{t}-\beta\left(1-\chi_{p}^{N}\right) \widehat{\bar{\pi}}_{t+1}
\end{aligned}
$$

Foreign country: 


$$
\begin{aligned}
& \widehat{m c}_{t}^{N, *}=-\hat{\varepsilon}_{t}^{a, N *}+\alpha_{N}^{*} \hat{r}_{t}^{k, *}+\left(1-\alpha_{N}^{*}\right) \hat{w}_{t}^{*} \\
\left(1+\beta \chi_{p}^{N, *}\right) \hat{\pi}_{N, t}^{*}= & \frac{\left(1-\xi_{p}^{N, *}\right)\left(1-\beta \xi_{p}^{N, *}\right)}{\xi_{p}^{N, *}}\left(\widehat{m c}_{t}^{N, *}+\frac{\lambda^{p, N *}}{1+\lambda^{p, N *}} \hat{\lambda}_{t}^{p, N *}-\gamma_{c}^{*} \hat{x}_{t}^{*}\right) \\
& +\chi_{p}^{N, *} \hat{\pi}_{N, t-1}^{*}+\beta \hat{\pi}_{N, t+1}^{*}+\left(1-\chi_{p}^{N, *}\right) \widehat{\bar{\pi}}_{t}-\beta\left(1-\chi_{p}^{N, *}\right) \widehat{\bar{\pi}}_{t+1}
\end{aligned}
$$

Tradables Home country:

$$
\begin{aligned}
& \widehat{m c}_{t}^{H}=-\hat{\varepsilon}_{t}^{a, H}+\alpha_{H} \hat{r}_{t}^{k}+\left(1-\alpha_{H}\right) \hat{w}_{t} \\
\left(1+\beta \chi_{p}^{H}\right) \hat{\pi}_{H, t}= & \frac{\left(1-\xi_{p}^{H}\right)\left(1-\beta \xi_{p}^{H}\right)}{\xi_{p}^{H}}\left(\begin{array}{c}
\widehat{m c}_{t}^{H}+\frac{\lambda^{p, H}}{1+\lambda^{p, H}} \hat{\lambda}_{t}^{p, H} \\
+(1-\varpi) \widehat{t t}_{t}+\left(1-\gamma_{c}\right) \hat{x}_{t}
\end{array}\right) \\
& +\chi_{p}^{H} \hat{\pi}_{H, t-1}+\beta \hat{\pi}_{H, t+1}+\left(1-\chi_{p}^{H}\right) \widehat{\bar{\pi}}_{t}-\beta\left(1-\chi_{p}^{H}\right) \widehat{\bar{\pi}}_{t+1}
\end{aligned}
$$

Foreign country:

$$
\begin{aligned}
& \widehat{m c}_{t}^{F}=-\hat{\varepsilon}_{t}^{a, F}+\alpha_{F} \hat{r}_{t}^{k, *}+\left(1-\alpha_{F}\right) \hat{w}_{t}^{*} \\
\left(1+\beta \chi_{p}^{F}\right) \hat{\pi}_{F, t}= & \frac{\left(1-\xi_{p}^{F}\right)\left(1-\beta \xi_{p}^{F}\right)}{\xi_{p}^{F}}\left(\begin{array}{c}
\widehat{m c}_{t}^{F}+\frac{\lambda^{p, F}}{1+\lambda^{p, F}} \hat{\lambda}_{t}^{p, F} \\
+\left(1-\varpi^{*}\right) \widehat{t t}_{t}+\left(1-\gamma_{c}^{*}\right) \hat{x}_{t}^{*}
\end{array}\right) \\
& +\chi_{p}^{F} \hat{\pi}_{F, t-1}+\beta \hat{\pi}_{F, t+1}+\left(1-\chi_{p}^{F}\right) \widehat{\bar{\pi}}_{t}-\beta\left(1-\chi_{p}^{F}\right) \widehat{\bar{\pi}}_{t+1}
\end{aligned}
$$

Demand functions Home country:

$$
\begin{gathered}
\hat{c}_{t}^{N}=-e \gamma_{c} \hat{x}_{t}+\hat{c}_{t} \\
\hat{c}_{t}^{H}=v(1-\varpi) \widehat{t t}_{t}+\hat{c}_{t}+e\left(1-\gamma_{c}\right) \hat{x}_{t} \\
\hat{c}_{t}^{F}=-v \varpi \widehat{t t}_{t}+\hat{c}_{t}+e\left(1-\gamma_{c}\right) \hat{x}_{t} \\
\hat{q}_{t}^{I, N}=-e \gamma_{i} \hat{x}_{t}+\hat{q}_{t}^{I} \\
\hat{q}_{t}^{I, H}=v(1-\varpi) \widehat{t t}_{t}+\hat{q}_{t}^{I}+e\left(1-\gamma_{i}\right) \hat{x}_{t} \\
\hat{q}_{t}^{I, F}=-v \varpi \widehat{t t}_{t}+\hat{q}_{t}^{I}+e\left(1-\gamma_{i}\right) \hat{x}_{t}
\end{gathered}
$$

Foreign country:

$$
\hat{c}_{t}^{N, *}=-e \gamma_{c}^{*} \hat{x}_{t}^{*}+\hat{c}_{t}^{*}
$$




$$
\begin{gathered}
\hat{c}_{t}^{H, *}=v \varpi^{*} \widehat{t t}_{t}+e\left(1-\gamma_{c}^{*}\right) \hat{x}_{t}^{*}+\hat{c}_{t}^{*} \\
\hat{c}_{t}^{F, *}=-v\left(1-\varpi^{*}\right) \widehat{t t}_{t}+e\left(1-\gamma_{c}^{*}\right) \hat{x}_{t}^{*}+\hat{c}_{t}^{*} \\
\hat{q}_{t}^{I, N, *}=-e \gamma_{i}^{*} \hat{x}_{t}^{*}+\hat{q}_{t}^{I, *} \\
\hat{q}_{t}^{I, H, *}=v \varpi^{*} \widehat{t t}_{t}+\hat{q}_{t}^{I, *}+e\left(1-\gamma_{i}^{*}\right) \hat{x}_{t}^{*} \\
\hat{q}_{t}^{I, F, *}=-v\left(1-\varpi^{*}\right) \widehat{t t}_{t}+\hat{q}_{t}^{I, *}+e\left(1-\gamma_{i}^{*}\right) \hat{x}_{t}^{*}
\end{gathered}
$$

\section{A.4.5 Fiscal policy}

$$
\begin{gathered}
\quad \frac{g}{y} p^{N} \hat{p}_{t}^{N}+p^{N} \hat{g}_{t}+\frac{b}{y} \frac{R}{\pi_{C} g_{z}} \hat{R}_{t-1}+\frac{R}{\pi_{C} g_{z}} \hat{b}_{t}-\frac{b}{y} \frac{R}{\pi_{C} g_{z}} \hat{g}_{z, t}-\frac{b}{y} \frac{R}{\pi_{C} g_{z}} \hat{\pi}_{C, t}+\widehat{t r}_{t} \\
=\hat{b}_{t+1}+\hat{t}_{t}+\frac{c}{y} \tau^{c} \hat{c}_{t}+\frac{w h}{c} \frac{c}{y}\left(\tau^{l}+\tau^{w h}+\tau^{w f}\right)\left(\hat{w}_{t}+\hat{h}_{t}\right) \\
+\frac{k}{y} \frac{\tau^{k}}{g_{z}}\left[\gamma_{u 1} \hat{r}_{t}^{k}+\left(\gamma_{u 1}-\delta\right)\left(\hat{k}_{t}-\hat{g}_{z, t}\right)-\delta\left(\gamma_{c}-\gamma_{i}\right) \hat{x}_{t}\right] \\
\frac{g^{*}}{y^{*}} p^{N, *} \hat{p}_{t}^{N, *}+p^{N, *} \hat{g}_{t}^{*}+\frac{b^{*}}{y^{*}} \frac{R}{\pi_{C}^{*} g_{z}} \hat{R}_{t-1}+\frac{R}{\pi_{C}^{*} g_{z}} \hat{b}_{t}^{*}-\frac{b^{*}}{y^{*}} \frac{R}{\pi_{C}^{*} g_{z}} \hat{g}_{z, t}-\frac{b^{*}}{y^{*}} \frac{R}{\pi_{C}^{*} g_{z}} \hat{\pi}_{C, t}^{*}+\widehat{t r}_{t}^{*} \\
=\hat{b}_{t+1}^{*}+\hat{t}_{t}^{*}+\frac{c^{*}}{y^{*}} \tau^{c, *} \hat{c}_{t}^{*}+\frac{w^{*} h^{*}}{c^{*}} \frac{c^{*}}{y^{*}}\left(\tau^{l, *}+\tau^{w h, *}+\tau^{w f, *}\right)\left(\hat{w}_{t}^{*}+\hat{h}_{t}^{*}\right) \\
+\frac{k^{*}}{y^{*}} \frac{\tau^{k, *}}{g_{z}}\left[\gamma_{u 1}^{*} \hat{r}_{t}^{k, *}+\left(\gamma_{u 1}^{*}-\delta^{*}\right)\left(\hat{k}_{t}^{*}-\hat{g}_{z, t}^{*}\right)-\delta^{*}\left(\gamma_{c}^{*}-\gamma_{i}^{*}\right) \hat{x}_{t}^{*}\right]
\end{gathered}
$$

\section{A.4.6 Market clearing}

Home country

$$
\begin{gathered}
\hat{y}_{t}^{N}=\frac{c^{N}}{y^{N}} \hat{c}_{t}^{N}+\frac{q^{I, N}}{y^{N}} \hat{q}_{t}^{I, N}+\frac{y}{y^{N}} \hat{g}_{t} \\
\hat{y}_{t}^{H}=\frac{c^{H}}{y^{H}} \hat{c}_{t}^{H}+\frac{i^{H}}{y^{H}} \hat{q}_{t}^{I, H}+\frac{1-s}{s} \frac{c^{H^{*}}}{y^{H}} \hat{c}_{t}^{H^{*}}+\frac{1-s}{s} \frac{i^{H^{*}}}{y^{H}} \hat{q}_{t}^{I, H, *} \\
\hat{y}_{t}=\frac{y^{H}}{y} \hat{y}_{t}^{H}+\frac{y^{N}}{y} \hat{y}_{t}^{N}-(1-\varpi) \frac{y^{H}}{y} \widehat{t t}_{t}+\left[\gamma_{c} \frac{y^{N}}{y}-\left(1-\gamma_{c}\right) \frac{y^{H}}{y}\right] \hat{x}_{t} \\
\hat{q}_{t}^{I}=\hat{\imath}_{t}+\frac{a^{\prime}(1)}{g_{z}} \frac{k}{y} \frac{y}{i} \hat{u}_{t}
\end{gathered}
$$

Foreign country: 


$$
\begin{gathered}
\hat{y}_{t}^{N, *}=\frac{c^{N, *}}{y^{N, *}} \hat{c}_{t}^{N, *}+\frac{q^{I, N, *}}{y^{N, *}} \hat{q}_{t}^{I, N, *}+\frac{y^{*}}{y^{N, *}} \hat{g}_{t}^{*} \\
\hat{y}_{t}^{F}=\frac{s}{1-s} \frac{c^{F}}{y^{F}} \hat{c}_{t}^{F}+\frac{s}{1-s} \frac{q^{I, F}}{y^{F}} \hat{q}_{t}^{I, F}+\frac{c^{F^{*}}}{y^{F}} \hat{c}_{t}^{F^{*}}+\frac{q^{I, F, *}}{y^{F}} \hat{q}_{t}^{I, F, *} \\
\hat{y}_{t}=\frac{y^{F}}{y^{*}} \hat{y}_{t}^{F}+\frac{y^{N, *}}{y^{*}} \hat{y}_{t}^{N, *} \\
-\left(1-\varpi^{*}\right) \frac{y^{F}}{y^{*}} \widehat{t t}_{t}+\left[\gamma_{c}^{*} \frac{y^{N, *}}{y^{*}}-\left(1-\gamma_{c}^{*}\right) \frac{y^{F}}{y^{*}}\right] \hat{x}_{t}^{*} \\
\hat{q}_{t}^{I, *}=\hat{\imath}_{t}^{*}+\frac{a^{\prime}(1)}{g_{z}} \frac{k^{*}}{y^{*}} \frac{y^{*}}{i^{*}} \hat{u}_{t}^{*}
\end{gathered}
$$

\section{Definition of exports and imports}

$$
\begin{gathered}
\widehat{e x}_{t}=\frac{\gamma_{c}^{*} \frac{c^{*}}{y^{*}}}{\gamma_{c}^{*} \frac{c^{*}}{y^{*}}+\gamma_{i}^{*} \frac{i^{*}}{y^{*}}} \hat{c}_{t}^{H, *}+\frac{\gamma_{i}^{*} \frac{i^{*}}{y^{*}}}{\gamma_{c}^{*} \frac{c^{*}}{y^{*}}+\gamma_{i}^{*} \frac{i^{*}}{y^{*}}} \hat{q}_{t}^{I, H, *} \\
\widehat{i m}_{t}=\frac{\gamma_{c} \frac{c}{y}}{\gamma_{c} \frac{c}{y}+\gamma_{i} \frac{i}{y}} \hat{c}_{t}^{F}+\frac{\gamma_{i} \frac{i}{y}}{\gamma_{c} \frac{c}{y}+\gamma_{i} \frac{i}{y}} \hat{q}_{t}^{F, I}
\end{gathered}
$$

\section{A.4.7 CPI inflation}

Home country:

$$
\hat{\pi}_{C, t}=\gamma_{c} \hat{\pi}_{t}^{T}+\left(1-\gamma_{c}\right) \hat{\pi}_{t}^{N}
$$

Foreign country:

$$
\hat{\pi}_{C, t}^{*}=\gamma_{c}^{*} \hat{\pi}_{t}^{T, *}+\left(1-\gamma_{c}^{*}\right) \hat{\pi}_{t}^{N, *}
$$

\section{A.4.8 Tradables inflation}

Home country:

$$
\hat{\pi}_{t}^{T}=(1-\varpi) \widehat{t t}_{t}-(1-\varpi) \widehat{t t}_{t-1}+\hat{\pi}_{t}^{H}
$$

Foreign country:

$$
\hat{\pi}_{t}^{T}=-\left(1-\varpi^{*}\right) \widehat{t t}_{t}+\left(1-\varpi^{*}\right) \widehat{t t}_{t-1}+\hat{\pi}_{t}^{F}
$$

\section{A.4.9 Relative price of non tradable goods}

$$
\begin{gathered}
\hat{x}_{t}-\hat{x}_{t-1}=\hat{\pi}_{t}^{N}-\hat{\pi}_{t}^{T} \\
\hat{x}_{t}^{*}-\hat{x}_{t-1}^{*}=\hat{\pi}_{t}^{N, *}-\hat{\pi}_{t}^{T, *}
\end{gathered}
$$


A.4.10 Real exchange rate

$$
\begin{aligned}
\widehat{R E R}_{t}= & \frac{\left(1-\gamma_{c}^{*}\right)}{R E R} \hat{x}_{t}^{*}-\frac{\left(1-\gamma_{c}\right)}{R E R} \hat{x}_{t}+\frac{\left(\varpi^{*}+\varpi-1\right)}{R E R} \widehat{t t}_{t} \\
& \widehat{R E R}_{t}-\widehat{R E R}_{t-1}=\hat{\pi}_{C, t}^{*}-\hat{\pi}_{C, t}
\end{aligned}
$$

\section{A.4.11 Monetary authority}

$$
\begin{gathered}
\hat{R}_{t}^{E C B}=\phi_{R} \hat{R}_{t-1}^{E C B}+\left(1-\phi_{R}\right)\left(\hat{\pi}_{t}^{E A}+\phi_{\pi}\left(\hat{\pi}_{t-1}^{E A}-\hat{\bar{\pi}}_{t}\right)+\phi_{y} \hat{y}_{t}^{E A}\right) \\
+\phi_{\Delta \pi}\left(\hat{\pi}_{t}^{E A}-\hat{\pi}_{t-1}^{E A}\right)+\phi_{\Delta y}\left(\hat{y}_{t}^{E A}-\hat{y}_{t-1}^{E A}\right)+\hat{\varepsilon}_{t}^{r} \\
\hat{\pi}_{t}^{E A}=s \hat{\pi}_{C, t}+(1-s) \hat{\pi}_{C, t}^{*} \\
\hat{y}_{t}^{E A}=s \hat{y}_{t}+(1-s) \hat{y}_{t}^{*}
\end{gathered}
$$

\section{A.4.12 Shocks}

The shocks included in all the specifications of the model are:

Transitory technology shocks:

$$
\begin{gathered}
\hat{\varepsilon}_{t}^{a, N}=\rho_{a, N} \hat{\varepsilon}_{t-1}^{a, N}+\eta_{t}^{a, N} \\
\hat{\varepsilon}_{t}^{a, N *}=\rho_{a, N *} \hat{\varepsilon}_{t-1}^{a, N *}+\eta_{t}^{a, N *} \\
\hat{\varepsilon}_{t}^{a, H}=\rho_{a, H} \hat{\varepsilon}_{t-1}^{a, H}+\eta_{t}^{a, H} \\
\hat{\varepsilon}_{t}^{a, F}=\rho_{a, F} \hat{\varepsilon}_{t-1}^{a, F}+\eta_{t}^{a, F}
\end{gathered}
$$

Preference shocks:

$$
\begin{gathered}
\hat{\varepsilon}_{t}^{c}=\rho_{c} \hat{\varepsilon}_{t-1}^{c}+\eta_{t}^{c} \\
\hat{\varepsilon}_{t}^{c, *}=\rho_{c, *} \hat{\varepsilon}_{t-1}^{c, *}+\eta_{t}^{c, *}
\end{gathered}
$$

Risk premium shocks:

$$
\begin{gathered}
\hat{\varepsilon}_{t}^{b}=\rho_{b} \hat{\varepsilon}_{t-1}^{b}+\eta_{t}^{b} \\
\hat{\varepsilon}_{t}^{b, *}=\rho_{b, *} \hat{\varepsilon}_{t-1}^{b, *}+\eta_{t}^{b, *}
\end{gathered}
$$

Investment specific shocks:

$$
\hat{\varepsilon}_{t}^{i}=\rho_{i} \hat{\varepsilon}_{t-1}^{i}+\eta_{t}^{i}
$$




$$
\hat{\varepsilon}_{t}^{i, *}=\rho_{i, *} \hat{\varepsilon}_{t-1}^{i, *}+\eta_{t}^{i, *}
$$

Price markup shocks:

$$
\begin{gathered}
\hat{\lambda}_{t}^{p}=\rho_{p} \hat{\lambda}_{t-1}^{p}+\eta_{t}^{p} \\
\hat{\lambda}_{t}^{p, *}=\rho_{p, *} \hat{\lambda}_{t-1}^{p, *}+\eta_{t}^{p, *}
\end{gathered}
$$

Wage markup shocks:

$$
\begin{gathered}
\hat{\lambda}_{t}^{w}=\rho_{w} \hat{\lambda}_{t-1}^{w}+\eta_{t}^{w} \\
\hat{\lambda}_{t}^{p, *}=\rho_{p, *} \hat{\lambda}_{t-1}^{p, *}+\eta_{t}^{p, *}
\end{gathered}
$$

Government spending shocks:

$$
\begin{gathered}
\hat{g}_{t}=\rho_{g} \hat{g}_{t-1}+\eta_{t}^{g} \\
\hat{g}_{t}^{*}=\rho_{g, *} \hat{g}_{t-1}^{*}+\eta_{t}^{g, *}
\end{gathered}
$$

Interest rate shock:

$$
\hat{\varepsilon}_{t}^{r}=\rho_{r} \hat{\varepsilon}_{t-1}^{r}+\eta_{t}^{r}
$$

Model A In Model A we add the following shocks.

An inflation objective shock:

$$
\widehat{\bar{\pi}}_{t}=\rho_{\bar{\pi}} \widehat{\bar{\pi}}_{t-1}+\eta_{t}^{\bar{\pi}}
$$

A permanent labor augmenting technology shock:

$$
\hat{g}_{z, t}=\rho_{g_{z}} \hat{g}_{z, t-1}+\eta_{t}^{g_{z}}
$$

Model B Model B is characterised by the following shocks. A risk sharing condition shock:

$$
\hat{\varepsilon}_{t}^{r s h}=\rho_{r s h} \hat{\varepsilon}_{t-1}^{r s h}+\eta_{t}^{r s h}
$$

A permanent labor augmenting technology shock:

$$
\hat{g}_{z, t}=\rho_{g_{z}} \hat{g}_{z, t-1}+\eta_{t}^{g_{z}}
$$


Model C Model specification C entails also differences concerning the model equations. The FOC for consumption of the foreign country is included:

$$
R_{t}^{E C B}=\frac{\pi_{C, t+1}^{*} g_{z, t+1} \varepsilon_{t}^{c, *}\left(c_{t}^{o, *}\right)^{-\sigma^{*}}\left(c_{t-1}^{*}\right)^{\zeta^{*}\left(\sigma^{*}-1\right)} \exp \left(\frac{\left(\sigma^{*}-1\right)}{1+\phi_{l}^{*}}\left(h_{t}^{*}\right)^{1+\phi_{l}^{*}}\right)}{\beta^{*} \varepsilon_{t+1}^{c, *}\left(c_{t+1}^{o, *}\right)^{-\sigma^{*}}\left(c_{t}^{*}\right)^{\zeta^{*}\left(\sigma^{*}-1\right)} \exp \left(\frac{\left(\sigma^{*}-1\right)}{1+\phi_{l}^{*}}\left(h_{t+1}^{*}\right)^{1+\phi_{l}^{*}}\right)}
$$

Then, the following equations are also needed:

$$
\begin{gathered}
R_{t}^{E C B}=R_{t} \Gamma\left(n w_{t}, \varepsilon_{t}^{r p}\right) \\
n w_{t}=R_{t-1} \frac{n w_{t-1}}{g_{z, t}}+n x_{t} \\
\Gamma\left(n w_{t}, \varepsilon_{t}^{r p}\right)=\exp \left\{\Gamma^{b}\left(\frac{n w_{t}}{y_{t}}-\frac{n w}{y}\right)-\varepsilon_{t}^{r p}\right\} \\
n x_{t}=\frac{P_{t}^{H}}{P_{C, t}} \frac{1-s}{s} e x_{t}-\frac{P_{t}^{F}}{P_{C, t}} i m_{t} \\
e x_{t}=c_{t}^{H, *}+q_{t}^{I, H, *} \\
i m_{t}=c_{t}^{F}+q_{t}^{I, F}
\end{gathered}
$$

In log-linear terms we obtain:

$$
\begin{aligned}
\hat{c}_{t}^{o, *}= & \hat{c}_{t+1}^{o, *}+\frac{\left(1-\sigma^{*}\right) b^{*}}{\sigma^{*}}\left(\hat{c}_{t}^{*}-\hat{c}_{t-1}^{*}\right)-\frac{1}{\sigma^{*}}\left(\hat{R}_{t}^{E C B}-\hat{\pi}_{C, t+1}^{*}-\hat{g}_{z, t+1}+\hat{\varepsilon}_{t+1}^{c, *}-\hat{\varepsilon}_{t}^{c, *}\right) \\
& +\frac{\left(1-\sigma^{*}\right)\left(h^{*}\right)^{1+\phi_{l}^{*}}}{\sigma^{*}}\left(\hat{h}_{t+1}^{*}-\hat{h}_{t}^{*}\right)
\end{aligned}
$$

For the following the equations, note that we imposed $n x=n w=0$ in steady state.

$$
\begin{gathered}
\hat{R}_{t}^{E C B}=\hat{R}_{t}+\hat{\Gamma}_{t} \\
\widehat{n w}_{t}=\frac{R}{g_{z}} \widehat{n w}_{t-1}-\widehat{n x}_{t} \\
\hat{\Gamma}_{t}=\Gamma^{b} \widehat{n w}_{t}-\varepsilon_{t}^{r p} \\
\widehat{n x}_{t}=\frac{1-s}{s} \frac{y^{*}}{y}\left[\left(1-\varpi^{*}\right) \gamma_{c}^{*} \frac{c^{*}}{y^{*}}+\left(1-\varpi^{*}\right) \gamma_{i}^{*} \frac{i^{*}}{y^{*}}\right]\left[\widehat{e x}_{t}-\left(1-\gamma_{c}\right) \hat{x}_{t}-(1-\varpi) \widehat{t t}_{t}\right] \\
-\left[(1-\varpi) \gamma_{c} \frac{c}{y}+(1-\varpi) \gamma_{i} \frac{i}{y}\right]\left[\widehat{i m}_{t}-\left(1-\gamma_{c}\right) \hat{x}_{t}+\varpi \widehat{t t}_{t}\right]
\end{gathered}
$$

where we define $\widehat{n w}_{t}=\frac{n w_{t}}{y}$ and $\widehat{n x}_{t}=\frac{n x_{t}}{y}$.

The shocks included in this specification are the following. 
A shock to the risk premium function:

$$
\varepsilon_{t}^{r p}=\rho_{r p} \varepsilon_{t-1}^{r p}+\eta_{t}^{r p}
$$

A permanent labor augmenting technology shock:

$$
\hat{g}_{z, t}=\rho_{g_{z}} \hat{g}_{z, t-1}+\eta_{t}^{g_{z}}
$$

Model D We suppose country specific shocks to the trend growth rate:

$$
\begin{gathered}
\hat{g}_{z, t}=\rho_{g_{z}} \hat{g}_{z, t-1}+\eta_{t}^{g_{z}} \\
\hat{g}_{z, t}^{*}=\rho_{g_{z}, *} \hat{g}_{z, t-1}^{*}+\eta_{t}^{g_{z}, *}
\end{gathered}
$$

The deterministic growth trend $g_{z}$ remains common to both economies. In the equations characterizing the foreign region, $\hat{g}_{z, t}$ is replaced by $\hat{g}_{z, t}^{*}$. 